\title{
Somogy nagylepke faunájának katalógusa (Lepidoptera: Macrolepidoptera)
}

\author{
ÁBrAHÁM LEVENTE ÉS UHERKOVICH ÁKOS
}

\begin{abstract}
ÁBRAHÁm L. \& UHERKovich Á.: Checklist of butterflies and larger moths of Somogy county (Lepidoptera: Macrolepidoptera)

Abstract: Based on the literature of butterfly and larger moth fauna, the authors comply the checklist of the fauna of Somogy county and present the short history of the investigations carried out in this field. In 46 papers, they found data proving the occurrence of 973 species of Bombycioidea, Sphingoidea, Papilionoidea, Geometroidea, Noctuidea taxa. A complete checklist is published, as well, with the relevant literary references.
\end{abstract}

\section{Bevezetés}

A lepkék a rovarok osztályának egyik legnépesebb rendjét képviselik, hazánkban fajszámuk eléri a 3500-at.

A lepkék vizsgálatával foglalkozó gyúijtók elsősorban a színpompás nappali lepkéket tanulmányozták, de ezek hazai fajszáma nem éri el a kétszázat. A nappali lepkéktốl teljesen eltérő gyúijtési módszert igénylố éjszakai lepkék már jóval kevesebb kutató és amatốr gyưjiő́ érdeklődését keltették fel, emellett gyújtésük is körülményesebb, ezért az elterjedési adataik száma is jelentôsen elmarad a nappali lepkék ismertté vált lelóhelyeinek számától.

Kutatásuk során a lepkéket - gyakorlati okok miatt - Microlepidoptera („,molylepkék”) és Macrolepidoptera („nagylepkék”) csoportokra osztották, amely elsốsorban a testméretekben megmutatkozó különbségeket tükrözte vissza. Mai szisztematikai tudásunk alapján ez a felosztási alap egyáltalán nem tekinthető tudományosnak, hiszen nem tükrözi a rend evolúcióját. Ámbár az egyes csoportok eltérő gyújitési és vizsgálati módszereiben - de ezen túl mégis leginkább a hagyományok miatt - napjainkig visszatükröződik ez a mesterséges felosztás. A taxonok nagy száma miatt a lepidopterológus kutatók pedig ennek a két csoportnak a feldolgozására specializálódtak. Ez természetesen a tudományos közleményekben is megjelenik. A fent említett okok miatt Somogy megye faunakatalógusának összeállításánál is a hagyományokat követve a Lepidoptera rendet két tanulmányban, mint a Microlepidopterák és Macrolepidopterák (Bombycoidea, Sphingoidea, Papilionoidea, Geometroidea, Noctuoidea) faunakatalógusa tesszük közzé.

Jelen tanulmánykötet publikálásának alapgondolata, a Magyar Birodalom Állatvilága (Fauna Regni Hungariae) „A Magyar Birodalomból eddig ismert állatok rendszeres lajstroma" alcímet viselố kötet még napjainkban is aktuális célkitúzéseit próbálja követni, azzal a megszorítással, hogy a kötet első megjelentetése óta a könyvtárnyi mennyiségúre duzzadt faunisztikai irodalmat ilyen formában hazánkból összefoglalni már nehezen lehetne, ezért azt rendszerezve, revíziózva hazánk csak egy kis területéről, Somogy megyéből ismertetjük. A 
megjelentetés aktualitását a millenniumi évforduló inspirálta.

Somogy megye lepkefaunájáról az elsô írásos információt a Fauna Regni Hungariae-ból ismerjük (ABAFI et al. 1899). A szerzók a kötet lepkékkel foglalkozó fejezetében 6 "nagylepke” fajt említettek meg Somogy területérôl: "Lycaena alciphron - Com. Somogy, Marumba quercus - Com Somogy, Zanclognatha tarsipennalis - Zákány, Idea laevigaria - Somogy-Szobb (ma: Somogyszob), Stegania dilectaria - Barcs, Drávafok (a II. világháború elótt még Somogy megyéhez tartozott), Lithina chlorosata (= patraria) - Zákány“.

Sajnos, nem tudjuk, hogy ezeket a példányokat ki gyújtötte és több esetben a lelöhely pontos közigazgatási egységét sem ismerjük, de a Lycaena alciphron, Marumba quercus és az Idaea laevigata a kutatások mai szintje alapján is figyelemre méltó adatnak számít.

Miért nem szerepelt több adat e nagyszerú munkában Somogy területéról?

Erre a kérdésre a lepidopterológiai kutatások hazai történetének vázlatos áttekintése adhatja meg a választ.

A történelmi Magyarországon Somogy megye területe hazánkban elfoglalt földrajzi helyzete és felszíni tagoltsága miatt nem hívta fel magára a gyưijtốk és kutatók figyelmét, és kutatások nélkül is sejteni lehetett, hogy a Kárpátok vagy a Tenger-mellék faunisztikai szempontból érdekesebbnek ígérkezett a gyújtoók számára. Társadalmi okai is lehetnek a kutatás hiányának, mivel a 20. század fordulóján Somogyban nem élt egy olyan polgári réteg, aki anyagilag megengedhette volna magának, hogy hobbiként a lepkék gyúitésével, vizsgálatával foglalkozzék. A lepkegyúités mindig is az egyik legdrágább rovarkutatási tevékenység volt. Így ismereteink az I. világháborúig szinte alig gyarapodtak. A Fauna Regni Hungariae megjelenése utân a megye lepkefaunájának kutatásáról először báró ROTHSCHILD (1909) tudósít. A Rovartani Lapok hasábjain 29 nagylepke fajról számol be, amelyet Fonyódon és Siófokon fogott Holz Márton.

A Trianoni Békeszerződés után a megváltozott magyar államhatárok már nem, vagy csak kevésbé tették lehetôvé a hazai kutatók számára, hogy immár a környezó országok magashegységeiben vagy a közeli mediterrán vidékeken végezzenek gyứjtő́munkát, ezért a zoológiai kutatások figyelme elsősorban a hazai középhegyvidékek felé irányult.

Az I. világháború alatt a Trencsénból származó Pazsiczky család kaposvári letelepedése a somogyi megyeszékhely Lepidoptera faunájának kutatásában pozitív változást hozott.

Először a Felvidéken élố jelentôs gyưitoó, kutató és publikáló tevékenységet is folytató Pazsiczky Jenőnek (1876-1919) jelent meg egy közleménye 1917-ben a Rovartani Lapokban egy Kaposváron fogott abberitív Spilosoma menthastri-ról (= lubricipeda). A szerzố sajnos tragikus hirtelenséggel fiatalon hunyt el. Unokaöccse, Pazsiczky Sándor (1881-1955) rajz- és természetrajz tanár volt a kaposvári Somsich Gimnáziumban. Tudós-kutatótanári tevékenysége mellett festőmúvészként is ismertté vált. Az ő tevékenységével kezdődött el az a korszak, melynek nagyon aktív idôszaka a 30-40-es évekre esett; és Kaposvár entomológiai körökben jól ismert lepidopterológiai centrummá vált. Gyújteményét a Magyar Természettudományi Múzeum (Budapest) örzi. Sajnos, kutatásait nem publikálta, csupán néhány rövidebb közleményt írt (PAZSICZKY S. 1942). Ma már kinyomozhatatlan, hogyan kerültek a Somogy Megyei Múzeum könyvtárba azok a Rovartani Lapok, amelyek között feltételezhetôen az ó és unokabátyja kézírásának nyomai láthatók.

Tanár lévén tudását magas színvonalon adta tovább, hiszen egész lepkésztársaság tevékenykedett körülötte és gyújtôtársai remek gyưjiteményeket állíthat- 


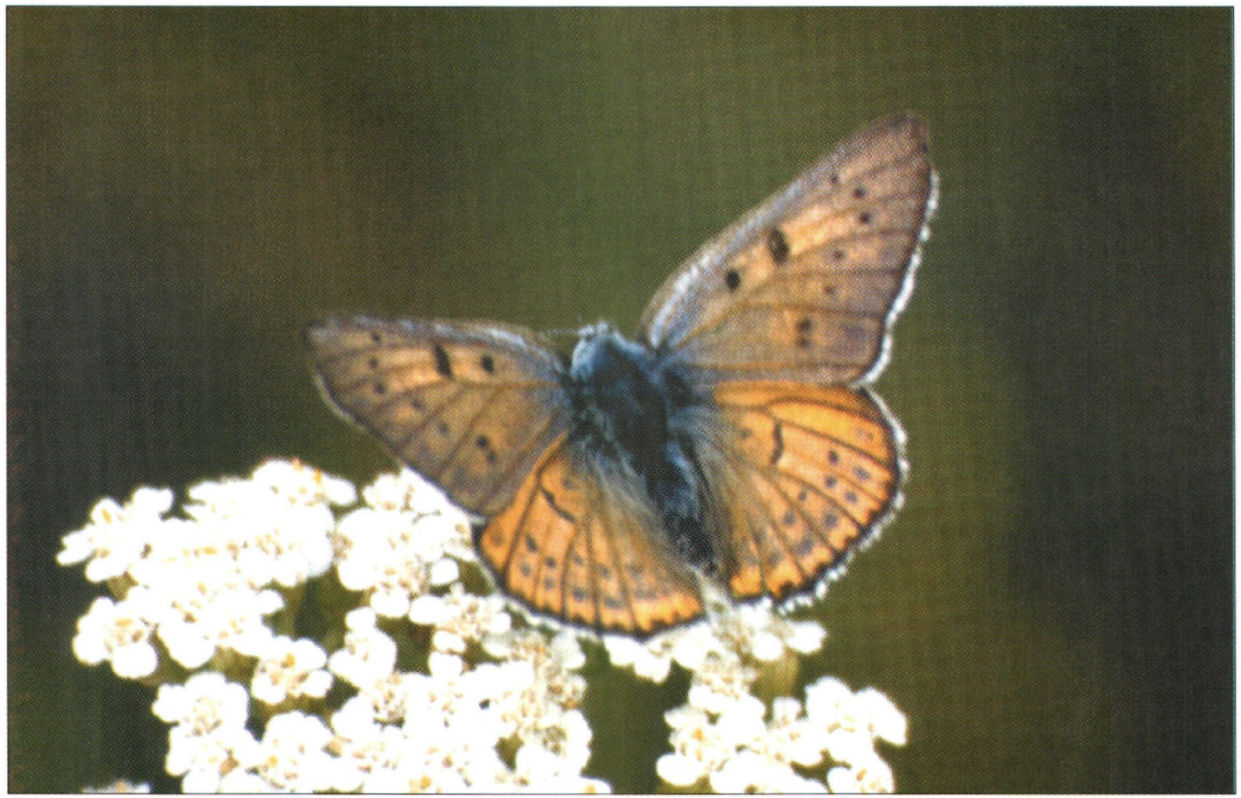

1. ábra: Ibolyás tû́zlepke (Lycaena alciphron) hím példánya, védett boglárka lepke faj Fotó: Ábrahám L.

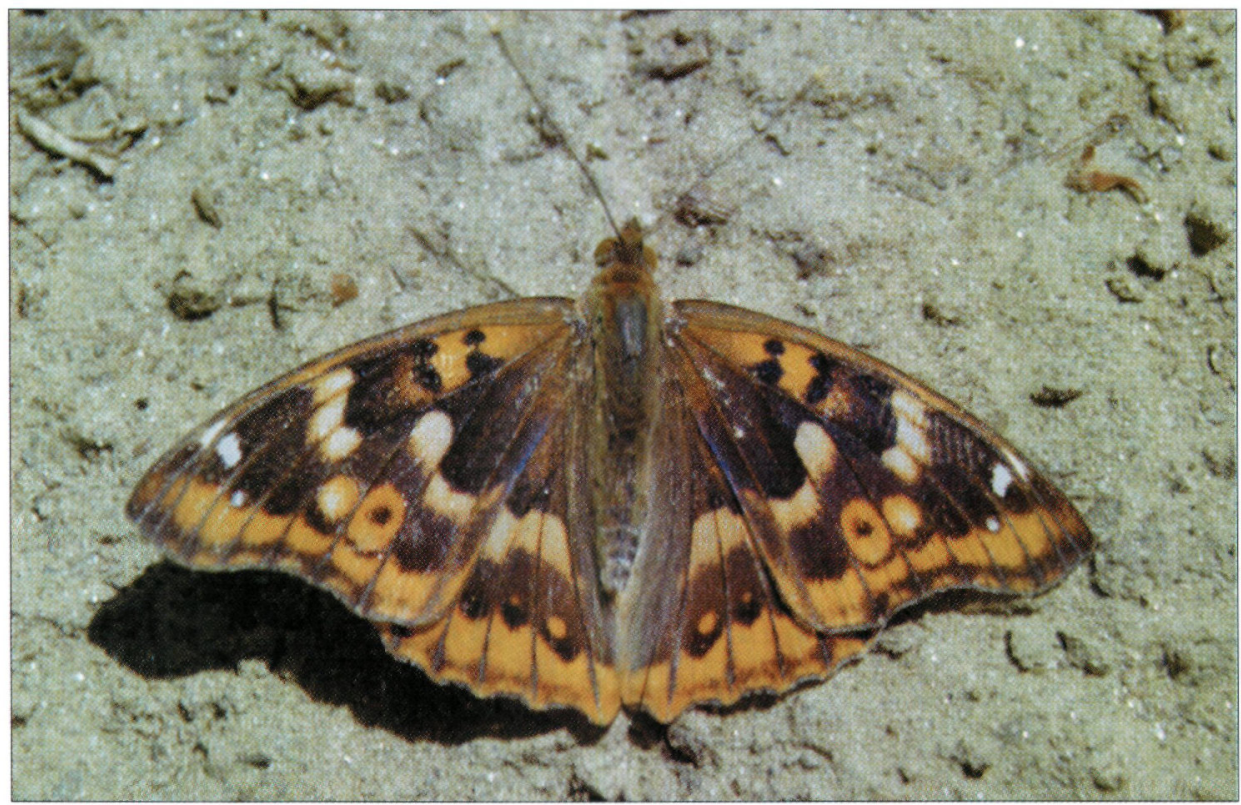

2. ábra: Magyar színjátszólepke (Apatura metis) folyómenti puhafaligeterdók védett faja Fotó: Ábrahám L. 


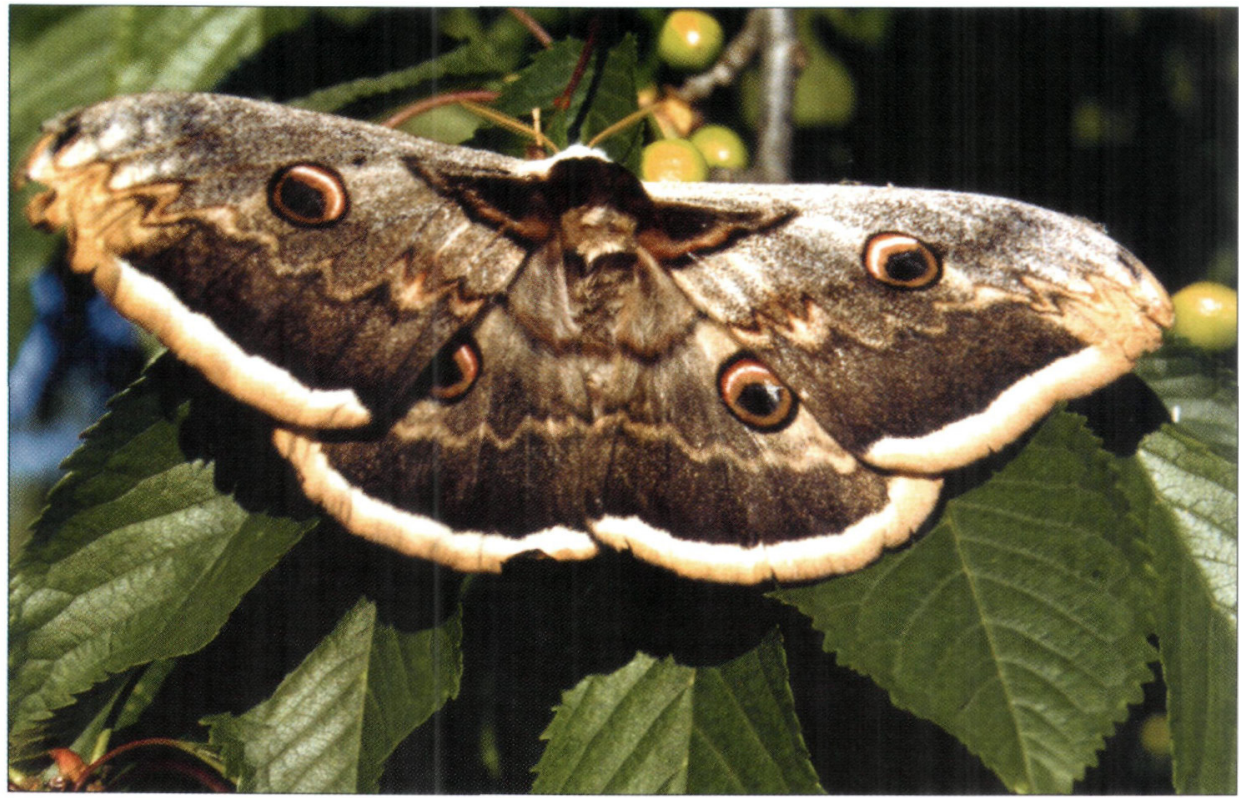

3. ábra: Nagy éjjeli pávaszem (Saturnia pyri) hazánk legnagyobb termetû fokozatosan gyérülő példányszámú éjjeli lepkéje Fotó: Abrahám L.

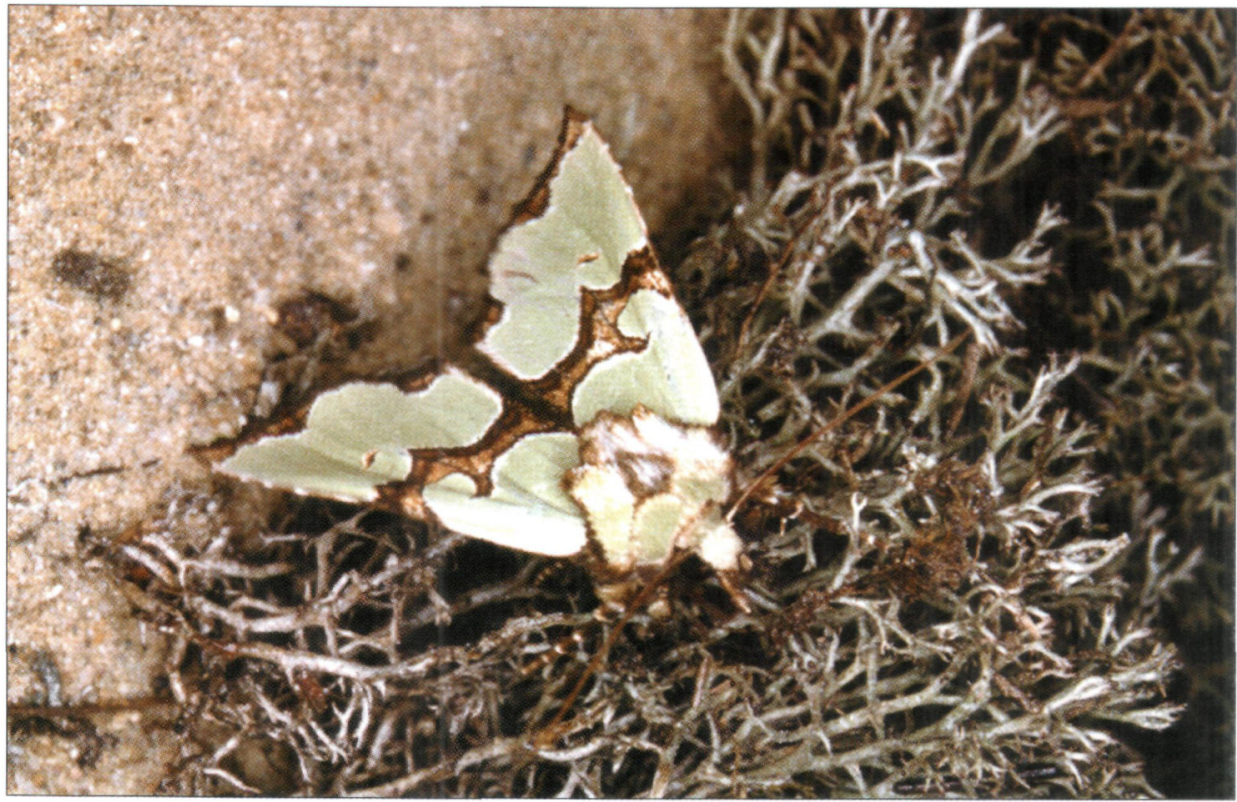

4. ábra: Belsô-Somogy homokvidékének jellegzetes kora ôszi faja a védett buckabagoly lepke (Staurophora celsia) Fotó: Ábrahám L. 
tak fel a II. világháború elôtt. Sajnos a háború nemcsak a gyújteményekben végzett óriási pusztítást, hanem személyi tragédiát is okozott. A két világháború között a legaktívabb három kaposvári lepkegyúitő Karvajszky István (1871-1943), Hámory Aladár (1878-1946), Ház Antal (1917?-1944?) volt, tudjuk meg PAZsiczky S. (1947) megemlékezéséból. Sajnos, 5-10 ezres gyúijteményük részben megsemmisült (Hortobágyi Béla szóbeli közlése). Szintén ekkor pusztult el Hortobágyi Béla kb. 7 ezres rovargyúijteménye is; bár természet szeretetét megórizte, de gyújteményét egészségi állapota miatt nem állíthatta fel ismét.

A II. világháború eloott Somogy megye területét, különösen a Kis-Balatont, mivel azt zoológiai körökben ismert madár-paradicsomként tartották számon - több külföldi, elsôsorban német gyúitő kereste fel. Hazánkban elóször ekkor fogták itt az Arytrura musculus-t., amely azóta is nagy ritkaságnak számít. A Somogyban folyó intenzív gyújtő́munka ellenére sajnos mégis nagyon kevés publikált adattal rendelkezünk a két világháború közötti időszakból (SzENT-IVÁNY 1938).

A II. világháború utáni idôszak lepidopterológiai kutatásai, különösen Kaposvár környékének faunafeltárása Nattán Miklós (1910-1970) nevéhez fúzódik. Mintegy 40 évi gyứjtômunka során rendkívül értékes anyagot hagyott hátra, melyet halála után a pécsi Janus Pannonius Múzeum megvásárolt. Ebben több mint 17 ezer Macrolepidoptera példány található, amelyeket fóleg Kaposvár környékén gyúittött (Ábrahám 1990).

Nattán Miklós gyúitốtevékenysége jelentôsen kiszélesítette a Dél-Dunántúlról alkotott korabeli állatföldrajzi ismereteinket. Gyújteményének adatait elóször KovÁCS (1953, 1956) nagyszerú, a hazai nagylepke fauna elterjedéséröl írt dolgozataiban publikálta, melyet újabb, hasonló témájú kiegészító dolgozatok követtek (KovÁCS 1954, 1955, 1957, 1958).

Nattán Miklós mellett egy fiatalabb lepkész generáció is tevékenykedett, akik elsősorban nappali lepkéket gyújtöttek, tagjai voltak: Novacsek Péter (1937-2001), Kapussy László (gyứjteménye megsemmisült), Z. Horváth József (saját gyújteménye jelenleg nincs).

A Somogy megyei Lepidoptera fauna kutatásának minőségileg egészen új állomását jelentette az 1976-tól a Barcsi Borókásban tervszerúen megindult faunafeltárás (UHERKOVICH 1978c).

Ezzel párhuzamosan különösen a Balaton déli partvidéke csábított több lepidopterológus kutatót, ahol számottevô faunisztikai adatot gyưjitöttek össze (RÉZBÁNYAI 1972, BUSCHMANN 1985). A hazai faunát feldolgozó munkákban a megye területét is érintố információkra bukkanhatunk (GOZMÁNY 1968, 1970, Fazekas 1977, 1980, Gyulai P. et al. 1974, Gyulai I. et al.1979, VOINITS 1976, 1980).

Somogy megye Macrolepidoptera faunájának kutatásában azonban a legaktívabb szerepet Uherkovich Akos munkássága jelenti (UHERKOVICH 1975, 1976a,b, 1978a,b,c,d, 1979, 1980a,b, 198 la,b,c 1983, 1984a,b, UHERKOVICH és ÁBRAHÁM 1995). Jól dokumentált vizsgálatai hatalmas információtömeget hordoznak, munkássága eredményeképpen a Janus Pannonius Múzeum természettudományi gyúijteménye több tízezer nagylepke példányt ơriz Somogy megye területéról. Ezek a kutatások a Barcsi Borókásban több mint egy évtizedig folytak, s ugyancsak hosszú évekig vizsgálta a Zselic nagylepkéit. Jelentős adatsort nyert Komlósd környékéról is, majd a somogyi Dráva mente nagylepkéit vizsgálta intenzíven, mintegy hat éven át Ábrahám Leventével. BelsóSomogy egyéb területein is vizsgálódott (Baláta-tó, Hedrehely, Mike stb.). Kutatásai és aktív kutatásszervezớ tevékenysége hozzájárult ahhoz, hogy a Drá- 
va mentén több területet - elsôsorban a Duna-Dráva Nemzeti Park területét - védetté nyilvánítsák.

1985-tôl kezdve a Somogy Megyei Múzeum Természettudományi Osztályának létrejöttével a megye faunájának kutatásában, így a lepidopterológiai vizsgálatokban is jelentôs elốrelépés történt, ugyanis a múzeum gyújteményében ma már közel harmincezer nagylepke példány származik a Somogy megyei faunafeltáró kutatások bizonyító példányaiból (ÁBRAHÁM 1992a,b, 1998, ÁBRAHÁM és UHERKOVICH 1994, 1998).

A lepkék vizsgálata iránti érdeklődés ma sem csökkent Kaposvárott. Nagyon sok tehetséges iskolás diák érdeklődik komolyan a rovarok, elsősorban a nappali lepkék iránt. Többen az iskolapadból kikerülve is megórizték érdeklődésüket, és ma is folytatnak gyứjtő tevékenységet. Feltétlenül meg kell említenünk Kollár Tamás nevét, aki több évig eredményesen gyújtött a Zaranyierdőben (Kaposvár). Kaposvárott ma a legnagyobb magángyújteménnyel (3000 példány) Orsik Mihály rendelkezik, aki elsôsorban Töröcske (Kaposvárhoz tartozó település) faunáját vizsgálja és nevéhez fúződik az Autographa bractea és a Aedias leucomelas első somogyi példányainak megtalálása. Barcson a Drávavölgye középiskolában Malgay Viktor középiskolai tanár (erdész) vizsgálja a helyi lepkefaunát diákjaival. Középrigócon rendszeresen üzemeltetnek fénycsapdát és az iskolában nagyon komoly rovargyújteményt, köztök lepkegyúiteményt állítottak fel.

Az elmúlt évtizedek során a megye több tájegységéról - elsősorban azokról, ahol a nagyobb természetvédelmi területek találhatók - rengeteg információ gyúlt össze: a Barcsi Borókás TK, a Duna-Dráva Nemzeti Park Dráva menti területei, a Zselici TK, a Boronka-melléki TK és a Látrány-puszta TT. Azonban szinte alig vannak adatok Külső-Somogyból.

Somogy megye teljes Macrolepidoptera faunájának mikrotaxonómiai, faunisztikai, állatföldrajzi, ökológiai és természetvédelmi feltárása és értékelése a következő kutatási évek, évtizedek feladata lesz, s ehhez talán a most összegzett faunalista összeállításával épp az elsô lépést tettük meg. 


\section{Somogyból ismert fajok jegyzéke}

\section{A fajlistában használt nevezéktan KGRSHOLT \& RAzOwSKI (1996) munkája} alapján készült. A listában használt rövidítések:

\author{
Abafi-Aigner 1899-A 1899 \\ Abafi-Aigner 1917 - A 1917 \\ Ábrahám 1990 - Á 1990 \\ Ábrahám 1992a - Á 1992a \\ Ábrahám 1992b - Á 1992b \\ Ábrahám 1998 - Á 1998 \\ Ábrahám 1998-99 - Á 1998-99 \\ Ábrahám, Uherkovich 1994 - Á-U 1994 \\ Ábrahám, Uherkovich 1998 - Á-U 1998 \\ Buschmann 1985 - B 1985 \\ Fazekas 1977 - F 1977 \\ Gyulai I. et al. 1979 - Gyl et al 1979 \\ Gyulai P. et al. 1974 - GyP et al 1974 \\ Kovács 1953 - K 1953 \\ Kovács 1954 - K 1954 \\ Kovács 1955 - K 1955 \\ Kovács 1956 - K 1956 \\ Kovács 1957 - K 1957 \\ Kovács 1958 - K 1958 \\ Kovács 1973 - K 1973 \\ Pazsiczky J 1916 - PJ 1916 \\ Pazsiczky S 1942 - PS 1942 \\ Rézbányai 1972 - Ré 1972
}

\author{
Rotschild 1909 - Ro 1909 \\ Szent-Ivány 1938 - Sz 1938 \\ Thúróczy 1983-1984 - T 1983-1984 \\ Uherkovich 1975 - U 1975 \\ Uherkovich 1976a - U 1976a \\ Uherkovich 1976b - U 1976b \\ Uherkovich 1978a - U 1978a \\ Uherkovich 1978b-U 1978b \\ Uherkovich 1978c-U 1978c \\ Uherkovich 1979 - U 1979 \\ Uherkovich 1980a - U 1980a \\ Uherkovich 1980b - U 1980b \\ Uherkovich 1981a - U 1981a \\ Uherkovich 1981b - U 1981b \\ Uherkovich 1981c-U 198 Ic \\ Uherkovich 1983 - U 1983 \\ Uherkovich 1984a - U 1984a \\ Uherkovich 1984b - U 1984b \\ Uherkovich 1985 - U 1985 \\ Uherkovich, Ábrahám 1995 - U-Á 1995 \\ Varga 1981 - V. 1981 \\ Vojnits 1976 - V 1976 \\ Z. Horváth 1999 - H 1999
}

\section{Lasiocampidae}

Poecilocampinae

Poecilocampa populi (Linnaeus, 1758) - Á 1992a; Á 1992b; Á-U 1994; Á-U 1998; K 1953; U 1976a; U 1978b; U 1978c; U 1981a; U 1981c; U-Á 1995;

Trichiura crataegi (Linnaeus, 1758) - Á 1990; Á 1992b; Á-U 1994; K 1953; U 1981a; U 198Ic;

\section{Lasiocampinae}

Eriogaster lanestris (Linnaeus, 1758) - Á 1990; Â 1992a; Á-U 1994; K 1953; U 1976a; U 1978b; U 1981a; U 1981c; U-Á 1995;

Eriogaster rimicola (Denis \& Schiffermüller, 1775) - Á 1990; Á 1992b; Á-U 1994; K 1953; U 1981a; U 1981c;

Eriogaster catax (Linnaeus, 1758) - Á 1990; Á 1992a; Á-U 1994; K 1953; U 1981a; U 1981c;

Malacosoma neustria (Linnaeus, 1758) - Á 1990; Á 1992a; Á 1992b; Á-U 1994; K 1953; Ré 1972; T 1983-1984; U 1976a; U 1978a; U 1978b; U 1978c; U 1981a; U 1981c; U 1983; U-Á 1995;

Lasiocampa (=Pachygastria) trifolii (Denis \& Schiffermüller, 1775) - Á 1990; Á 1992a; Á-U 1994; Á-U 1998; K 1953; Ré 1972; U 1976a;
U 1976b; U 1978a; U 1978b; U 1978c; U 1981c; U 1983; U-Á 1995;

Lasiocampa quercus (Linnaeus, 1758) - Á 1990; ヘ́ 1992a; Á 1992b; Á-U 1994; Á-U 1998; K 1953; U 1976a; U 1976b; U 1978a; U 1978b; U 1978c; U 1981a; U 1981c; U 1983; U-Á 1995;

Macrotylacia rubi (Linnaeus, 1758) - Á 1990; Á 1992a; Á 1992b; Á-U 1994; Á-U 1998; K 1953; Ré 1972; T 1983-1984; U 1976a; U 1976b; U 1978a; U 1978b; U 1978c; U 1981a; U 1981c; U 1983; U-Á 1995;

Dendrolimus pini (Linnaeus, I758) - Á 1990; Á 1992a; Á 1992b; Á-U 1994; Á-U 1998; K 1953; Ré 1972; T 1983-1984; U 1976a; U 1978a; U 1978c; U 1981a; U 198Ic; U 1983; U-Á 1995;

Euthrix potatoria (Linnaeus, 1758) - Á 1990; Á 1992a; Á 1992b; Á-U 1994; Á-U 1998; K 1953; T 1983-1984; U 1976a; U 1976b; U 1978a; U 1978b; U 1978c; U 1981a; U 1981c; U 1983; U-Á 1995;

Phyllodesma ilicifolia (Linnaeus, 1758) - K 1953; 'Téves határozás! Nincs példány.

Phyllodesma tremulifolia (Hübner, 1810) - Á 1990; Á 1992a; Á 1992b; Á-U 1994; Á-U 
I998; K 1953; Ré 1972; U 1976a; U 1976b; U I978a; U 1978b; U 1978c; U 1981c; U 1983; U-Á 1995;

Gastropacha quercifolia (Linnaeus, 1758) - Á 1990; Á 1992a; Á 1992b; Á-U 1994; Á-U 1998; K 1953; Ré 1972; T 1983-1984; U I976a; U 1976b; U 1978a; U 1978b; U 1978c; U 1981a; U 1981c; U 1983; U-Á 1995;

Gastropacha populifolia (Denis \& Schiffermüller, 1775) - Á 1990; Á 1992a; Á-U 1994; ÁU 1998; K 1953; U 1976a; U 1976b; U 1978b; U 1978c; U 1981c; U-Á 1995;

Odonestis pruni (Linnaeus, 1758) - Á 1990; Á 1992a; Á 1992b; Á-U 1994; Á-U 1998; K 1953; Ré 1972; T 1983-1984; U 1976a; U 1976b; U 1978a; U 1978b; U 1981 a; U 198 lc; U 1983; U-Á 1995;

\section{Endromidae}

Endromis persicolora (Linnacus, 1758) - Á 1992a; Á 1992b; Á-U 1994; Gyl el al 1979; GyP et al 1974; K 1953; U 1976a; U 1978a; U 1978b; U 1978c; U 198Ia; U 1981c; U 1983; U 1984a; U 1984b; U.Á 1995;

\section{Saturniidae}

Agliinae

Aglia tau (Linnaeus, 1758) - Á 1990; Á 1992a; Á 1992b; Á-U 1994; Á-U 1998; K 1953; U 1981a; U 1981c;

\section{Saturniinae}

Saturnia pyri (Denis \& Schiffermüller, 1775) - Á 1990; $\Lambda$ 1992a; $\Lambda$ 1992b; $\Lambda$-U 1994; Á-U 1998; K 1953; K 1956; Ré 1972; U 1976a; U 1976b; U 1978a; U 1978b; U 1978c; U 1981a; U 1981c; U-Á 1995;

Saturnia (=Eudia) paronia (Linnaeus, 1758) Á 1990; Á 1992a; Á 1992b; ᄉ́-U 1994; Á-U 1998; K 1953; Ré 1972; T 1983-1984; U 1976a; U 1978a; U 1978b; U 1978c; U 1981 a; U 1981c; U 1983; U-Á 1995;

Saturnia spini (Denis \& Schiffermüller, 1775) - Á 1990; Á-U 1994;

Antherea yamamai (Guérin-Méneville, 1861 ) - ᄉ́ 1990; ́́ 1992a; Á 1992b; Á-U 1994; Á-U 1998; GyP et al 1974; U 1976a; U 1976b; U 1978a; U 1978b; U 1978c; U 1981a; U 1981c; U 1983; U 1984b; U-Á 1995;

\section{Lemoniidae}

Lemonia dumi (Linnaeus, 1761) - Á 1992b; Á-U 1994; K 1953;

Lemonia taraxaci (Denis \& Schiffermüller, 1775) - Á 1990; Á 1992b; Á-U 1994; K 1953;

\section{Sphingidae}

\section{Smerinthinae}

Marumba quercus (Denis \& Schiffermüller, 1775) - A 1899; Á 1990; Á-U 1994; K 1953; K 1956; Ré 1972;

Mimas tiliae (Linnaeus, 1758) - Á 1990; Á 1992a; Á 1992b; Á-U 1994; Á-U 1998; K 1953; Ré 1972; T 1983-1984; U 1976a; U 1976b; U 1978a; U 1978b; U 1978c; U 198la; U 1981c; U 1983; U-Á 1995;

Smerinthus ocellata (Linnaeus, 1758) - Á 1990; Á 1992a; Á 1992b; Á-U 1994; Á-U I998; K 1953; Ré 1972; T 1983-1984; U 1976a; U 1976b; U 1978a; U 1978b; U 1978c; U 1981a; U I981c; U 1983; U-Á 1995;

Laothoe populi (Linnaeus, 1758) - Á 1990; Á I992a; Á 1992b; Á-U 1994; Á-U 1998; K 1953; Ré 1972; 'T 1983-1984; U 1976a; U 1976b; U 1978a; U 1978b; U 1978c; U 1981a; U 1981c; U 1983; U-Á 1995;

\section{Sphinginae}

Agrius convolvuli (Linnacus, 1758) - Á 1990;

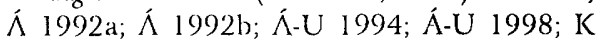
1953; Ré 1972; U 1976a; U 1976b; U 1978a; U 1978b; U 1978c; U 1979; U 1981a; U 198 Ic; U-Á 1995;

Acherontia atropos (Linnaeus, 1758) - Á 1990; Á-U 1994; A-U 1998; K 1953; PS 1942; Ré 1972; U 1976a; U 1976b; U 1978b; U $1981 \mathrm{~b}$; U 1981c; U-Á 1995;

Sphinx ligustri Linnaeus, 1758; Á 1990; Á 1992a; Á 1992b; Á-U 1994; Á-U 1998; K 1953; Ré 1972; U 1976a; U 1976b; U 1978a; U 1978b; U 1978c; U 1979; U 1981a; U 198 lc; U-Á 1995;

Hyloicus pinastri (Linnaeus, 1758) - Á 1990; Á 1992a; Â 1992b; Á-U 1994; Á-U 1998; K 1953; Ré 1972; U 1976a; U 1978a; U 1978b; U 1978c; U 1981 a; U 1981c; U 1983; U-Á 1995;

\section{Macroglossinae}

Hemaris tityus (Linnaeus, 1758) - Á 1990; Á.U 1994; K 1953;

Hemaris fuciformis (Linnaeus, 1758) - Á-U 1994; K 1953;

Macroglossum stellatarum (Linnaeus, 1758) Á 1990; Á 1992a; Á 1992b; Á-U 1994; K 1953; Ré 1972; U 1976a; U 1978b; U 1978c; U 1981c; U-Á 1995;

Daphnis nerii (Linnaeus, 1758) - Á-U 1994; K 1953;

Proserpinus proserpina (Pallas, 1772) - Á 1990; Á 1992a; Á 1992b; Á-U 1994; Á-U 1998; Gyl et al 1979; K 1953; U 1976a; U 
1978c; U 1981á; U 1981c; U-Á 1995;

Hyles (=Celeiro) euphorbiae (Linnaeus, 1758) - Á 1990; Á 1992a; Á 1992b; Á-U 1994; Á-U 1998; K 1953; PS 1942; Ré 1972; U 1976a; U 1976b; U 1978a; U 1978b; U 1978c; U 1981a; U 1981c; U-Á 1995;

Hyles (=Celerio) galii (Rottemburg, 1775) Á 1990; Â-U 1994; K 1953;

Hyles (=Celerio) livornica (Esper, 1779) - Á 1990; Á-U 1994; Á-U 1998; K 1953; Ré 1972; U 1978a; U 1978c; U 1979; U 1981c; U-Á 1995;

Deilephila elpenor (Linnacus, 1758) - Á 1990; Á 1992a; Á 1992b; Á.U 1994; Á-U 1998; K 1953; Ré 1972; U 1976a; U 1976b; U 1978a; U 1978b; U 1978c; U 1981a; U 198Ic; U 1983; U-Á 1995;

Deilephila porcellus (Linnaeus, 1758) - Á 1990; Á 1992a; Á 1992b; Á-U 1994; Á-U 1998; K 1953; Ré 1972; U 1976a; U 1976b; U 1978a; U 1978b; U 1978c; U 1981a; U 1981c; U 1983; U-Á 1995;

\section{Hesperiidae}

\section{Pyrginae}

Erynnis tages (Linnaeus, 1758) - Á 1990; ÁU 1994; Á.U 1998; K 1953; U 1976a; U 1976b; U 1978c; U 1981c; U-Á 1995;

Carcharodus alceae (Esper, 17 80) - Á 1992a; Á 1992b; Á-U 1994; Á-U 1998; K 1953; Ré 1972; U 1976a; U 1976b; U 1978a; U 1978b; U 1978c; U 198Ic; U-Á 1995; 1972;

Carcharodus lavatherae (Esper, 1783) - Ré

Carcharodus floccifera (Zeller, 1847) - Á 1990; Á-U 1994; K 1953; Ré 1972;

Spialia orbifer (Hübner, 1823) - Á 1990;

Pyrgus carthami (Hübner, 1813) - Á 1990; Á 1992a; Á 1992b; Á-U 1994; K 1953; Ré 1972; U 1976a; U 1976b; U 1978c; U 1981c; U-Á 1995;

Pyrgus malvae (Linnaeus, 1758) - Á 1990; Á 1992a; Á 1992b; Á-U 1994; Á-U 1998; K 1953; Ré 1972; Ro 1909; U 1976a; U 1976b; U 1978b; U 1978c; U 1981a; U 1981 c; U-Á 1995; Pyrgus serratulae (Rambur, 1839) - Á 1990; Á 1992a; Á-U 1994; K 1953; Ré 1972;

Pyrgus armoricanus (Oberthür, 1910) - Á 1990; Á 1992a; Á-U 1998; K 1953; Ré 1972; U 1976a; U 1976b; U 1978b; U-Á 1995;

Pyrgus alveus (Hübner, 1803) - A 1917; K 1953;

\section{Heteropterinae}

Heteropterus morpheus (Pallas, 1771) - Á 1992a; Á 1992b; Á-U 1994; Á-U 1998; K 1953; PS 1942; Ré 1972; U 1976a; U 1978c; U 1981 a; U 1981c; U-Á 1995;
Carterocephalus palaemon (Pallas, 1771) - Á 1990; Á 1992a; Á 1992b; Á-U 1994; Á-U 1998; K 1953; U 1976a; U 1976b; U 1978c; U 1981c; U-Á 1995;

\section{Hesperiinae}

Thymelicus lineola (Ochsenheimer, 1808) - Á 1990; Á 1992a; Á 1992b; Á-U 1994; Á-U 1998; K 1953; K 1956; Ré 1972; U 1976a; U 1976b; U 1978b; U 1978c; U-Á 1995;

Thymelicus sylvestris (Poda, 1761) (=flarus) Á 1990; Á 1992a; Á 1992b; Á-U 1994; Á-U 1998; K 1953; Ré 1972; U 1976a; U 1978a; U 1978b; U 1978c; U 1981a; U 198lc; U-Á 1995;

Hesperia comma (Linnaeus, 1758) - Á 1990; Á 1992a; Á-U 1994; Á.U 1998; K 1953; Ré 1972; U 1976a; U 1976b; U 1978c; U 1981c; U-Á 1995;

Ochlodes penata (Bremer \& Grey, 1853) - Á 1990; Á 1992a; Á 1992b; Á-U 1994; Á-U 1998; K 1953; Ré 1972; U 1976a; U 1976b; U 1978a; U 1978b; U 1978c; U 1981a; U 1981c; U 1983; U-Á 1995;

\section{Papilionidae}

\section{Parnassiinae}

Zerynthia polyxena (Denis \& Schiffermüller, 1775) - Á 1990; Á-U 1994; Á-U 1998; Ré 1972; U-Á 1995;

Parnassius mnemosyne (Linnaeus, 1758) - Á 1990; Á 1992a; Á 1992b; Á-U 1994; Á-U 1998; K 1953; Ré 1972; U 1976a;

\section{Papilioninae}

Iphiclides podalirius (Linnaeus, 1758) - Á 1990; Á 1992a; Á 1992b; Á-U 1994; Á-U 1998; K 1953; Ré 1972; U 1976a; U 1976b; U 1978b; U 1978c; U 1981c; U-Á 1995;

Papilio machaon Linnaeus, 1758; Á 1990; Á I992a; Á 1992b; Á-U 1994; Á-U 1998; K 1953; Ré 1972; U 1976a; U 1976b; U 1978b; U 1978c; U 1981a; U 1981c; U.Á 1995;

\section{Pieridae}

\section{Dismorphiinae}

Leptidea sinapis (Linnaeus, 1758) - Á 1990; Á 1992a; Á 1992b; Á 1998; Á-U 1994; Á-U 1998; K 1953; Ré 1972; U 1976a; U 1976b; U 1978a; U 1978b; U 1978c; U 1981a; U 1981c; U-Á I995;

Leptidea reali Reissinger, 1989; Ábrahám 1999; Á-U 1998;

Leptidea morsei Fenton, 1881; Á 1990; Á 1992b; Á-U 1994; K 1953; Ré 1972; U 1981a; U 1981c; 


\section{Pierinae}

Anthocharis cardamines (Linnaeus, 1758) - Á 1990; Á 1992a; Á 1992b; Á-U 1994; Á-U 1998; K 1953; Ré 1972; U 1976a; U I976b; U 1978c; U 1981a; U 198 Ic; U.Á 1995;

Aporia crataegi (Linnaeus, 1758) - Á 1990; Á-U 1994; K 1953; Ré 1972; U 1976a; U 1978b; U 1978c; U-Á 1995;

Pieris brassicae (Linnaeus, 1758) - Á 1990; Á 1992a; Á 1992b; Á-U 1994; Á-U 1998; K 1953; Ré 1972; U 1976a; U 1976b; U 1978a; U 1978b; U 1978c; U I98Ia; U I98lc; U-Á 1995;

Pieris rapae (Linnaeus, 1758) - Á 1990; Á 1992a; Á I992b; Á-U 1994; Á-U 1998; K 1953; Ré 1972; U 1976a; U 1976b; U 1978a; U 1978b; U 1978c; U 1981a; U 1981c; U-Á 1995;

Pieris napi (Linnaeus, 1758) - Á 1990; Á 1992a; Á 1992b; Á-U 1994; Á-U 1998; K 1953; Ré 1972; U 1976a; U 1976b; U 1978a; U 1978b; U 1978c; U I981a; U 198Ic; U-Á 1995;

Pontia edusa (Fabricius, 1777) (=daplidice) Á 1990; Á 1992a; Á-U 1994; Á-U I998; K 1953; Ré 1972; U 1976a; U 1978c; U 198Ic; U-Á 1995;

\section{Coliadinae}

Colias erate (Esper, 1805) - Á 1992a; Á-U I998;

Colias croceus (Fourcroy, 1785) - Á 1990; Á 1992a; Á 1992b; Á-U 1994; Á-U 1998; K 1953; Ré 1972; Ro 1909; U 1976a; U 1976b; U 1978a; U 1978c; U 1981 c; U-Á 1995;

Colias myrmidone (Esper, 1780) - K 1953

Colias chrysotheme (Esper, 1781) - Ré 1972;

Colias hyale (Linnaeus, 1758) - Á 1990; Á 1992a; Á 1992b; Á-U 1994; Á-U 1998; K 1953; Ré 1972; U 1976a; U 1976b; U 1978a; U 1978b; U 1978c; U 1981a; U 1981c; U-Á 1995;

Colias alfacariensis Ribbe, 1905 (=australis, Vrty.) - Á 1990; Á 1992a; Á-U 1994; Á-U 1998; Ré 1972; U 1978a; U 198 Ic; U-Á 1995;

Gonepteryx rhamni (Linnaeus, 1758) - $\hat{A}$ 1990; Á 1992a; Á 1992b; Á-U 1994; Á-U 1998; K 1953; PS 1942; Ré 1972; U 1976a; U 1976b; U 1978a; U 1978b; U 1978c; U 1981c; U-Á 1995;

\section{Lycaenidae}

\section{Riodininae}

Hainearis lucina (Linnaeus, 1758) - Á 1990; Á 1992a; Á 1992b; Á-U 1994; Á-U I998; K 1953; Ré 1972; U 1976a; U 1976b; U 1978b; U 1978c; U 1981a; U 1981c; U-Á 1995;

\section{Lycaeninae}

Lycaena phlaeas (Linnaeus, 1761) - Á 1990;
Á 1992a; Á 1992b; Á-U 1994; Á-U 1998; K 1953; Ré 1972; U 1976a; U 1976b; U 1978a; U 1978b; U 1978c; U 1981c; U-Á I995;

Lycaena dispar (Haworth, 1802) - Á 1990; $\hat{\Lambda}$ 1992a; $\Lambda$ 1992b; Á-U 1994; Á-U 1998; K 1953; Ré 1972; U 1976a; U 1976b; U 1978a; U 1978b; U 1978c; U I981á; U 1981 c; U-Á 1995; Lycaena virgaureae (Linnacus, 1758) - $\hat{\Lambda}-\mathrm{U}$ 1994; K 1953;

Lycaena titynes (Poda, 1761) - Á 1990; Á I992a; Á 1992b; Á-U 1994; Á-U 1998; K 1953; Ré 1972; U 1976a; U 1976b; U 1978a; U 1978b; U I978c; U I98Ia; U 1981c; U-Á 1995;

Lycaena alciphron (Rottemburg, 1775) - A 1899; K 1953;

Lycaena hippothoe (Linnaeus, 1761) - Á 1990; Á 1992a; Á-U I 994; Á-U 1998; K 1953; PS 1942; U 1976a; U 1976b; U 1978a; U 1978b; U 1978c; U-Á 1995;

Lycaena thersamon (Esper, 1784) - Á 1990; Á-U 1994; K 1953; Ré 1972;

Thecla betulae (Linnaeus, 1758) - Á 1990; Á-U 1994; K 1953; Ré 1972;

Neozephynus quercus (Linnaeus, 1758) - Á 1990; Á-U 1994; K 1953; Ré 1972; U 1981a; U 1981c; Callophrys rubi (Linnaeus, 1758) - Á 1990; Á 1992a; Â-U 1994; Á-U 1998; K 1953; Ré 1972; U 1976a; U 1978c; U-Á 1995;

Satyrium w-album (Knoch, 1782) - Á 1990; Á-U 1994; K 1953; PS 1942; Ré 1972;

Satyrium pruni (Linnaeus, 1758) - Á 1990; Á-U 1994; K 1953; Ré 1972;

Satyrium spini (Denis \& Schiffermüller, 1775; Á 1992a; Á-U 1994; PS 1942;

Satyrium ilicis (Esper, 1779) - Á 1992a; Á-U 1994; Á-U 1998; K 1953; Ré 1972; U 1976a; U 1976b; U 1978c; U 198Ia; U 198Ic; U-Á 1995; Satyrium acaciae (Fabricius, 1787) - Á 1990; Á 1992a; Á-U 1994; Á-U 1998; K 1953;

Leptotes pirithous (Linnaeus, 1767) (=Syntarocus telicanus) - K 1953;

Cupido minimus (Fuessly, 1775) - Á-U 1994; K 1953; Ré 1972;

Cupido argiades (Pallas, 1771) - Á 1990; Á 1992a; Á 1992b; Á-U 1994; Á-U 1998; K 1953; Ré 1972; U 1976a; U 1976b; U 1978a; U 1978b; U 1978c; U 198 Ia; U 1981c; U-Á 1995;

Cupido decolorata (Staudinger, 1886) - Á 1990; Á 1992b; Á-U 1994; K 1953; Ré 1972; U 1976a; U 1981a; U 1981c;

Cupido alcetas (Hoffmannsegg, 1804) - Á 1990; Á 1992a; Á 1992b; Á-U 1994; Á-U 1998; K 1953; U 1976a; U 1981a; U 1981b; U 1981c; U 1984b; U-Á 1995; 
Celastrina argiolus (Linnaeus, 1758) - Á 1990; Á 1992a; Á 1992b; Á-U 1994; Á-U 1998; K 1953; K 1956; Ré 1972; U 1976a; U 1976b; U 1978a; U 1978b; U 1978c; U 198la; U 1981c; U-Á 1995;

Pseudophilotes (=Lycaena) picrama (Moore, 1865) - Á 1990; Â-U 1994; K 1953; Ré 1972; U 1978c; U 1981c; U-Á 1995;

Scolitantides orion (Pallas, 1771) - Á 1990; Á-U 1994; Á-U 1998; K 1953; U 1976a; U 1976b; U 1978c; U 1981c; U-Á 1995;

Glaucopsyche alexis (Poda, 1761) - Á 1990; Á-U 1994; K 1953; Ré 1972;

Iolana iolas (Ochsenheimer, 1816) - Ré 1972; Maculinea arion (Linnaeus, 1758) - K 1953; Maculinea teleius (Bergsträsser, 1779) - Á 1990; Á 1992a; Á-U 1998; B 1985; K 1953; Ré 1972; U 1976a; U 1978a; U 1981c; U-Á 1995;

Maculinea nausithous (Bergsträsser, 1779) (=arcas) - Á 1990; Á 1992a; Á-U 1994; Á-U 1998; B 1985; Gyl et al 1979; K 1956; Ré 1972; U 1976a; U 1978a; U-Á 1995;

Maculinea alcon (Denis \& Schiffermüller, 1775) - Á 1990; Â-U 1994;

Plebeius argus (Linnaeus, 1758) - Á 1990; Á 1992a; Á 1992b; Á-U 1994; Á-U 1998; K 1953; Ré 1972; U 1976a; U 1976b; U 1978a; U 1978b; U 1978c; U 1981c; U-Á 1995;

Plebeius idas (Linnaeus, 1761) - B 1985; K 1953;

Plebeius argyrognomon (Bergsträsser, 1779) - Á 1990; Á 1992a; Â 1992b; Á-U 1994; Á-U 1998; K 1953; Ré 1972; U 1976a; U 1976b; U 1978a; U 1978b; U 1978c; U 1981c; U-Á 1995;

Aricia agestis (Denis \& Schiffermüller, 1775) - Á 1990; Á 1992a; Á-U 1994; Á-U 1998; K 1953; U-Á 1995;

Polyommatus semiargus (Rottemburg, 1775) Á 1990; Á 1992a; Â-U 1994; Á-U 1998; K 1953; Ré 1972; U 1976a; U 1978b; U-Á 1995;

Polyommatus dorylas (Denis \& Schiffermüller, 1775) - Á 1990; Á-U 1994; Ré 1972;

Polyommatus icarus (Rottemburg, 1775) - Á 1990; Á 1992a; Á 1992b; Á-U 1994; Á-U 1998; K 1953; PS 1942; Ré 1972; U 1976a; U 1976b; U 1978a; U 1978b; U 1978c; U 1981a; U 1981c; U-Á 1995;

Polyommatus daphnis (Denis \& Schiffermüller, 1775) (=meleager) Á 1990; Á-U 1994; K 1953;

Polyommatus bellargus (Rottemburg, 1775) Á 1990; Á-U 1994; K 1953; Ré 1972;

Polyommatus coridon (Poda, 1761) - Á 1990; K 1953; Ré 1972;

\section{Nymphalidae}

Libytheinae

Libythea celtis (Laicharting, 1782) - Á 1990; Á-U 1994; K 1953; K 1955;

\section{Heliconiinae}

Agynnis paphia (Linnaeus, 1758) - Á 1990; Á 1992a; Á 1992b; Á-U 1994; Á-U 1998; K 1953; PS 1942; Ré 1972; U 1976a; U 1976b; U 1978b; U 1978c; U 1981a; U 1981c; U-Á 1995;

Argynnis pandora (Denis \& Schiffermüller, 1775) - Á 1990; Á-U 1994; K 1953; Ré 1972; Argynnis aglaja (Linnaeus, 1758) - Á 1992a; Á 1992b; Á-U 1994; K 1953; Ré 1972;

Argynnis adippe (Denis \& Schiffermüller, 1775) (=berecynthia) - Á 1990; Á 1992a; Á 1992b; Á-U 1994; Á-U 1998; K 1953; Ré 1972; Ro 1909; U 1976a; U 1978c; U 1981c; U-Á 1995;

Issoria lathonia (Linnaeus, 1758) - Á 1990; Á 1992a; Á 1992b; Á-U 1994; Á-U 1998; K 1953; Ré 1972; U 1976a; U 1976b; U 1978a; U 1978b; U 1978c; U 1981c; U-Á 1995;

Brenthis daphne (Denis \& Schiffermüller, 1775) - Á 1990; Á 1992a; Á 1992b; Á-U 1994; Á-U 1998; K 1953; PS 1942; Ré 1972; U 1976a; U 1976b; U 1978c; U 1981a; U 1981c; U-Á 1995;

Boloria euphrosyne (Linnaeus, 1758) - Á 1990; Á 1992a; Á-U 1994; K 1953; U 1976a; U 1981c;

Boloria (=Clossiana) selene (Denis \& Schiffermüller, 1775) - Á 1990; Á 1992a; Á 1992b; Á-U 1994; K 1953; PS 1942; U 1976a; U 1976b; U 1978c; U 1981c; U-Á 1995;

Boloria (=Clossiana) dia (Linnaeus, 1767) Á 1990; Á 1992a; Á-U 1994; Á-U 1998; K 1953; Ré 1972; U 1976a; U 1976b; U 1978a; U 1978b; U 1978c; U 1981c; U-Á 1995;

\section{Nymphalinae}

Vanessa atalanta (Linnaeus, 1758) - Á 1990; Á 1992a; Á 1992b; Á-U 1994; Á-U 1998; K 1953; Ré 1972; U 1976a; U 1976b; U 1978a; U 1978b; U 1978c; U 1981a; U-Ấ 1995;

Vanessa cardui (Linnaeus, 1758) - Á 1990; Á 1992a; Á 1992b; Á-U 1994; Á-U 1998; K 1953; PS 1942; Ré 1972; U 1976a; U 1976b; U 1978a; U 1978b; U 1978c; U 1979; U 1981a; U 198lc; U-Á 1995;

Inachis io (Linnaeus, 1758) - Á 1992a; Á 1992b; Á-U 1994; Á-U 1998; K 1953; K 1956; Ré 1972; U 1976a; U 1976b; U 1978a; U 1978b; U 1978c; U 1981a; U 1981c; U-Á 1995; 
Aglais urticae (Linnaeus, 1758) - Á 1990; Á 1992a; Á 1992b; Á-U 1994; Á-U 1998; K 1953; PS 1942; Ré 1972; U 1976a; U 1976b; U 1978a; U 1978b; U 1978c; U 1981a; U 1981c; U-Á 1995;

Polygonia c-album (Linnaeus, 1758) - Á 1990; Â 1992a; Á 1992b; Á-U 1994; Á-U 1998; K 1953; PS 1942; Ré 1972; Ro 1909; U 1976a; U 1976b; U 1978a; U 1978b; U 1978c; U I981a; U 1981c; U.人́ 1995;

Araschnia lesana (Linnaeus, 1758) - $\Lambda$ 1990; Á 1992a; Á 1992b; Á-U I994; Á-U 1998; K 1953; Ré 1972; Ro 1909; U 1976a; U 1976b; U 1978a; U 1978b; U 1978c; U 1981a; U 1981 c; U-Á 1995;

Nymphalis antiopa (Linnaeus, 1758) - $A$ 1990; Â 1992a; Á 1992b; Á-U 1994; Á-U I998; H 1999; K 1953; PS 1942; Ré I972; U 1976a; U 1976b; U 1978c; U 198 Ia; U 198 Ic; U-Á 1995;

Nymphalis polychloros (Linnacus, 1758) - Á 1990; $\Lambda$ 1992b; $\hat{\Lambda}-\mathrm{U} 1994 ; \mathrm{H} 1999 ; \mathrm{K} 1953$; Ré 1972; U 1976a; U 1976b; U 1978c; U 1981a; U 198Ic; U-Á 1995;

Nymphalis xanthomelas (Esper, 178I) - Á 1990; Á 1992b; Á-U 1994; H 1999; K I953;

Nymphalis vaualbum (Denis \&

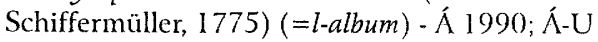
1994; H 1999; K 1953;

Euphydryas maturna (Linnaeus, 1758) - Á 1990; Á 1992a; Á 1992b; Á-U 1994; Á-U 1998; K 1953; PS 1942; U 1981c; U-Á 1995;

Euphydryas aurinia (Rottemburg, 1775) coll: SMM;

Melitaea cinxia (Linnaeus, 1758) - Á 1990; Á 1992a; Á 1992b; Á-U 1994; K 1953; PS 1942; Ré 1972; U 1976a; U 1976b; U 1978c; U I981c; U-Á 1995;

Melitaea phoebe (Denis \& Schiffermüller, 1775) - Á 1990; Á 1992a; Á 1992b; Á-U 1994; Á-U 1998; K 1953; Ré 1972; U 1976a; U 1976b; U 1978b; U 1978c; U I 98lc; U-Á 1995;

Melitaea trivia (Denis \& Schiffermüller, 1775) - Á 1990; Á-U 1998; K 1953; PS 1942; Ré 1972; U 1976b; U 1978c; U 1981c; U-Á 1995;

Melitaea didyma (Esper, 1778) - Á 1990; ÁU 1994; Á.U 1998; K 1953; U 1978c; U 1981c; U-Á 1995;

Melitaea diamina (Lang, 1789) - Á 1990; Á 1992a; Á 1992b; Á-U 1994; Á-U 1998; K 1953; PS 1942; U 1981c; U-Á 1995;

Melitaea aurelia Nickerl, 1850; Á 1990; Á 1992a; Á-U 1994; K 1953;

Melitaea britomartis Assmann, 1847; Á 1990; Á 1992b; Á-U 1994; K 1953; Ré 1972;
U 1976a; U 1978c; U-Á 1995;

Melitaea athalia (Rottemburg, 1775) - Á 1990; Á 1992a; Á 1992b; Á-U I994; Á-U 1998; K 1953; PS 1942; Ré 1972; U 1976a; U 1976b; U 1978a; U 1978b; U 1978c; U I981a; U 1981c; U-Á 1995;

\section{Limenitinae}

Neptis sappho (Pallas, 1771) (=aceris) - Á 1990; Á 1992a; Á 1992b; Á-U 1994; Á.U 1998; K 1953; K 1956; U 1976a; U 1976b; U 1978b; U 1978c; U 1981c; U-Á 1995;

Neptis rinularis (Scopoli, 1763) (=lucilla) Á-U 1994; Gyl et al 1979; K 1953; U 1976a; U 1978c; U-Á 1995;

\section{Apaturinae}

Apatura metis Freyer, 1829; Á-U 1998; U-Á 1995; Apatura ilia (Denis \& Schiffermüller, 1775) Á 1990; Á 1992a; $\hat{\Lambda}$ 1992b; $\hat{A}-U$ 1994; Á-U 1998; K 1953; U 1975; U 1976a; U 1978c; U 1981c; U.Á 1995;

Apatura iris (Linnacus, 1758) - $\Lambda$ 1990; $\hat{\Lambda}$ 1992a; Á 1992b; Á-U 1994; Á-U 1998; K 1953;

\section{Satyrinae}

Pararge aegeria (Linnaeus, 1758) - Á 1990; Á 1992a; Á 1992b; Á-U 1994; Á-U 1998; K 1953; Ré 1972; U 1976a; U 1978a; U 1978b; U 1978c; U 1981a; U 1981c; U-Á 1995;

Lasiommata megera (Linnaeus, 1767) - Á 1990; Á 1992a; Á 1992b; Á-U 1994; Á-U 1998; K 1953; Ré 1972; Ro 1909; U I976a; U 1976b; U 1978a; U 1978b; U 1978c; U 198lc; U-Á 1995 ;

Lasiommata maera (Linnaeus, 1758) - Á 1990; Á 1992a; Á 1992b; Á-U 1994; Á-U 1998; K 1953; Ré 1972; U 1976a; U 1976b; U 1978c; U 1981c; U-Á 1995;

Lopinga achine (Scopoli, 1763) - Á-U I994; K 1953; U 1978c; U 1981c; U-Á 1995;

Coenonympha arcania (Linnaeus, 1761) - Á 1990; Á 1992a; Á 1992b; Á-U 1994; Á-U 1998; K 1953; Ré 1972; U 1976a; U 1976b; U 1978c; U 1981a; U 1981c; U-Á 1995;

Coenonympha glycerion (Borkhausen, 1788) (=iphis, Denis \& Schiffermüller) - Á 1990; A 1992a; Á 1992b; Á-U 1994; Á-U 1998; K 1953; Ré 1972; Ro 1909; U 1976a; U 1976b; U 1978a; U 1978b; U 1978c; U 1981a; U 1981c; U-Á 1995;

Coenonympha pamphilus (Linnaeus, I7581; Á 1990; ヘ 1992a; Á 1992b; Á-U 1994; Á-U 1998; K 1953; Ré 1972; Ro 1909; U 1976a; U 1976b; U I978a; U 1978b; U 1978c; U 1981a; U 1981c; U-Á 1995; 
Pyronia tithonus (Linnaeus, 1767) - Á 1990; Á 1992a; Á-U 1994; Á-U 1998; K 1953; U 1976a; U 1976b; U 1978c; U-Á 1995;

Aphantopus hyperantus (Linnaeus, 1758) - Á 1992a; Á 1992b; Á-U 1994; Á-U 1998; K 1953; Ré 1972; U 1976a; U 1976b; U 1978a; U 1978b; U 1978c; U 1981a; U 1981c; U-Á 1995;

Maniola jurtina (Linnaeus, 1758) - Á 1990; Á 1992a; Á 1992b; Á-U 1994; Á-U 1998; K 1953; Ré 1972; U 1976a; U 1976b; U 1978a; U 1978b; U 1978c; U 1981a; U 198I c; U-Á 1995;

Melanargia galathea (Linnaeus, 1758) - Á 1992a; Á 1992b; Á-U 1994; Á-U 1998; K 1953; Ré 1972; U 1976a; U 1976b; U 1978a; U 1978c; U 1981a; U 1981c; U- $\Lambda$ 1995;

Minois dryas (Scopoli, 1763) - Á 1992a; Á 1992b; Á-U 1994; Á-U I998; K 1953; Ré 1972; Ro 1909; U 1976a; U 1976b; U 1978a; U 1978c; U 1981a; U 1981c; U-Á 1995;

Hipparchia fagi (Scopoli, 1763) - Á 1990; ÁU 1994; K 1953; Ré 1972;

Hipparchia semele (Linnaeus, 1758) - Á-U 1994; K 1953; Ré 1972;

Arethusana arethusa (Denis \& Schiffermüller, 1775) - K 1953; Ré 1972; Ro 1909;

Brintesia circe (Fabricius, 1775) - Á 1990; Á 1992a; Á 1992b; Á-U 1994; Á-U 1998; K 1953; U 1976a; U 1978c; U 1981a; U 1981c; U 1983; U-Á 1995;

Chazara briseis (Linnaeus, 1764) - K 1953; Ré 1972;

\section{Drepanidae}

\section{Thyatirinae}

Thyatira batis (Linnaeus, 1758) - Á 1990; $\hat{\Lambda}$ 1992a; Á 1992b; Á-U 1994; Á-U 1998; K 1953; Ré 1972; T 1983-1984; U 1976a; U 1976b; U 1978a; U 1978b; U 1978c; U 198 Ia; U 198Ic; U 1983; U-Á 1995;

Habrosyne pyritoides (Hufnagel, 1766) - $A$ 1990; Á 1992a; Á 1992b; Á-U 1994; Á-U 1998; K 1953; Ré 1972; T 1983-1984; U 1976a; U 1976b; U 1978a; U 1978b; U 1978c; U 1981a; U 1981c; U 1983; U-Á 1995;

Tethea ocularis (Linnaeus, 1767) - Á 1990; Á 1992a; Á 1992b; Á-U 1994; Á-U 1998; K 1953; Ré 1972; U 1976a; U 1976b; U 1978a; U 1978b; U 1978c; U 1981c; U 1983; U-Á 1995;

Tethea or (Denis \& Schiffermüller, 1775) Á 1990; Á 1992a; Á 1992b; Á-U 1994; Á-U 1998; K 1953; Ré 1972; T 1983-1984; U 1976a; U 1976b; U 1978a; U 1978b; U 1978c; U 1981a; U 1981c; U 1983; U-Á 1995;

Tetheella fluctuosa (Hübner, 1803) - Á 1992a; Á-U 1994; GyI et al 1979; U 1976a; U 1976b; U 1978b; U 1978c; U 1984a; U 1984b; U-Á 1995;
Ochropacha duplaris (Linnaeus, 176I) - Á 1990; Á 1992a; Á 1992b; Á-U 1994; Á-U 1998; K 1953; Ré 1972; U 1976a; U 1976b; U 1978a; U 1978b; U 1978c; U 198la; U 198Ic; U 1983; U 1984a; U-Á 1995;

Cymatophorima (=Polyploca) diluta (Denis \& Schiffermüller, 1775) - Á 1990; Á 1992a; Á 1992b; Á-U 1994; K 1953; Ré 1972; U 1978a; U 1981a; U 1981c; U 1983;

Polyploca ridens (Fabricius, 1787) - Á 1990; Á 1992a; Á 1992b; Á-U 1994; Á-U 1998; K 1953; Ré 1972; U 1976a; U 1978a; U 1978c; U 1981a; U 1981c; U-Á 1995;

Asphalia (=Polyploca) ruficollis (Denis \& Schiffermüller, 1775) - Á 1990; Á 1992a; Á I992b; Á-U 1994; K 1953; Ré 1972; U 1978a; U I98Ia; U 1981c;

Achlya (=Polyploca) flaricornis (Linnaeus, 1758) - Á 1990; Á 1992a; Á-U 1994; Á-U 1998; GyI et al 1979; K 1953; U 1978a; U 1978c; U 1981a; U 1981c; U 1983; U 1984a; U-Á 1995;

\section{Drepaninae}

Falcaria lacertinaria (Linnaeus, 1758) - Á 1990; Á 1992a; Á 1992b; Á-U 1994; Á-U 1998; K 1953; T 1983-1984; U 1976a; U 1976b; U 1978a; U 1978b; U 1978c; U 1981a; U 1981b; U 1981c; U 1983; U 1984a; U-Á 1995;

Watsonalla binaria (Hufnagel, 1767) - Á 1990; Á 1992a; Á 1992b; Â-U 1994; Á-U 1998; K 1953; Ré 1972; U 1976a; U 1976b; U 1978a; U 1978b; U 1978c; U 1981a; U 1981c; U-Á 1995;

Watsonalla cultraria (Fabricius, 1775) - Á 1990; Á 1992b; Á-U 1994; Á-U 1998; K 1953; U 1981a; U 1981c;

Drepana curvatula (Borkhausen, 1790) - Á 1990; Á 1992a; Á 1992b; Á-U 1994; Á-U 1998; K 1953; U 1976a; U 1978a; U 1978b; U 1978c; U 1981a; U 1981b; U 1981c; U 1983; U-Á 1995;

Drepana falcataria (Linnaeus, 1758) - Á 1990; Á 1992a; Á 1992b; Á-U 1994; Á-U 1998; Ré 1972; T 1983-1984; U 1976a; U 1976b; U 1978a; U 1978b; U 1978c; U 1981a; U 1981c; U 1983; U-Á 1995;

Sabra harpagula (Esper, 1786) - Á 1992a; Á 1992b; Á-U 1994; Á-U 1998; K 1953; T 19831984; U 1976a; U 1976b; U 1978a; U 1978b; U 1978c; U 1981a; U 1981c; U-Á 1995;

Cilix glaucata (Scopoli, 1763) - Á 1990; Á 1992a; Â 1992b; Á-U 1994; Á-U 1998; K 1953; Ré 1972; T 1983-1984; U 1976a; U 1976b; U 1978a; U 1978b; U 1978c; U 1981a; U 1981c; U 1983; U-Á 1995; 


\section{Geometridae}

\section{Archiearinae}

Archiearis parthenias (Linnaeus, 1761) - Á 1990; Á-U 1994; Á-U 1998; GyI et al 1979; K 1953; U 1976a; U 1976b; U 1978c; U 1984a; U.Á 1995;

Archiearis notha (Hübner, 1803) - Á 1990; A-U 1994; K 1953; U 1981a; U 1981c;

Archiearis puella (Esper, 1787) - Á 1990; ÁU 1994; Á-U 1998; K 1953;

\section{Ennominae}

Abraxas grossulariata (Linnaeus, 1758) - Á 1990; Á 1992a; Á 1992b; Á-U 1994; Á-U 1998; K 1953; PS 1942; Ré 1972; T 19831984; U 1976a; U 1978a; U 1978b; U 1978c; U 1981 a; U 1981c; U 1983; U-Á 1995;

Calospilos sylvata (Scopoli, 1763) - Á 1992a; Á 1992b; Á-U 1994; Á-U 1998; K 1953; U 1976a; U 1978a; U 1981a; U 1981b; U 198I c; U-Á 1995;

Lomaspilis marginata (Linnaeus, 1758) - Á 1990; Á 1992a; Á 1992b; Á-U 1994; Á-U 1998; K 1953; Ré 1972; T 1983-1984; U 1976a; U 1976b; U 1978a; U 1978b; U 1978c; U 1981a; U 1981c; U 1983; U-Á 1995;

Ligdia adustata (Denis \& Schiffermüller, 1775) - Á 1990; Á 1992a; Á 1992b; Á-U I 994; Á-U 1998; K 1953; Ré 1972; T 1983-1984; U 1976a; U 1976b; U 1978a; U 1978b; U 1978c; U 1981a; U 1981c; U 1983; U-Á 1995;

Stegania (=Lomographa) cararia (Hübner, 1790) - Á 1990; Á 1992a; Á 1992b; Á-U I 994; Á-U 1998; K 1953; U 1976a; U 1976b; U 1978a; U 1978b; U 1978c; U 1981a; U 198lb; U 1981c; U 1984b; U-Á 1995;

Stegania (=Lomographa) dilectaria (Hübner, 1790) - A 1899; Á 1990; Á 1992a; Á-U 1994; Á-U 1998; K 1953; Ré 1972; T 1983-1984; U 1976a; U 1976b; U 1978a; U 1978b; U 1978c; U 1981c; U 1983; U-Á 1995;

Heliomata (=Semiothisa) glarearia (Denis \& Schiffermüller, 1775) - Á 1990; Á 1992a; Á 1992b; K 1953; Ré 1972; T 1983-1984; U 1976a; U 1978a; U 1978c; U 1981a; U 1981c; U-Á 1995;

Macaria (=Semiothisa) notata (Linnaeus, 1758) - Á 1990; Á 1992a; Á 1992b; Á-U 1994; Á-U 1998; K 1953; U 1976a; U 1976b; U 1978a; U 1978c; U 1981a; U 198lc; U 1983; U-Á 1995;

Macaria (=Semiothisa) alternata (Denis \& Schiffermüller, 1775) - Á 1990; Á 1992a; Á I992b; Á-U 1994; Á-U 1998; K I953; T 19831984; U 1976a; U 1976b; U 1978a; U 1978b; U 1978c; U 1981a; U 1981c; U 1983; U-র́ 1995;
Macaria (=Semiothisa) liturata (Clerck, 1759) - Á 1990; Á 1992a; Á 1992b; Á-U 1994; Á-U 1998; K 1953; T 1983-1984; U 1976a; U 1978a; U 1978b; U 1978c; U 1980a; U 1981a; U 1981c; U 1983; U-Á 1995;

Macaria wauaria (Linnaeus, 1758) - Á-U 1994;

Macaria artesiaria (Denis \& Schiffermüller, 1775) - Á 1990; Á-U 1994; Á-U 1998; K 1953;

Chiasmia (=Semiothisa) clathrata (Linnaeus, 1758) - Á 1990; Á 1992a; Á 1992b; Á-U 1994; Á-U 1998; K 1953; Ré 1972; T 1983-1984; U 1976a; U 1976b; U 1978a; U 1978b; U 1978c; U 1981a; U 1981c; U 1983; U-Á 1995;

Narraga fasciolaria (Hufnagel, 1767) - K 1953;

Tephrina murinaria (Denis \& Schiffermüller, 1775) - Á 1992b; Á-U 1994; K 1953; Ré 1972; U-Á I995;

Tephrina arenacearia (Denis \& Schiffermüller, 1775) - Á 1990; Á 1992a; Á 1992b; ÁU 1994; Á-U 1998; K 1953; Ré I972; T 19831984; U 1976a; U 1976b; U I978a; U 1978b; U 1978c; U 1981a; U 1981c; U 1983; U-Á 1995;

Cepphis advenaria (Hübner, 1790) - Á 1990; Á 1992a; Á 1992b; Á.U 1994; Á-U 1998; K 1953; Ré 1972; U 1976a; U 1978a; U 1978b; U I978c; U 1981a; U.Á 1995;

Petrophora chlorosata (Scopoli, 1763) - A 1899; Á 1990; Á 1992a; Á 1992b; Á-U 1994; Á-U 1998; K 1953; Ré 1972; U 1976a; U I976b; U 1978a; U 1978b; U 1978c; U 1981 a; U 1981b; U 1981c; U 1983; U-Á 1995;

Plagodis pulveraria (Linnaeus, 1758) - Á 1990; Á 1992a; Á 1992b; Á-U 1994; Á-U 1998; K 1953; Ré 1972; T 1983-1984; U I976a; U 1976b; U 1978a; U 1978b; U 1978c; U 1981a; U 1981c; U 1983; U-Á 1995;

Plagodis dolabraria (Linnaeus, 1767) - Á 1990; Á 1992a; Á 1992b; Á-U 1994; Á-U 1998; K 1953; Ré 1972; U 1976a; U 1976b; U 1978a; U 1978b; U 1978c; U 1981a; U 1981c; U 1983; U-Á 1995;

Pachycnemia hippocastanaria (Hübner, 1799) K I958;

Opisthograptis luteolata (Linnaeus, 1758) - Á 1990; Á 1992a; Á 1992b; Á-U 1994; Á-U 1998; K 1953; K 1956; Ré 1972; T 19831984; U 1976a; U 1978a; U 1978c; U 1981a; U I981c; U 1983;

Epione repandaria (Hufnagel, 1767) - Á 1990; Á 1992a; Á 1992b; Â-U 1994; Á-U 1998; K 1953; Ré 1972; T 1983-1984; U 1976a; U 1978a; U I978b; U 1978c; U 1981 a; U 1981c; U 1983; U-Á 1995; 
Therapis flavicaria (Denis \& Schiffermüller, 1775) - Á 1990; Á 1992a; Á 1992b; Á-U 1994; K 1953; Ré 1972; T 1983-1984; U 1976a; U 1976b; U 1978a; U 1978b; U 1978c; U 1981a; U 1981c; U 1983; U-Á 1995;

Pseudopanthera macularia (Linnaeus, 1758) Á 1990; Á 1992a; Á 1992b; Á-U 1994; Á-U 1998; K 1953; PS 1942; Ré 1972; U 1976a; U 1978c; U 1981a; U I981c; U 1983; U-Á 1995;

Eilicrinia cordiaria (Hübner, 1790) - Á 1990; Á-U 1998; K 1953; Ré 1972;

Eilicrinia trinotata (Metzner, 1845) - Á 1990; Á-U 1994; K 1953; K 1956; Ré 1972;

Hypoxystis pluviaria (Fabricius, 1787) - Á 1990; Á 1992a; Á 1992b; Á-U 1994; Á-U I998; K 1953; T 1983-1984; U 1976a; U I978b; U-Á 1995;

Apeira syringaria (Linnaeus, 1758) - Á 1990; Á 1992a; Á I992b; Á-U I994; Á-U 1998; K 1953; Ré 1972; T 1983-1984; U 1976a; U 1978a; U 1978b; U 1978c; U 1981a; U 1981c; U 1983; U-ᄉ́ 1995;

Ennomos autumnaria (Werneburg, 1859) - Á I992a; Á 1992b; Á-U 1994; K 1953; Ré 1972; U 1976a; U 1978a; U 1978b; U 1978c; U I981a; U 1981c; U 1983; U-Á 1995;

Ennomos quercinaria (Hufnagel, 1767) - Á I992a; Á 1992b; Á-U 1994; K 1953; Ré 1972; U 1976a; U 1978c; U 1981a; U 1981c; U-Á 1995;

Ennomos fuscantaria (Haworth, 1809) - Á 1990; Á-U 1994; K 1953; Ré 1972; U 1976a; U 1976b; U 1978a; U 1978b; U 1978c; U 198Ic; U 1983;

Ennomos erosaria (Denis \& Schiffermüller, 1775) (=tiliaria) - Á 1990; Á 1992a; Á 1992b; Á-U 1994; K 1953; U 1976a; U 1976b; U 1978b; U 1978c; U 1981a; U 1981c; U 1983; U-Á 1995;

Ennomos quercaria (Hübner, 1813) - Á-U 1994; Á-U 1998;

Selenia dentaria (Fabricius, 1775) (=bilinaria) Á 1990; Á 1992a; Á 1992b; Á-U 1994; Á-U 1998; K 1953; Ré 1972; T 1983-1984; U 1976a; U 1976b; U 1978a; U 1978b; U 1978c; U 1981a; U 1981c; U 1983; U-Á 1995;

Selenia lunularia (Hübner, 1788) (=lunaria) Á 1990; Á 1992a; Á 1992b; Á-U 1994; Á-U 1998; K 1953; K 1956; Ré I972; T 19831984; U 1976a; U 1976b; U 1978a; U 1978b; U 1978c; U 1981a; U 1981c; U 1983; U-Á 1995;

Selenia tetralunaria (Hufnagel, 1767) - Á 1990; Á 1992a; Á 1992b; Á-U 1994; Á-U 1998; K 1953; U 1976a; U 1976b; U 1978a; U 1978b; U 1978c; U 1981a; U 1981c; U 1983; U-Á 1995;
Artiora evonymaria (Denis \& Schiffermüller, 1775) - Á 1990; Á 1992a; Á 1992b; Á-U 1994; Á-U 1998; K 1953; Ré 1972; T 1983-1984; U 1976a; U 1978a; U 1978b; U 1978c; U 1981a; U 1981c; U 1983; U-Á 1995;

Crocallis tusciaria (Bokhausen, 1793) - Á 1990; Á 1992b; Á-U 1994; Ré 1972;

Crocallis elinguaria (Linnaeus, 1758) - Á 1990; Á 1992b; Á-U 1994; K 1953; Ré 1972; U 1976a; U 1978a; U 1978c; U 1981a; U 1981c; U 1983; U-Á 1995;

Ourapteryx sambucaria (Linnaeus, 1758) - Á 1990; Â 1992a; Á 1992b; Á-U 1994; Á-U 1998; K 1953; U 1976a; U 1976b; U 1978b; U 1981a; U 1981c; U 1983; U-Á 1995;

Colotois pennaria (Linnaeus, 1761) - Á 1990; Á 1992a; Á 1992b; Á-U 1994; Á-U 1998; K 1953; Ré 1972; U 1976a; U 1978b; U 1978c; U 1981a; U 1981c; U 1983; U-Á 1995;

Angerona prunaria (Linnaeus, 1758) - Á 1990; Á 1992a; Á 1992b; Á-U 1994; Á-U 1998; K 1953; Ré 1972; T 1983-1984; U 1976a; U 1976b; U 1978a; U 1978b; U 1978c; U 1981 a; U 198Ic; U 1983; U-Á 1995;

Apocheima hispidaria (Denis \& Schiffermüller, 1775) - Á 1990; Á 1992a; Á 1992b; ÁU 1994; K 1953; Ré 1972; U 1976a; U 1978a; U 1978b; U 1978c; U 1981a; U 1981c; U-Á 1995;

Apocheima (=Phigalia) pilosaria (Denis \& Schiffermüller, 1775) (=pedaria) - Á 1990; Á 1992a; Á 1992b; Á-U 1994; K 1953; U 1976a; U 1978b; U 1978c; U 1981a; U 1981c; U 1983; U-Á 1995;

Lycia hirtaria (Clerck, 1759) - Á 1990; Á 1992a; Á 1992b; Á-U 1994; Á-U 1998; K 1953; Ré 1972; T 1983-1984; U 1976a; U 1978a; U 1978b; U 1978c; U 1981 a; U 198 lc; U 1983; U-Á 1995;

Lycia (=Nyssia) zonaria (Denis \& Schiffermüller, 1775) - Á 1990; Á-U 1994; K 1953; U 1976a; U 1978b; U-Á 1995;

Lycia pomonaria (Hübner, 1790) - Á 1992a; ÁU 1994; U 1981a; U 1981b; U 1981c; U-Á 1995;

Biston strataria (Hufnagel, 1767) - Á 1990; Á 1992a; Á 1992b; Á-U 1994; Á-U 1998; K 1953; Ré 1972; U 1976a; U 1978a; U 1978b; U 1978c; U 1981a; U 1981c; U 1983; U-Á 1995;

Biston betularia (Linnaeus, 1758) - Á 1990; Á 1992a; Á 1992b; Á-U 1994; Á-U 1998; K 1953; PS 1942; Ré 1972; T 1983-1984; U 1976a; U 1976b; U 1978a; U 1978b; U 1978c; U 1981a; U 1981c; U 1983; U-Á 1995;

Agriopis (=Erannis) leucophaearia (Denis \& Schiffermüller, 1775) - Á 1990; Á 1992a; Á 
1992b; Á-U 1994; K 1953; Ré 1972; U 1976a; U 1978a; U 1978b; U 1978c; U 1981a; U 198Ic; U-Á 1995;

Agriopis (=Erannis) bajaria (Denis \& Schiffermüller, 1775) - Á 1990; Á 1992b; Á-U 1994; Á-U 1998; K 1953; Ré 1972; U 1978c; U 1981a; U 1981c; U-Á 1995;

Agriopis (=Erannis) aurantiaria (Hübner, 1799) - Á 1990; Á I992a; Á-U 1994; Á-U 1998; K 1953; Ré 1972; U 1976a; U 1978a; U 1978b; U 1978c; U 1981a; U 1981c; U-Á 1995;

Agriopis (=Erannis) marginaria (Fabricius, 1776) - Á 1990; Á 1992a; Á 1992b; Á-U 1994; Á-U 1998; K 1953; Ré 1972; U 1976a; U 1978a; U 1978b; U 1978c; U 1981a; U 1981c; U 1983; U-Á 1995 ;

Erannis defoliaria (Clerck, 1759) - Á 1990); Á 1992a; Á 1992b; Á-U 1994; Á-U 1998; K 1953; Ré 1972; U 1976a; U 1978a; U 1978b; U 1978c; U 1981a; U 1981c; U 1983; U-Á 1995;

Synopsia sociaria (Hübner, 1799) - Á 1990; Á-U 1994; Á-U 1998; K 1953; Ré 1972; U 1976a; U 1978a; U 1978c; U 1981c; U 1983; U-Á 1995;

Paraboarmia vientlii (Bohatsch, 1883) - Ré 1972;

Peribatodes rhomboidaria (Denis \& Schiffermüller, 1775) - Á 1990; Á 1992a; Á 1992b; ÁU 1994; Á-U 1998; K 1953; Ré 1972; T 19831984; U 1976a; U 1976b; U 1978a; U 1978b; U 1978c; U 1981a; U 1981c; U 1983; U-Á 1995;

Cleora cinctaria (Denis \& Schiffermüller, 1775) - Á 1990; Á 1992a; Á 1992b; Á-U 1994; Á-U 1998; K 1953; Ré 1972; U 1976a; U 1978a; U 1978b; U 1978c; U 1981a; U 1981c; U 1983; U-Á 1995;

Alcis repandata (Linnaeus, 1758) - Á 1990; Á 1992a; Á 1992b; Á-U 1994; Á-U 1998; K 1953; U 1981a; U 1981c;

Hypomecis (=Boarmia) roboraria (Denis \& Schiffermüller, 1775) - Á 1990; Á 1992a; Á 1992b; Á-U 1994; Á.U 1998; K 1953; Ré 1972; U 1976a; U 1978a; U 1978b; U 1978c; U 1981a; U 1981c; U.Á 1995;

Hypomecis (=Boarmia) punctinalis (Scopoli, 1763) - Á 1990; Á 1992a; Á 1992b; Á-U 1994; Á-U 1998; K 1953; Ré 1972; U 1976a; U 1976b; U 1978a; U 1978b; U 1978c; U 1981a; U 1981c; U 1983; U-Á 1995;

Hypomecis (=Boarmia) danieli (Wehrli, 1932) - Á 1990; Á 1992b; Á-U 1994; Á-U 1998; K 1953; Ré 1972; U 1978a; U 1978c; U 1981a; U 1981c; U 1983; U-Á 1995;

Cleorodes lichenaria (Hufnagel, 1767) - Á 1990; Á-U 1994; K 1953; U 1981c; U-Á 1995;
Fagiporina arenaria (Hufnagel, 1767) - Á 1990; Á 1992a; Á 1992b; Á-U 1994; K 1953; K 1956; Ré 1972; U 1981a; U 1981c; U-Á 1995;

Ascotis selenaria (Denis \& Schiffermüller, 1775) - Á 1990; Á 1992a; Á 1992b; Á-U 1994; Á-U 1998; K 1953; Ré 1972; Ro 1909; T 19831984; U 1976a; U 1976b; U 1978a; U 1978b; U 1978c; U 1981a; U 1981c; U-Á 1995;

Ectropis crepuscularia (Denis \& Schiffermüller, 1775) (=bistortata) - Á 1990; Á 1992a; Á 1992b; Á-U 1994; Á-U 1998; K 1953; Ré 1972; T 1983-1984; U 1976a; U 1976b; U 1978a; U 1978b; U 1978c; U 1981a; U 198lc; U 1983; U-Á 1995;

Paradarisa consonaria (Hübner, 1799) - Á 1990; Á-U 1994; K 1953; K 1958; U 1981a; U 1981c;

Parectropis (=Ectropis) similaria (Hufnagel, 1767) (=extersaria) - Á 1990; Á 1992a; Á 1992b; ヘ́-U 1994; Á-U 1998; K 1953; T 1983 1984; U 1976a; U 1978a; U 1978b; U 1978c; U 1981a; U 1981c; U 1983;

Aethalura punctulata (Denis \& Schiffermüller, 1775) - Á 1990; Á 1992a; Á 1992b; Á-U 1994; Á-U 1998; K 1953; U 1976a; U 1976b; U 1978a; U 1978b; U 1978c; U 1981a; U 1981c; U 1983; U 1984a; U-Á 1995;

Ematurga atomaria (Linnaeus, 1758) - Á 1990; Á 1992a; Á 1992b; Á-U 1994; Á-U 1998; K 1953; Ré 1972; T 1983-1984; U 1976a; U 1976b; U 1978a; U 1978b; U 1978c; U 1981a; U 1981c; U 1983; U-Á 1995;

Tephronia sepiaria (Hufnagel, 1767) - Á 1990; Á-U 1994; K 1953; U 1976a; U 1976b; U 1978a; U 1978b; U 1981c; U-Á 1995;

Bupalus piniaria (Linnaeus, 1758) - Á 1990; Á 1992a; Á 1992b; Á-U 1994; Á-U 1998; K 1953; U 1976a; U 1978a; U 1978b; U 1978c; U 1981a; U 1981c; U 1983; U-Á 1995;

Cabera pusaria (Linnaeus, 1758) - Á 1990; Á 1992a; Á 1992b; Á-U 1994; Á-U 1998; K 1953; Ré 1972; T 1983-1984; U 1976a; U 1976b; U 1978a; U 1978b; U 1978c; U 1981a; U 1981c; U 1983; U-Á 1995;

Cabera exanthemata (Scopoli, 1763) - Á 1990; Á 1992a; Á 1992b; Á-U 1994; Á-U 1998; K 1953; Ré 1972; T 1983-1984; U 1976a; U 1976b; U 1978a; U 1978b; U 1978c; U 1981a; U 1981c; U 1983; U-Á 1995;

Lomographa (=Bapta) bimaculata (Fabricius, 1775) - Á 1990; Á 1992a; Á 1992b; Á-U 1994; Á-U 1998; K 1953; Ré 1972; T 1983-1984; U 1976a; U 1976b; U 1978a; U 1978b; U 1978c; U 1981 a; U 1981c; U 1983; U-Á 1995;

Lomographa (=Bapta) temerata (Denis \& Schiffermüller, 1775) - Á 1990; Á 1992a; Á 
1992b; Á-U 1994; Á-U 1998; K 1953; T 19831984; U 1976a; U 1976b; U 1978a; U 1978b; U 1978c; U 1981a; U 1981c; U 1983; U-Á 1995;

Theria rupicapraria (Denis \& Schiffermüller, 1775) - Á 1990; Á 1992a; Á 1992b; Á-U 1994; K 1953; U 1978b; U 1978c; U 1981a; U 1981c; U-Á 1995;

Campaea margaritata (Linnacus, 1767) - Á

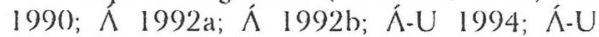
1998; K 1953; Ré 1972; U 1976a; U 1976b; U 1978a; U 1978b; U 1978c; U 1981a; U 1981c; U 1983; U-Á 1995;

Hylaea fasciaria (Linnaeus, 1758) - Á 1990); Á 1992a; Á 1992b; Á-U 1994; K 1953; U 1976a; U 1978c; U 1980a; U 1981a; U 1981c; Uherkovich 1984; U-Á 1995;

Gnophos furvata (Denis \& Schiffermüller, 1775) - U 1978b; U 1981b; U 1981c; U-Á 1995;

Odontognophos dumetata (Treitschke, 1827) . K 1953; U 1978b;

Charissa obscurata (Denis \& Schiffermüller, 1775) Á 1990; Á-U 1994; K 1953; Ré 1972; U 1978b;

Siona lineata (Scopoli, 1763) - Á 1990; Á 1992a; Á 1992b; Á-U 1994; K 1953; Ré 1972; T 1983-1984; U 1976a; U 1976b; U 1978a; U 1978b; U 1978c; U 1981a; U 1981c; U 1983; U-Á 1995;

Chariaspilates formosaria (Eversmann, 1837) K 1953; Sz 1938; U 1978b; V 1976

Aspilates gilvaria (Denis \& Schiffermüller, 1775) - Á-U 1998; K 1953; U 1978b; U 1981b; U 1981c; U-Á 1995;

Perconia strigillaria (Hübner, 1787) - Á-U 1994; U 1978b; U 1981a; U 1981c;

\section{Oenochrominae}

Alsophila aescularia (Denis \& Schiffermüller, 1775) - Á 1990; Á 1992a; Á 1992b; Á-U 1994; Á-U 1998; K 1953; Ré 1972; U 1976a; U 1978a; U 1978b; U 1978c; U 1981a; U 1981c; U 1983; U-Á 1995;

Alsophila aceraria (Denis \& Schiffermüller, 1775) (=quadripunctaria) - Á 1990; Á 1992a; Á 1992b; Á-U 1994; K 1953; U 1976a; U 1978b; U 1978c; U 1981a; U 1981c; U-Á 1995;

\section{Geometrinae}

Aplasta ononaria (Fuessly, 1783) - U 1978b;

U 1981b; U 1981c; U-Á 1995;

Pseudoterpna pruinata (Hufnagel, 1767) - Á 1990; Á-U 1994; Á-U 1998; K 1953; Ré 1972; T 1983-1984; U 1976a; U 1978b; U 1978c; U 1981a; U 1981c; U 1983; U-Á 1995;

Geometra (=Hipparchus) papilionaria (Linnaeus, 1758) - Á 1990; Á 1992a; Á 1992b;
Á-U 1994; Á-U 1998; K 1953; U 1976a; U 1978a; U 1978b; U 1978c; U 1981a; U 1981c; U 1983; U 1984a; U-Á 1995;

Comibaena bajularia (Denis \& Schiffermüller 1775) (=pustulata) - Á 1990; Á 1992a; Á 1992b; Á-U 1994; K 1953; U 1976a; U 1978a; U 1978b; U 1978c; U 1981a; U 1981c; U 1983; U-Á 1995;

Antnechloris smaragdaria Fabricius, 1787) - Á 1990; Á 1992a; Á 1992b; Á-U 1994; Á-U 1998; K 1953; Ré 1972; Ro 1909; T 1983-1984; U 1976a; U 1976b; U 1978a; U 1978b; U 1978c; U 1981a; U 1981c; U 1983; U-Á 1995;

Hemithea aestivaria (Hübner, 1789) - Á 1990; Á 1992a; Á 1992b; Á-U 1994; Á-U 1998; K 1953; Ré 1972; U 1976a; U 1978a; U 1978b; U 1978c; U 1981a; U 1981c; U 1983; U-Á 1995;

Chlorissa piridata (Linnaeus, 1758) - Á 1990; Á 1992a; Á 1992b; Á-U 1994; Á-U 1998; K 1953; Ré 1972; Ro 1909; T 1983-1984; U 1976a; U 1976b; U 1978a; U 1978b; U 1978c; U 1981a; U 1981c; U 1983; U-Á 1995;

Chlorissa cloraria (Hübner, 1813) - Á 1990; Á 1992a; Á 1992b; Á-U 1994; Á-U 1998; K 1953; Ré 1972; U 1976a; U 1976b; U 1978a; U I978b; U I98Ic; U-Á I995;

Chlorissa etruscaria (Zeller, 1849) (=pulmentaria) - Á 1990; Á-U 1994; K 1953; Ré 1972; U 1976a; U 1978b;

Thalera fimbrialis (Scopoli, 1763) - Á 1990; Á 1992a; Ả 1992b; Á-U 1994; Á-U 1998; K 1953; Ré 1972; T 1983-1984; U 1976a; U 1976b; U 1978a; U 1978b; U 1978c; U 1981a; U 1981c; U 1983; U- $\Lambda$ 1995;

Hemistola chrysoprasaria (Esper, 1795) - Á 1990; Á 1992a; Á 1992b; Á-U 1994; Á-U 1998; K 1953; K 1956; Ré 1972; T $1983-$ 1984; U 1976a; U 1978a; U 1978b; U 1978c; U 1981a; U 1981c; U 1983; U-Ấ 1995;

Jodis lactearia (Linnaeus, 1758) - Á 1990; Á 1992a; Á 1992b; Á-U 1994; Á-U 1998; K 1953; Ré 1972; T 1983-1984; U 1976a; U 1976b; U 1978a; U 1978b; U 1978c; U 1981a; U 1981c; U 1983; U-Á 1995;

\section{Sterrhinae}

Cyclophora (=Ephyra) pendularia (Clerck, 1759) (=orbicularia) - Á 1990; Á 1992a; Á 1992b; Á-U 1994; K 1953; T 1983-1984; U 1976a; U 1976b; U 1978b; U 1978c; U 1981a; U 1981c; U 1983; U-Á 1995;

Cyclophora albiocellaria (Hübner, 1789) - Á 1990; K 1953; K 1956; Ré 1972; U 1978b; 
Cyclophora annularia (Fabricius, 1775) - Á 1990; Â 1992a; Á 1992b; Â-U 1994; Á-U 1998; K 1953; Ré 1972; T 1983-1984; U 1976a; U 1976b; U 1978a; U 1978b; U 1978c; U 1981a; U 1981c; U 1983; U-Á 1995;

Cyclophora albipunctata (Hufnagel, 1767) Á 1992a; ᄉ́ 1992b; $\Lambda$-U 1994; Á-U 1998; U 1976a; U 1976b; U 1978a; U 1978b; U I978c; U 1981a; U 1981b; U 1981c; U 1983; U-Á I995;

Cyclophora pupillaria (Hübner, 1799) - K 1953; U 1978b; U 1979;

Cyclophora ruficiliaria (Herrich- Schäffer, 1855) - Á 1992a; Á 1992b; Á-U 1994; Á-U 1998; K 1953; K 1956; Ré 1972; T 19831984; U 1976a; U 1976b; U 1978a; U 1978b; U 1978c; U 1981a; U 1981c; U-Á 1995;

Cyclophora porata (Linnaeus, 1767) - $A$ 1990; Á 1992a; Á-U 1994; Á-U 1998; K 1953; Ré I972; T 1983-1984; U 1976a; U 1976b; U 1978a; U 1978b; U 1978c; U I981a; U 198 Ic; U 1983; U-Á 1995;

Cyclophora quercimontaria (Bastelberger, 1897) - Á 1990; Á 1992a; Á-U 1994; K 1953; Ré 1972; U 1976a; U 1978a; U 1978b; U 1978c; U 1981a; U 1981c; U-Á 1995;

Cyclophora punctaria (Linnaeus, 1758) - Á 1990; Á 1992a; Á 1992b; Á-U 1994; Á-U 1998; K 1953; Ré 1972; U 1976a; U I976b; U 1978a; U 1978b; U 1978c; U I 98 Ia; U 198 Ic; U 1983; U-Á 1995;

Cyclophora subpunctaria (Zeller, 1847) - Ré 1972; U 1978b;

Cyclophora linearia (Hübner, 1799) - $\Lambda$ 1990; Á 1992a; Á 1992b; $A-U$ 1994; $\hat{\Lambda}-U$ 1998; K 1953; Ré 1972; T 1983-1984; U 1976a; U 1976b; U 1978a; U 1978b; U 1978c; U 1981a; U 1981c; U 1983; U-Á 1995;

Timandra (=Calothysanis) comae $\Lambda$. Schmidt, 1931 (=amata) - Á 1990; Á 1992a; 1992b; Á-U 1994; Á-U 1998; K 1953; Ré 1972; Ro 1909; T 1983-1984; U 1976a; U 1976b; U 1978a; U 1978b; U 1978c; U 1981a; U 1981c; U 1983; U-Á 1995;

Scopula immorata (Linnaeus, 1758) $-\hat{\Lambda}$ 1990; Á 1992a; Á 1992b; Á-U 1994; Á-U 1998; K 1953; Ré 1972; T 1983-1984; U 1976a; U 1976b; U 1978a; U 1978b; U 1978c; U 1981a; U 1981c; U 1983; U-Á 1995;

Scopula corrivalaria (Kretschmar, 1862) - Á 1990; Á 1992a; Á 1992b; Á-U 1994; Á-U 1998; K 1953; Ré 1972; Ro 1909; T 1983. 1984; U 1976a; U 1978a; U 1978b; U 1978c; U 1981 a; U 1981c; U.Á 1995;

Scopula caricaria (Reutti, 1853) - Á 1990; Á 1992a; Á 1992b; Â-U 1994; Á-U 1998; K
1953; Ré 1972; T 1983-1984; U 1976a; U 1976b; U 1978a; U 1978b; U 1978c; U 198 a; U 1981c; U 1983; U-Á 1995;

Scopula umbelaria (Hübner, 1813) - Á 1992a; U 1978b;

Scopula nigropunctata (Hufnagel, 1767) - Á

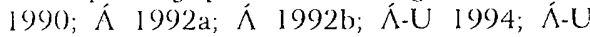
1998; K I953; Ré 1972; T 1983-1984; U 1976a; U 1976b; U 1978a; U 1978b; U 1978c; U 1981a; U 1981c; U 1983; U-Á 1995;

Scopula virgulata (Denis \& Schiffermüller, 1775) - Á 1990; Á 1992a; Á 1992b; Á.U 1994; Á-U 1998; K 1953; Ré 1972; T 1983-1984; U $1976 a ;$ U 1976b; U 1978a; U 1978b; U 1978c; U 1981a; U 1981c; U 1983; U-Á 1995;

Scopula ornata (Scopoli, 1763) - Á 1990; $\Lambda$ I992a; Á 1992b; Á-U 1994; Á-U 1998; K 1953; Ré 1972; T 1983-1984; U 1976a; U 1978a; U 1978b; U 1978c; U 198 Ia; U I98Ic; U 1983; U-Á 1995;

Scopula decorata (Denis \& Schiffermüller, 1775) - Á 1990; K 1953; U 1978b;

Scopula rubiginata (Hufnagel, 1767) - Á 1990; Á 1992a; Á 1992b; Â-U I994; Á-U 1998; K 1953; Ré 1972; T 1983-1984; U 1976a; U 1976b; U 1978a; U 1978b; U 1978c; U 1981c; U 1983; U-Á 1995;

Scopula marginepunctata (Goeze, 1781) - Á 1990; Á 1992b; Á-U 1994; Á-U 1998; K 1953; Ré 1972; T 1983-1984; U 1978a; U 1978b; U 1981 á; U 1981b; U 1981c; U.Á 1995;

Scopula incanata (Linnaeus, 1758) - Á 1992a; Á I992b; Á-U 1994; Á-U 1998; Ré 1972; U 1976a; U 1976b; U 1978a; U 1978b; U 1978c; U 198Ia; U 1981c; U 1983; U-Á 1995;

Scopula immutata (Linnaeus, 1758) - Á 1990); Á 1992a; Á 1992b; Á-U 1994; Á.U 1998; K 1953; Ré 1972; T 1983-1984; U 1976a; U 1976b; U 1978a; U 1978b; U 1978c; U 1981c; U 1983; U-Á 1995;

Scopula flaccidaria (Zeller, 1852) - Á 1990; Á-U 1994; Á-U 1998; K 1953; Ro 1909; U I976a; U 1978b; U 1978c; U 1981c; U 1983; U-Á I995:

Scopula floslactata (Haworth, 1809) - Á-U 1998; K 1953; Ré 1972; U 1978b; U-Á 1995;

Idaea (=Sterrha) rufaria (Hübner, 1799) - Á 1990; Á-U 1994; Á-U 1998; K 1953; Ré 1972; T 1983-1984; U 1976a; U 1976b; U 1978a; U 1978b; U 1978c; U 1981a; U 1981c; U-Á 1995;

Idaea (=Sterrha) ochrata (Scopoli, 1763) - Á 1990; Á 1992a; Á 1992b; Á-U 1994; K 1953; Ré 1972; Ro 1909; U 1976a; U 1978a; U 1978b; U 1978c; U 1981c; U 1983; U.Á 1995; 
Idaea (=Sterrha) serpentata (Hufnagel, 1767) - Á 1990; Á 1992b; Á-U 1994; K 1953. Ré 1972; U 1976a; U 1976b; U 1978a; U 1978b; U 1978c; U 1981a; U 1981c; U-Á 1995;

Idaea (=Sterrha) aureolaria (Denis \& Schiffermüller, 1775) - Á-U 1994; K 1953; U 1978b;

Idaea (=Sterrha) muricata (Hufnagel, 1767) Á 1990; Á 1992a; Á 1992b; Á-U 1994; Á-U 1998; K 1953; Ré 1972; 'T' 1983-1984; U 1976a; U 1976b; U 1978a; U 1978b; U 1978c; U 1981a; U 1981c; U 1983; U-Á 1995;

Idaea (=Sterrha) rusticata (Denis \& Schiffermüller, 1775) - Á 1990; Á 1992a; Á 1992b; Á-U 1994; K 1953; Ré 1972; U 1978a; U 1978b; U 1978c; U 1981b; U 1983; U-Á 1995;

Idaea (=Sterrha) filicata (Hübner, 1799) - Á 1992a; K 1953; Ré 1972; U 1976a; U 1978a; U 1978b;

Idaea (=Sterrha) laevigata (Scopoli, 1763) A 1899; Á 1990; B 1985; K 1953; Ré 1972; U 1978b;

Idaea (=Sterrha) moniliata (Denis \& Schiffermüller, 1775) - Á 1990; Á 1992a; Á 1992b; Á-U 1994; Á-U 1998; K 1953; Ré 1972; U 1976a; U 1978b; U 1978c; U 1981a; U 1981c; U-Á 1995;

Idaea (=Sterrha) sylvestraria (Hübner, 1799) Á 1990; K 1956; Ré 1972; T 1983-1984; U I976a; U 1978a; U 1978b; U 1978c; U 1981c; U 1983; U-Á 1995;

Idaea (=Sterrha) biselata (Hufnagel, 1767) Á 1990; Á 1992a; Á 1992b; Á-U 1994; Á-U 1998; K 1953; Ré 1972; U 1976a; U 1976b; U 1978a; U 1978b; U 1978c; U 1981a; U 198lc; U 1983; U-Á 1995;

Idaea (=Sterrha) inquinata (Scopoli, 1763) Á 1990; Á-U 1994; K 1953; U 1978b;

Idaea (=Sterrha) dilutaria (Hübner, 1799) Á 1992a; Á-U 1994; K 1953; Ré 1972; U 1978b;

Idaea (=Sterrha) fuscovenosa (Goeze, 1781) Á 1990; Á 1992a; Á 1992b; Â-U 1994; Á-U 1998; K 1953; Ré 1972; T 1983-1984; U 1976a; U 1978a; U 1978b; U 1978c; U 1981c; U 1983; U-Á 1995;

Idaea (=Sterrha) humiliata (Hufnagel, 1767) Á 1990; Á 1992a; Á 1992b; Á-U 1994; Á-U 1998; K 1953; Ré 1972; T 1983-1984; U 1976a; U 1978a; U 1978b; U 1978c; U-Á 1995; Idaea (=Sterrha) politaria (Hübner, 1799) - ÁU 1994; Á-U 1998; K 1953; Ré 1972; 'T 1983. 1984; U 1976a; U 1976b; U 1978a; U 1978b; U 1978c; U 1981a; U 1981c; U 1983; U-Á 1995;
Idaea (=Sterrha) seriata (Schrank, 1802) - Á 1990; Á 1992a; Á-U 1994; Á-U 1998; K 1953; Ré 1972; T 1983-1984; U 1976a; U 1978b; U 1981b; U 1981c; U-Á 1995;

Idaea (=Sterrha) dimidiata (Hufnagel, 1767) Á 1990; Á 1992a; Á 1992b; Á-U 1994; Á-U 1998; K 1953; Ré 1972; Ro 1909; T 1983-1984; U 1976a; U 1976b; U 1978a; U 1978b; U 1978c; U 1981a; U 1981c; U 1983; U- $\Lambda$ 1995;

Idaea (=Sterrha) subsericeata (Haworth, 1809) - Á 1990; Á 1992a; Á 1992b; Á-U 1994; Á-U 1998; K 1953; Ré 1972; T 1983-1984; U 1976a; U 1976b; U 1978a; U 1978b; U 1978c; U 1981 a; U 1981c; U 1983; U-Á 1995;

Idaea (=Sterrha) pallidata (Denis \& Schiffermüller, 1775) - A 1990; Á-U 1994; U 1978b;

Idaea (=Sterrha) trigeminata (Haworth, 1809) Á 1990; Á 1992a; Á 1992b; Á-U 1994; Á-U 1998; K 1953; Ré 1972; U 1978b; U-Á 1995;

Idaea (=Sterrha) nitidata (Herrich-Schäffer, 1861) - U 1976a; U 1978b; U 1978c; U-Á 1995;

Idaea (=Sterrha) emarginata (Linnaeus, 1758) - Á 1990; Á 1992a; Á 1992b; Á-U 1994; K 1953; T 1983-1984; U 1976a; U 1978a; U 1978b; U 1981a; U 1981b; U 1981 c; U 1983; U-Á 1995;

Idaea (=Sterrha) arersata (Linnaeus, 1758) Á 1990; Á 1992a; Á 1992b; Á-U 1994; Â-U 1998; K 1953; Ré 1972; T 1983-1984; U 1976a; U 1976b; U 1978a; U 1978b; U 1978c; U 1981a; U 1981c; U 1983; U-Á 1995;

Idaea (=Sterrha) rubraria (Staudinger, 1901) - Á 1992a; Á 1992b; Á-U 1994; U 1978b; U 1981b; U 198Ic; U-Á 1995;

Idaea (=Sterrha) degeneraria (Hübner, 1799) Á 1990; Á 1992a; Á-U 1994; Á-U 1998; K 1953; Ré 1972; T 1983-1984; U 1976a; U 1976b; U 1978a; U 1978b; U 1978c; U 1981a; U 1981c; U 1983; U-Á 1995;

Idaea (=Sterrha) straminata (Borkhausen, 1794) (=inornata, Haworth) - Á-U 1994; K 1953; Ré 1972; T 1983-1984; U 1976a; U 1976b; U 1978a; U 1978b; U 1978c; U 1981a; U 1981c; U 1983; U-Á 1995;

Idaea (=Sterrha) deversaria (HerrichSchäffer, 1847) - Á 1990; Á 1992a; Á 1992b; Á-U 1994; Á-U 1998; K 1953; K 1956; Ré 1972; U 1976a; U 1976b; U 1978a; U 1978b; U 1978c; U 1981a; U 1981c; U-Á 1995;

Rhodostrophia vibicaria (Clerck, 1759) - Á 1990; Á 1992a; Á 1992b; Á-U 1994; Á-U 1998; K 1953; Ré 1972; T 1983-1984; U $1976 a ; U 1978 a ;$ U 1978b; U 1978c; U 1981a; U 1981c; U 1983; U-Á 1995; 
Rhodometra sacraria (Linnaeus, 1767) - Á I992a; Á 1992b; Á-U 1994; K 1953; U 1978b;

\section{Larentiinae}

Lythria purpararia (Linnacus, I758) - Á 1990; $\Lambda$ 1992a; $\Lambda$-U 1994; $\Lambda$-U 1998; K 1953; Ré 1972; U 1976a; U 1976b; U 1978a; U 1978b; U 1978c; U 198Ic; U.Á 1995;

Lythria cruentaria (Hufnagel, 1767) (=purpurata) - Á 1990; Á-U 1994; K 1953; U 1976a; U 1978b; U 1978c; U-Á 1995;

Cataclysme riguata (Hübner, 1813) - Ré 1972; U 1978b;

Phibalapteryx virgata (Hufnagel, 1767) - Á 1990; Á 1992b; X́-U 1994; K 1953; Ré 1972; U 1976a; U 1978a; U 1978b;

Scotopteryx moeniata (Scopoli, 1763) - Ré 1972; U 1978b;

Scotopteryx bipunctaria (Denis \& Schiffermüller, 1775) - K 1953; U 1978b;

Scotopteryx chenopodiata (Linnaeus, 1758) Á 1990; Â 1992b; Á-U 1994; K 1953; Ré 1972; U 1978b; U 1981a; U 198Ic;

Scotopteryx (=Ortholita) mucronata (Scopoli, 1763) - A I 992b; Á-U 1994; K I953; U 1978b;

Scotopteryx (=Ortholita) luridata (Hufnagel, 1767) (=plumbaria) - Á 1990; $\Lambda$ 1992a; $\Lambda$-U 1998; U 1976a; U 1978b; U 1978c; U 1981a; U 198Ic; U 1983; U.Á 1995;

Orthonama (=Cidaria) pittata (Borkhausen, 1794) (=lignata) - Á 1990; Á-U 1994; Á-U 1998; K 1953; Ré 1972; 'T 1983-1984; U 1976a; U 1978a; U 1978b; U 1978c; U 1981 a; U 1981c; U 1983; U-Á 1995;

Orthonama obstipata (Fabricius, 1794) - Á 1990; Á 1992a; A 1992b; Á-U 1994; Á-U 1998; K 1953; Ré 1972; T' 1983-1984; U 1976a; U 1976b; U 1978b; U 1978c; U 1979; U I981a; U I981c; U- $\Lambda$ 1995;

Xanthorhoe biripiata (Borkhausen, 1794) - Á 1990; Á 1992a; ᄉ́ 1992b; Á-U 1994; Á-U 1998; K 1953; U 1976a; U 1978a; U 1978b; U 1978c; U 1981b; U 1981 c; U 1983; U-Á 1995;

Xanthorhoe designata (Hufnagel, 1767) - Á 1990; Á 1992a; Á 1992b; Á-U 1994; Á-U 1998; K 1953; T 1983-1984; U 1976a; U 1976b; U 1978a; U 1978b; U 1978 c; U 1981a; U 1981c; U 1983; U-ᄉ́ 1995;

Xanthorhoe spadicearia (Denis \& Schiffermüller, 1775) - Á 1992a; Á 1992b; Á-U 1994; Á. U 1998; K 1953; T 1983-1984; U 1976a; U 1978a; U 1978b; U 1978c; U-Á 1995;

Xanthorhoe ferrugata (Clerck, I759) - Á 1990; Á 1992a; Á 1992b; Á-U 1994; Á-U I998; K 1953; K 1956; Ré 1972; T 1983-1984;
U 1976a; U 1976b; U 1978a; U 1978b; U I978c; U 1981a; U 198Ic; U 1983; U-Á 1995;

Xanthorhoe quadrifasciata (Clerck, 1759) - $\Lambda$ 1990; Á 1992a; Á 1992b; Á-U 1994; Á-U 1998; K 1953; Ré 1972; U I976a; U 1978b; U 1981a; U 1981b; U 1981c; U 1983; U-র́ 1995;

Xanthorhoe fluctuata (Linnaeus, 1758) - Á 1990; Á 1992a; Á 1992b; Á-U 1994; Á-U I998; K 1953; K 1956; Ré 1972; T 1983-1984; U 1976a; U 1976b; U I978a; U 1978b; U 1978c; U 1981a; U 198Ic; U 1983; U-Á I995;

Catarhoe (=Euphyia) rubidata (Denis \& Schiffermüller, I775) - Á 1992a; Á 1992b; Á-U 1994; Á-U 1998; K 1953; Ré 1972; T 19831984; U 1976a; U 1976b; U 1978a; U 1978b; U 1981a; U 1981c; U 1983; U-Á 1995;

Catarhoe (=Euphyia) cuculata (Hufnagel, 1767) - Á 1990; Á I992a; Á 1992b; Á-U 1994; Á-U 1998; K 1953; K 1956; Ré 1972; T 19831984; U 1976a; U 1976b; U 1978a; U 1978b; U 1978c; U 1981a; U 1981c; U 1983; U-Á 1995;

Epirrhoe hastulata (Hübner, 1790) - Á 1992b; Á.U 1994; U 1978b;

Epirrhoe tristata (Linnaeus, 1758) - Á 1990; Á 1992a; Á 1992b; Á-U 1994; Á-U 1998; K 1953; T 1983-1984; U 1976a; U 1978a; U 1978b; U 1978c; U 1981a; U 1981c; U 1983; U-Á 1995;

Epirrhoe alternata (Müller, 1764) - Á 1990; Á 1992a; Á 1992b; Á-U 1994; Á-U 1998; K 1953; Ré 1972; T 1983-1984; U 1976a; U 1976b; U 1978a; U 1978b; U 1978c; U I981a; U 1981c; U 1983; U-Á 1995;

Epirrhoe rivata (Hübner, 1813) - Á-U 1994; Á-U 1998; K I953; U 1976a; U 1978b; U 1978c; U 1981a; U 1981c; U-Á 1995;

Epirrhoe galiata (Denis \& Schiffermüller, 1775) - Á 1990; Á 1992a; Á 1992b; Á-U 1994; K 1953; Ré 1972; U 1978a; U 1978b; U $1981 \mathrm{a} ;$ U 1981c;

Costaconvexa polygrammata (Borkhausen, 1794; Á 1990; Á 1992a; Á 1992b; Á-U 1994; Á-U 1998; K 1953; Ré 1972; T 1983-1984; U 1976a; U 1976b; U 1978a; U 1978b; U 1978c; U 1981a; U 1981c; U 1983; U-Á 1995;

Camptogramma bilineata (Linnaeus, 1758) Á 1990; Á 1992a; Á 1992b; Á-U 1994; K 1953; Ré 1972; T 1983-1984; U 1976a; U 1976b; U 1978a; U 1978b; U 1978c; U I 981a; U 198Ic; U 1983; U-Á 1995;

Larentia claparia (Haworth, 1809) - Á 1990; Á 1992a; Á 1992b; U 1978b; U 1981c; U 1983; U 1984b; U-Á 1995;

Anticlea (=Larentia) badiata (Denis \& Schiffermüller, 1775) - Á-U 1994; K 1953; K 
1956; Ré 1972; U 1978a; U 1978b; U 1978c; U 1981a; U 198lc; U 1983; U-Á 1995;

Anticlea derivata (Denis \& Schiffermüller, 1775) Á 1990; Á-U 1994; K 1953; Ré 1972; U 1978b;

Mesoleuca albicillata (Linnaeus, 1758) - Á 1992a; Á 1992b; Á-U 1994; Á-U 1998; K 1953; Ré 1972; T 1983-1984; U 1976a; U 1976b; U 1978a; U 1978b; U 1978c; U 1981a; U 198Ic; U 1983; U-Á 1995;

Pelurga comitata (Linnaeus, 1758) - A 1990; Á 1992a; Á 1992b; Á-U 1994; K 1953; Ré 1972; Ro 1909; T 1983-1984; U 1976a; U 1976b; U I978a; U I978b; U 1978c; U I98Ia; U 198Ic; U 1983; U-Á 1995;

Lampropteryx suffumata (Denis \& Schiffermüller, I775) - Á 1990; Á 1992a; X́ 1992b; ÁU 1994; Á-U 1998; K 1953; U 1978b; U 1981a; U 1981c; U 1983; U-Á 1995;

Cosmorhoe (=Larentia) ocellata (Linnaeus, 1758) - Á 1990; Á 1992a; Á 1992b; Á-U 1994; Á-U 1998; K 1953; Ré 1972; T 1983-1984; U 1976a; U 1978a; U 1978b; U 1978c; U 1981a; U 1981c; U 1983; U-Á 1995;

Eulithis testata (Linnaeus, 1761,) - Á 1990; K 1956; K 1958; U 1978b;

Eulithis mellinata (Fabricius, 1787) - $\Lambda$ 1990; Á 1992a; Á 1992b; Á-U 1994; T 19831984; U 1978c; U 1981a; U 1981c; U 1983; U 1984b; U-Á 1995;

Eulithis (=Lygris) pyraliata (Denis \& Schiffermüller, 1775) - Â 1990; Á 1992a; Á I992b; Â-U 1994; Á-U 1998; K 1953; T 19831984; U 1976a; U 1978a; U 1978b; U 1978c; U 1981a; U 1981c; U 1983; U-Á 1995;

Ecliptopera silaceata (Denis \& Schiffermüller, 1775) - Á 1990; Á 1992a; Á 1992b; ÁU 1994; Á-U 1998; K 1953; U 1976a; U 1976b; U 1978b; U 1978c; U 1981a; U 1981c; U 1983; U-Á 1995;

Ecliptopera capitata (Herrich-Schäffer, 1839) Á 1990; Â-U 1994; U 1978b; U 1981a; U 1981c; U-Á 1995;

Chloroclysta siterata (Hufnagel, 1767) - $\Lambda$ 1990; Á 1992a; Á-U 1994; Á-U 1998; K 1953; U 1976a; U 1978b; U 1978c; U 1981b; U 1981c;

Cidaria fulvata (Forster, 1771) - Á 1990; Á 1992a; Á 1992b; Á-U 1994; K 1953; Ré 1972; U 1978b; U 1981a; U 1981c;

Plemyria (=Larentia) rubiginata (Denis \& Schiffermüller, 1775) (=bicolorata) - Á 1992a; Á 1992b; Á-U 1994; Á-U 1998; K 1953; U 1976a; U 1978b; U 1978c; U $1981 \mathrm{a}$; U 1981c; U 1983; U 1984a; U-Á 1995;

Pennithera firmata (Hübner, 1822) - Á 1990; Á 1992a; Á 1992b; Á-U 1994; K 1953; U 1976a; U 1978a; U 1978b; U 1978c; U 1980a; U 1981c; U-Á 1995;

Thera obeliscata (Hübner, 1787) - Á 1992a; Á-U 1994; U 1976a; U 1978b; U 1978c; U 1980a; U I981a; U 1981b; U 1981c; U 1983; U-Á 1995;

Thera variata (Denis \& Schiffermüller, 1775) - Á 1992a; Á 1992b; Á-U 1994; T 19831984; U 1976a; U 1978b; U 1978c; U 1980a; U-Á 1995;

Thera vetustata (Denis \& Schiffermüller, 1775) (=stragulata) - GyI et al 1979; U 1978c; U 1980a;

Thera juniperata (Linnacus, 1758) - A 1990; Á 1992a; Á 1992b; Á-U 1994; U 1976a; U 1978b; U 1978c; U 1980a; U-Á 1995;

Electrophaes corylata (Thunberg, 1792) - Á 1990; Á 1992a; Á 1992b; Á-U 1994; ́́-U 1998; K 1953; Ré 1972; T 1983-1984; U 1976a; U 1978a; U 1978b; U 1978c; U 1981a; U 1981c; U 1983; U-Á 1995;

Colostygia pectinataria (Knoch, 1781) - Á 1990; Á 1992a; Á 1992b; Á-U 1994; Á-U 1998; K 1953; T 1983-1984; U 1976a; U 1976b; U 1978a; U 1978b; U 1978c; U 1981a; U 1981c; U 1983; U-Á 1995;

Hydriomena furcata (Thunberg, 1784) - Á 1992a; Á 1992b; Á-U 1994; U 1978b; U 1981a; U 1981c; U-Á 1995;

Hydriomena impluviata (Denis \& Schiffermüller, 1775) (=coerulata) - Á 1990; Á 1992a; Á 1992b; Á-U 1994; Â.U 1998; K 1953; K 1956; T 1983-1984; U 1976a; U 1976b; U 1978a; U 1978b; U 1978c; U 1981a; U 1981c; U 1983; U 1984a; U-Á 1995;

Horisme vitalbata (Denis \& Schiffermüller, 1775) - Á 1990; Á 1992a; Á 1992b; Á-U 1994; Á-U 1998; K 1953; U 1978b; U 1981a; U 1981b; U 1981c; U 1983; U-Á 1995;

Horisme corticata (Treitschke, 1835) - Á 1990; Á 1992a; 'Á 1992b; Á-U 1994; Á-U 1998; K 1953; Ré 1972; T 1983-1984; U 1976a; U 1976b; U 1978a; U 1978b; U 1981a; U 1981b; U 1981c; U-Á 1995;

Horisme tersata (Denis \& Schiffermüller, 1775) - Á 1990; Á 1992a; Á 1992b; Á-U 1994; Á-U 1998; K 1953; Ré 1972; T 1983-1984; U 1976a; U 1976b; U 1978a; U 1978b; U 1978c; U 1981a; U 1981c; U 1983; U.Á 1995;

Melanthia procellata (Denis \& Schiffermüller, 1775) - Á 1990; Á 1992a; Á 1992b; Á-U 1994; Á-U 1998; K 1953; Ré 1972; T 1983-1984; U 1976a; U 1976b; U 1978a; U 1978b; U 1978c; U 1981a; U 1981c; U 1983; U-Á 1995; 
Pareulype berberata (Denis \& Schiffermüller, 1775) - Á 1990; Á 1992a; K 1953; Ré 1972; U 1976a; U 1978a; U 1978b; U-ᄉ 1995;

Rheumaptera (=Calocalpe) cervinalis (Scopoli, 1763) - $\Lambda$ 1990; Á-U 1994; T 1983-1984; U 1978b;

Rheumaptera undulata (Linnacus, 1758) - Á 1992a; Á 1992b; Á-U 1994; Gyl et al 1979; U 1978a; U 1978b; U 1981a; U I981c; U 1984a; U 1984b;

Triphosa dubitata (Linnacus, 1758) - Á 1990; Á 1992b; Á-U 1994; Á-U 1998; K 1953 ; Ré 1972; U 1976a; U 1978b; U 1978c; U $1981 \mathrm{c}$; U-Á 1995 ;

Philereme vetulata (Denis \& Schiffermüller, 1775) - Á 1990; ᄉ́ 1992a; Á 1992b; Á-U 1994; Á-U 1998; K 1953; Ré 1972; U 1976a; U 1978a; U 1978b; U 1978c; U 1981a; U 1981c; U-Á 1995;

Philereme transpersata (Hufnagel, 1767) - Á 1990; Á 1992a; Á 1992b; Á-U 1994; K 1953; U 1976a; U 1978b; U 1978c; U 1981a; U 1981 c; U-Á 1995;

Euphyia (=Larentia) biangulata (Haworth, 1809) (=picata) - Á 1992a; Á 1992b; Á-U 1994; Á-U 1998; K 1953; U 1976a; U 1976b; U 1978a; U 1978b; U 1981a; U 1981b; U 1981c; U 1983; U-Á 1995;

Euphyia unangulata (Haworth, 1809) - Á 1992a; Á 1992b; Á-U 1994; Á-U 1998; K 1953; U 1976a; U 1976b; U 1978a; U 1978b; U 1978c; U 1981a; U 1981b; U 1981c; U 1983; U-Á 1995;

Epirrita (=Oporina) dilutata (Denis \& Schiffermüller, 1775; $\Lambda$ 1990; $\Lambda$ 1992b; $\Lambda$-U 1994; Á-U 1998; K 1953; Ré 1972; T 1983. 1984; U 1978b; U 1978c; U 1981a; U 1981c; U-Á 1995;

Epirita christyi (Allen, 1906) - Á 1992a; Á 1992b; Á-U 1994; K 1953; U 1978b; U 1981 a; U 1981c;

Epirrita autumnata (Borkhauscn, 1794) - U 1976a; U 1978c; U 1980a; U I984a; U 1984b; U-Á 1995;

Operophtera brumata (Linnacus, 1758) - Á 1990; Á 1992a; Á 1992b; Á-U 1994; Á-U 1998; K 1953; Ré 1972; U 1976a; U 1976b; U I978a; U 1978b; U 1978c; U 1981 a; U 1981c; U 1983; U-Á 1995;

Operophtera fagata (Scharfenberg, 1805) Á-U 1998; U 1978b;

Perizoma alchemillata (Linnaeus, 1758) - Á 1990; Á 1992a; Á 1992b; Á-U 1994; Á-U I998; K I953; Ré 1972; T 1983-1984; U I976a; U 1976b; U 1978a; U 1978b; U 1978c; U 1981a; U 1981c; U 1983; U-Á 1995;

Perizoma hydrata (Treitschke, 1829) - Á
1990; Á-U 1994; Á-U 1998; K 1953; Ré 1972; U 1976a; U 1976b; U 1978b; U 1978c; U $1981 \mathrm{a}$; U 1981c; U 1983; U-Á 1995;

Perizoma lugdunaria (Herrich-Schäffer, 1855) - Á 1992b; Ré 1972; T 1983-1984; U 1978a; U 1978b; U $1981 \mathrm{a}$;

Perizoma bifaciata (Haworth, 1809) - Á 1990; Á 1992a; Á 1992b; Á-U 1994; Á-U 1998; K 1953; K 1956; Ré 1972; T 19831984; U 1978a; U 1978b; U 1981b; U $1981 \mathrm{c}$; U 1983; U-Á 1995;

Perizoma flarofasciata (lhumberg, 1792) - Á 1990; A 1992b; Ré 1972; T 1983-1984; U 1976a; U 1978a; U 1978b; U 1978c; U 1981a; U 198lc; U 1983; U.Á 1995;

Perizoma (=Coenotephira) sagittata (Fabricius, 1787) - Á 1992a; Á-U 1994; U 1978b; U 1981a; U 1981c; U-Á 1995;

Perizoma parallelolineata (Retzius, 1783) - Á 1990; Á-U 1994; K 1953; U 1978b;

Eupithecia tenuiata (Hübner, 1813) - Á 1990; Á-U 1994; F 1977; K 1953; U 1978b;

Eupithecia inturbata (Hübner, 1817) - Á 1990; A 1992b; Á-U 1994; U 1978b; U 1981a; U 1981c; U 1985; U-Á 1995;

Eupithecia haworthiata Doubleday, 1856; Á 1990; Á 1992a; Á 1992b; Á-U 1994; Á-U 1998; F 1977; K 1953; Ré 1972; U 1976a; U 1978a; U 1978b; U 1981a; U 1981b; U 1981c; U-Á 1995;

Eupithecia plumbeolata (Haworth, 1809) - Á 1990; Á I992a; Á 1992b; Á-U 1994; Á-U 1998; F 1977; I 1983-1984; U 1976a; U 1976b; U 1978a; U 1978b; U 1978c; U-Á 1995;

Eupithecia abietaria (Goeze, 1781) (=pini) Á-U 1998; U 1978b;

Eupithecia linariata (Denis \& Schiffermüller, 1775) - Á I 990; Á I 992a; Á 1992b; Á-U 1994; Á-U 1998; F 1977; K 1953; Ré 1972; T 19831984; U 1976a; U 1978a; U 1978b; U 1978c; U 1981 a; U 198 Ic; U-Á 1995;

Eupithecia pulchellata (Stephens, 1831) - F 1977; K 1953; U 1981c;

Eupithecia pyreneata Mabille, 1871; Á 1990; ᄉ́-U 1994; U 1978b;

Eupithecia laquaearia Herrich-Schäffer, 1848; Á-U 1994; F 1977; K 1953; U 1978b; U-Á 1995;

Eupithecia insigniata (Hübner, 1790) - Á 1990; A-U 1994; F 1977; K 1953; U 1978b;

Eupithecia valerianata (Hübner, 1813) - F 1977; K 1953; U 1978b;

Eupithecia pygmaeata (Hübner, 1799) (=palustraria) - Á 1990; Á-U 1994; F 1977; 
Eupithecia nenosata (Fabricius, 1787) - Á 1990; Á-U 1994; F 1977; K 1953; Ré 1972; U 1978b;

Eupithecia silenicolata Mabille, 1867; F 1977; K 1953; U 1978b;

Eupithecia centaureata (Denis \& Schiffermüller, 1775) - Á 1990; Á 1992a; Á 1992b; Á-U 1994; Á-U 1998; F 1977; K 1953; K 1956; Ré 1972; T 1983-1984; U 1976a; U $1976 b ;$ U 1978a; U 1978b; U 1978c; U 1981a; U-Á 1995;

Eupithecia gueneata Milliare, 1862; Á 1990; Á-U 1994; F 1977; U 1978b;

Eupithecia breviculata (Donzel, 1837) - F 1977; Ré 1972; U 1978b;

Eupithecia selinata Herrich-Schäffer, I861; Á 1990; Á-U 1994; F 1977; K 1953; U 1976a; U 1978b; U 1978c; U 1981a; U 1981c; U-Á 1995;

Eupithecia trisignaria Herrich-Schäffer, 1848; F 1977; U 1978b;

Eupithecia intricata (Zetterstedt, 1839) - $\Lambda$ 1990; Á-U 1994; F 1977; GyI et al 1979; K 1957; U 1978b; U 1978c; U 1980a; U 1981b; U 1981c; U-Á 1995;

Eupithecia veratraria Herrich-Schäffer, 1850 ; F 1977; U 1978b;

Eupithecia absinthiata (Clerck, 1759) - Á 1990; Á 1992a; Á 1992b; Á-U 1994; Á-U 1998; F 1977; K 1953; K 1956; U 1976a; U 1978b; U 1978c; U 1981a; U 1981c; U-Á 1995;

Eupithecia catharinae Vojnits, 1969; Á 1992a; Á 1992b; Á-U 1994; F 1977; Ré 1972; U 1978b; U 1981a;

Eupithecia assimilata Doubleday, 1856; $A$ 1990; Á 1992a; Á 1992b; Á-U 1994; Á-U 1998; F 1977; K 1953; Ré 1972; T 1983-1984; U 1976a; U 1978a; U 1978b; U 1978c; U I981a; U 1981c; U-Á 1995;

Eupithecia vulgata (Haworth, I809) - Á 1990; Á 1992a; Â 1992b; Á-U 1994; F 1977; K 1953; Ré 1972; U 1978b; U 1981a; U 1981b; U 1981c; U-Á 1995;

Eupithecia tripunctaria Herrich-Schäffer, 1852; Á 1990; Á 1992a; Á 1992b; Á-U 1994; Á-U 1998; F 1977; K 1953; U 1976a; U 1976b; U 1978a; U 1978b; U 1978c; U 198 la; U 198Ic; U-Á 1995;

Eupithecia denotata (Hübner, 1813) - Á 1992b; ÁU 1994; F 1977; K 1953; U 1978b; U 1981a;

Eupithecia subfuscata (Haworth, 1809) (=castigata) - Á 1992a; Á 1992b; Á-U 1994; Á-U 1998; F 1977; K 1953; U 1976a; U 1978b; U 1978c; U I981a; U 1981c; U-Á 1995;

Eupithecia icterata (Villers, 1789) - Á 1992a; Á 1992b; Á-U 1994; F 1977; K 1953; Ré 1972; U 1976b; U 1978a; U 1978b; U 1978c; U 1981c; U 1983; U-Á 1995;

Eupithecia succenturiata (Linnaeus, 1758) - Á 1990; Á 1992a; Á 1992b; Á-U 1994; Á-U 1998; F 1977; K 1953; T 1983-1984; U 1976a; U 1976b; U 1978a; U 1978b; U 1978c; U 198Ia; U 1981c; U 1983; U-Á 1995;

Eupithecia orphnata W. Petersen, 1909; U 1978b; U 1978c; U-Á 1995;

Eupithecia semigraphata Bruand, 1850; $\Lambda$-U 1994; F 1977; K 1953; U 1978b;

Eupithecia millefoliata Rössler, 1866; Á 1990; Á-U 1994; Á-U 1998; F 1977; K 1953; Ré 1972; U 1978b; U 1981a; U 1981c; U 1985; U-Á 1995;

Eupithecia wettsteini Vojnits, 1974; F 1977; U 1978b;

Eupithecia simpliciata (Haworth, 1809) (=subnotata) - Á 1990; Á-U 1994; F 1977; K 1953; Ré 1972; T 1983-1984;

Eupithecia gemellata Herrich-Schäffer, 1861; F 1977; U 1978b;

Eupithecia graphata (Treitschke, 1828) - F 1977; Ré 1972; U 1978b;

Eupithecia indigata (Hübner, 1813) - Á-U 1994; F 1977; U 1976a; U 1978b; U 1978c; U 1980a; U 1981a; U 1981c; U-Á 1995;

Eupithecia pimpinellata (Hübner, 1813) - Á 1992a; Á 1992b; Á-U 1994; F 1977; Ré 1972; U 1978b;

Eupithecia nanata (Hübner, 1813) - F 1977; U 1978b; U 1981b; U 198Ic; U-Á 1995;

Eupithecia innotata (Hufnagel, 1767) - Á 1990; Â-U 1994; Á-U 1998; K 1953; Ré 1972; U 1976a; U $4978 \mathrm{a} ;$ U 1978b; U 1978c; U 198Ia; U 1981c; U-Á 1995;

Eupithecia ochridata Schütze \& Pinker, 1968; F 1977; U 1976b; U 1978b;

Eupithecia pirgaureata Doubleday, 1861; Á 1990; Á 1992a; Á 1992b; Á-U 1994; Á-U 1998; F 1977; K 1953; T 1983-1984; U 1976a; U 1978a; U 1978b; U 1978c; U 1981a; U 1981c; U-Á 1995;

Eupithecia abbreviata Stephens, 1831; Á 1990; Á 1992a; Á 1992b; Á-U 1994; Á-U 1998; F 1977; GyP et al 1974; K 1953; U 1976a; U 1978a; U 1978b; U 1978c; U 1981a; U 1981c; U-Á 1995;

Eupithecia dodoneata Guenée, 1857; Á 1990; Á 1992a; Á 1992b; Á-U 1994; Á-U 1998; F 1977; K 1953; U 1976a; U 1978b; U 1978c; U 1981a; U 1981c; U-Á 1995;

Eupithecia (=Tephroclystia) pusillata (Denis \& Schiffermüller, 1775) (=sobrinata) - Á 1990; Á 1992a; Á-U 1998; F 1977; Ré 1972; U 1976a; U 1978a; U 1978b; U 1978c; U 1980a; U-Á 1995; 
Eupithecia ericeata (Rambur, 1833) - $\hat{A}$ 1990; Á-U 1994; F 1977; K 1953; K 1958; U 1978b;

Eupithecia lanceata (Hübner, 1825) - U 1978b; U 1985; U-Á 1995;

Eupithecia lariciata (Freyer, 1841) - F 1977; Gyl et al 1979; U 1976a; U 1978b; U 1978c; U 1980a; U-Á 1995;

Eupithecia tantillaria Boisduval, 1840; Á 1992a; Á 1992b; Á-U 1994; U 1978b; U 1981b; U 1981c; U.Á 1995;

Gymnoscelis rufifasciata (Haworth, 1809) (=pumilata) - Á 1990; Á 1992a; Á 1992b; Á-U 1994; Á-U 1998; F 1977; K 1953; Ré 1972; U 1978b; U 1981a; U 1981c; U 1983; U-Á 1995;

Chloroclystis p-ata (Haworth, 1809) (=coronata) - Á 1990; Á 1992a; Á 1992b; Á-U 1994; Á-U 1998; F 1977; K 1953; U 1976a; U 1976b; U 1978a; U 1978b; U 1978c; U 1981 a; U 1981c; U 1983; U-Á 1995;

Rhinoprora (=Calliclystis) rectangulata (Linnaeus, 1758) - Á 1992a; $\Lambda$ 1992b; Á-U 1994; Á-U 1998; F 1977; K 1953; T 19831984; U 1976a; U 1976b; U 1978a; U 1978b; U 1978c; U 1981a; U 198Ic; U-Á 1995;

Rhinoprora chloerata (Mabille, 1870) - $\Lambda-U$ 1998; F 1977; U 1978b; U 1985; U-Á 1995;

Rhinoprora debiliata (Hübner, 1817) - U 1978b; U 1981c;

Anticollix sparsata (Treitschke, 1828) - Á 1992a; Á 1992b; Á-U 1994; Á-U 1998; F 1977; K 1953; U 1976a; U 1978b; U 1978c; U 1981a; U 1981c; U-Á 1995;

Aplocera (=Anaitis) plagiata (Linnaeus, 1758) - Á 1990; Á 1992a; Á 1992b; Á-U 1994; K 1953; Ré 1972; Ro 1909; T 1983-1984; U 1976a; U 1976b; U 1978a; U 1978b; U 1978c; U 1981a; U 198Ic; U 1983; U-Á 1995;

Aplocera (=Anaitis) efformata (Guenée, 1857) - Á 1990; Á 1992a; Â 1992b; Á-U 1994; Á-U 1998; K 1953; T 1983-1984; U 1976a; U 1978b; U 1978c; U 1981a; U 1981c; U 1983; U-Á 1995;

Lithostege griseata (Denis \& Schiffermüller, 1775) (=asinata) - Á 1990; Á 1992a; Á-U 1994; K 1953; K 1956; Ré 1972; U 1978b; U $1978 \mathrm{c}$; U I981c; U-Á 1995;

Lithostege farinata (Hufnagel, 1767) - Á 1990; Á-U 1994; K 1953; K 1956; Ré 1972; T 1983-1.984; U 1978b; U 1978c; U 1981a; U 1981c; U-Á 1995;

Euchoeca nebulata (Scopoli, 1763) - Á 1990; Á 1992a; Á 1992b; Á.U 1994; Á-U 1998; K 1953; T 1983-1984; U 1976a; U 1976b; U 1978a; U 1978b; U 1978c; U 1981a; U 1981c;
U 1983; U 1984a; U- $\Lambda$ 1995;

Asthena albulata (Hufnagel, 1767) - Á

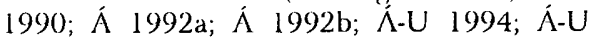
1998; K 1953; Ré 1972; T 1983-1984; U 1976a; U 1976b; U 1978a; U 1978b; U 1978c; U 1981a; U 1981c; U 1983; U-Á 1995;

Asthena anseraria (Herrich-Schäffer, 1855) Á 1992a; Á 1992b; Á-U 1994; Á-U 1998; K 1953; U 1976a; U 1976b; U 1978b; U 1978c; U 1981a; U 1981c; U-Á 1995;

Hydrelia flammeolaria (Hufnagel, 1767) - Á 1990; $\hat{\Lambda}$ 1992a; $\hat{\Lambda}$ 1992b; $\Lambda-U$ 1994; $\hat{\Lambda}-U$ 1998; K 1953; Ré 1972; U 1976a; U 1978a; U 1978b; U 1978c; U 1981a; U 1981c; U 1984a; $\mathrm{U}-\hat{\Lambda} 1995$;

Hydrelia sylvata (Denis \& Schiffermüller, 1775) - U 1978b; U 1984a;

Minoa murinata (Scopoli, 1763) - Á 1990; Á 1992a; Á 1992b; Á-U 1994; Á-U 1998; K 1953; Ré 1972; U 1976a; U 1976b; U 1978a; U 1978b; U 1978c; U I981a; U 1981c; U-Á 1995;

Lobophora halterata (Hufnagel, 1767) - Á 1990; Â 1992a; $\hat{-}-U$ 1994; K 1953; U 1976a; U 1978b; U 1978c; U 1981a; U 198lc; U-Á 1995;

Trichopteryx polycommata (Denis \& Schiffermüller, 1775) - $\Lambda$ 1990; $\hat{\Lambda}$ 1992a; $\hat{\Lambda}$ 1992b; $A-U$ 1994; K 1953; Ré 1972; U 1978a; U 1978b; U 1978c; U 1981a; U 1981c; U-ᄉ́ 1995;

Trichopteryx carpinata (Borkhausen, 1794) Á 1992a; Á 1992b; $\Lambda$-U 1994; Á-U 1998; K 1953; U 1978b; U 1978c; U 1981a; U 1981b; U 1981c; U-Á 1995;

Pterapherapteryx sexalata (Retzius, 1783) - Á 1992a; Á 1992b; Á-U 1994; Á-U 1998; K 1953; K 1956; Ré 1972; T' 1983-1984; U 1976a; U 1976b; U 1978a; U 1978b; U 1978c; U 1981a; U 1981c; U 1983; U-Á 1995;

Acasis piretata (Hübner, 1799) - Á 1990; Á 1992a; Á 1992b; Á-U 1994; Á-U 1998; Gyl et al 1979; K 1953; K 1958; U 1978b; U 1978c; U 1981a; U 1981b; U 1981c; U-Á 1995;

\section{Notodontidae}

\section{Thaumetapoeinae}

Thaumetopoea processionea (Linnaeus, 1758) Á 1990; Á 1992a; Á 1992b; Á-U 1994; Á-U 1998; K 1953; Ré 1972; U 1976a; U 1976b; U 1978a; U 1978b; U 1978c; U 1981a; U 1981c; U 1983; U-Á I995;

\section{Pygaerinae}

Clostera curtula (Linnacus, 1758) $-\hat{\Lambda} 1992 \mathrm{a}$;

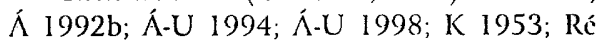
1972; T 1983-1984; U 1976a; U 1976b; U 1978a; U 1978b; U 1978c; U 1981a; U 1981c; U I983; U-Á 1995; 
Clostera pigra (Hufnagel, 1766) - Á 1990; Á 1992a; Á 1992b; Á-U 1994; Á-U 1998; K 1953; Ré 1972; T 1983-1984; U 1976a; U 1976b; U 1978a; U 1978b; U 1978c; U 1981a; U 198Ic; U 1983; U-Á 1995;

Clostera anachoreta (Denis \& Schiffermüller, 1775) - Á 1992a; Á-U 1998; K 1953; T 19831984; U 1976a; U 1976b; U 1978a; U 1978b; U 1978c; U 1983; U-Á 1995;

Clostera anastomosis (Linnaeus, 1758) - Á 1990; Á 1992a; Á 1992b; Á-U 1994; Á-U 1998; K 1953; Ré 1972; U 1976a; U 1976b; U 1978a; U 1978b; U 1978c; U 1981a; U 198lc; U 1983; U-Á 1995;

\section{Notodontinae}

Cerura vinula (Linnaeus, 1758) - Á 1990; Á 1992a; Á-U 1994; K 1953; Ré 1972; U 1976a; U 1976b; U 1978a; U 1978b; U 1978c; U 198Ic; U-Á 1995;

Cerura erminea (Esper, 1783) - Á 1990; Á 1992a; Á 1992b; Á-U 1994; Á-U 1998; U 1976a; U 1976b; U 1978a; U 1978b; U 1978c; U 1981a; U 1981c; U-Á 1995;

Furcula (=Cerura) furcula (Clerck, 1759) - Á 1992a; Á 1992b; Á-U 1994; Á-U 1998; K 1953; T 1983-1984; U 1976a; U 1976b; U 1978a; U 1978b; U 1978c; U 1981 a; U 1981c; U 1984a; U 1984b; U-Á 1995;

Furcula bicuspis (Borkhausen, 1790) - Á 1990; Á 1992a; Á 1992b; Á-U 1994; Á-U 1998; GyI et al 1979; K 1953; U 1976a; U 1978a; U 1978b; U 1978c; U 1981a; U 1981c; U-Á 1995;

Furcula bifida (Brahm, 1787) - Á 1990; Á 1992a; Á 1992b; Á-U 1994; Á-U 1998; K 1953; Ré 1972; U 1976a; U 1976b; U 1978a; U 1978b; U 1978c; U 1981a; U 1981c; U 1983; U-Á 1995;

Dicranura ulmi (Denis \& Schiffermüller, 1775) - Á 1990; Á-U 1994; K 1953; T $1983-$ 1984; U 1978a; U 1981c;

Notodonta dromedarius (Linnaeus, 1758) - Á 1990; Á 1992a; Á 1992b; Á-U 1994; Á-U 1998; K 1953; T 1983-1984; U 1976a; U 1976b; U 1978a; U 1978b; U 1978c; U 1981a; U 1981c; U 1983; U-Á 1995;

Notodonta tritophus (Denis \& Schiffermüller, 1775) (=phoebe) - Á 1990; Á 1992a; Á 1992b; Á-U 1994; Á-U 1998; K 1953; U 1976a; U 1976b; U 1978a; U 1978b; U 1978c; U 1981a; U 1981c; U-Á 1995;

Notodonta ziczac (Linnaeus, 1758) - Á 1990; Á 1992a; Á 1992b; Á-U 1994; Á-U 1998; K 1953; Ré 1972; U 1976a; U 1976b; U 1978a; U 1978b;
U 1978c; U 1981a; U 1981c; U-Á 1995;

Drymonia dodonaea (Denis \& Schiffermüller, 1775) (=trimacula) - Á 1990; Á 1992a; Á 1992b; Á-U 1994; Á-U 1998; K 1953; U 1976a; U 1976b; U 1978a; U 1978b; U 1978c; U 1981a; U 1981c; U 1983; U-Á 1995;

Drymonia ruficornis (Hufnagel, 1766) (=chaonia) - Á 1990; Á 1992a; Á 1992b; Á-U 1994; Á-U 1998; K 1953; T 1983-1984; U 1976a; U 1978a; U 1978b; U 1978c; U 1981a; U 1981c; U 1983; U-Á 1995;

Drymonia obliterata (Esper, 1785) - Á 1990; Á 1992a; Á 1992b; Á-U 1994; Á-U 1998; K 1953; T 1983-1984; U 1981a; U 1981c; U 1985; U-Á 1995;

Drymonia querna (Denis \& Schiffermüller, 1775) - Á 1990; Á 1992a; Á 1992b; Á-U 1994; Á-U 1998; K 1953; Ré 1972; U 1976a; U 1978a; U 1978c; U 1981a; U 1981c; U-Á 1995;

Drymonia velitaris (Hufnagel, 1766) $-\hat{\Lambda}$ 1990; Á 1992a; Á 1992b; ÂU 1994; Á-U 1998; U 1976a; U 1978a; U 1978c; U 1981a; U 198Ic; U-Á 1995;

Pheosia tremula (Clerck, 1759) - Á 1990; Á 1992a; Á 1992b; Á-U 1994; Á-U 1998; K 1953; Ré 1972; T 1983-1984; U 1976a; U 1976b; U 1978a; U 1978b; U 1978c; U 1981a; U 198Ic; U 1983; U-Á 1995;

Pheosia gnoma (Fabricius, 1776) - Á 1990; Á 1992a; Á-U 1994; Á-U 1998; GyI et al 1979; U 1976a; U 1978a; U 1978b; U 1978c; U 1981a; U 1981b; U 1981c; U 1983; U 1984a; U 1984b; U-Á 1995;

Pterostoma (=Euchila) palpina (Clerck, 1759) Á 1990; Á 1992a; Á 1992b; Á-U 1994; Á-U 1998; K 1953; Ré 1972; Ro 1909; T 1983-1984; U 1976a; U 1976b; U 1978a; U 1978b; U 1978c; U 1981a; U 1981c; U 1983; U-Á 1995;

Ptilophora plumigera (Denis \& Schiffermüller, 1775) - Á 1990; Á 1992a; Á 1992b; ÁU 1994; Á-U 1998; K 1953; Ré 1972; U 1976a; U 1978a; U 1978b; U 1978c; U 1981a; U 1981c; U 1983; U-Á 1995;

Leucodonta bicoloria (Denis \& Schiffermüller, 1775) - Á-U 1998; U 1981 b; U 1981c; U 1984a; U 1984b; U-Á 1995;

Ptilodon (=Lophopteryx) capucina (Linnacus, 1758) (=camellina) - Á 1990; Á 1992a; Á 1992b; Á-U 1994; Á-U 1998; K 1953; Ré 1972; U 1976a; U 1976b; U 1978a; U 1978b; U 1978c; U 1981a; U 1981c; U 1983; U-Á 1995;

Ptilodon (=Lophopteryx) cucullina (Denis \& Schiffermüller, 1775) (=cuculla) - Á 1990; Á 1992a; Á 1992b; Á-U 1994; Á-U 1998; K 1953; Ré 1972; U 1976a; U 1976b; U 1978a; 
U 1978b; U 1978c; U 1981a; U 1981c; U-Á 1995; Gluphisia crenata (Esper, I 785) - Á I 990; Á 1992a; Á 1992b; Á-U 1994; Á-U I998; K 1953; T 1983-1984; U 1976a; U 1976b; U 1978a; U 1978b; U 1978c; U $1981 \mathrm{a}$ U $1981 \mathrm{c}$; U-Á 1995;

\section{Phalerinae}

Phalera bucephala (Linnacus, 1758) - Á 1990; Á 1992a; Á 1992b; ́́-U 1994; Á-U 1998; K I953; Ré 1972; T 1983-1984; U 1976a; U I 978a; U 1978b; U 1978c; U $1981 \mathrm{a}$; U 1981c; U 1983; U-Á 1995;

Phalera bucephaloides (Ochsenheimer, 1810) Á 1990; K 1953; Ré 1972;

Peridea anceps (Goeze, 1781) - Á 1990; Á 1992a; Á I992b; Á-U 1994; ́́-U 1998; K 1953; T 1983-1984; U 1976a; U 1978a; U 1978c; U 1981a; U 1981c; U 1983; U-Á 1995;

\section{Heterocampinae}

Stauropus fagi (Linnacus, 1758) - Á 1990; Á 1992a; Á 1992b; Á-U 1994; Á-U 1998; K 1953; Ré 1972; U 1976a; U 1976b; U 1978a; U 1978b; U 1978c; U 198la; U 198lc; U 1983; U-Á 1995;

Harpyia milhauseri (Fabricius, 1775) - Á 1990; Á 1992a; Á-U 1994; Á-U 1998; K 1953; U 1976a; U 1976b; U 1978a; U 1978b; U 1978c; U 1981a; U 1981c; U.Á 1995;

Spatalia argentina (Denis \& Schiffermüller, 1775) - Á 1990; Á 1992a; Á I992b; Á-U 1994; Á-U 1998; K 1953; Ré 1972; U 1976a; U 1976b; U 1978a; U 1978b; U 1978c; U 1981a; U 198Ic; U 1983; U-Á 1995;

\section{Noctuidae}

\section{Acronictinae}

Oxicesta geographica (Fabricius, 1787) - Á 1990; Á-U 1994; K 1953; Ré I972;

Moma alpium (Osbeck, 1778) - Á 1990; Á 1992a; Á 1992b; Á-U 1994; Á-U 1998; K 1953; U 1976a; U 1976b; U 1978a; U 1978b; U 1978c; U 1981a; U 198lc; U 1983; U-Á 1995; Acronicta (=Apatele) alni (Linnaeus, 1767) Á 1990; Á 1992a; Á 1992b; Á-U 1994; Á-U 1998; GyP et al 1974; T 1983-1984; U 1976a; U 1976b; U 1978a; U 1978b; U 1978c; U $198 \mathrm{la}$; 1981b; U I981c; U 1983; U 1984a; U 1984b; U-Á 1995;

Acronicta (=Apatele) cuspis (Hübner, 1813) Á 1990; Á 1992a; Á 1992b; Á-U 1994; Á-U 1998; GyP et al 1974; U 1976a; U 1976b; U 1978a; U 1978b; U 1978c; U 1981a; U 1981b; U 1981c; U 1984a; U-Á 1995;
Acronicta (=Apatele), tridens (Denis \& Schiffermüller, 1775) - Á 1990; Á 1992a; Á 1992b; Á-U 1994; K 1953; K 1956; Ré 1972; T 1983-1984; U 1976a; U 1976b; U 1978a; U 1978b; U 1978c; U 1981a; U 1981c; U-Á 1995;

Acronicta (=Apatele) psi (Linnaeus, 1758) Á 1990; Á 1992a; Á-U 1994; Á-U 1998; K 1953; U 1976a; U 1976b; U 1978a; U 1978b; U I978c; U 1981c; U-ᄉ́ 1995;

Acronicta (=Apatele) aceris (Linnaeus, 1758) Á 1990; Á-U 1994; ヘ́.U 1998; K 1953; Ré 1972; U 1976a; U I 976b; U I978a; U 1978b; U 1981b; U $1981 \mathrm{c}$; U-ᄉ́ 1995;

Acronicta (=Apatele) leporina (Linnaeus, 1758) - Á 1990; Á 1992a; Á 1992b; Á-U 1994; Á-U 1998; K 1953; U 1976a; U 1976b; U 1978a; U 1978b; U 1978c; U 1981c; U 1983; U 1984a; U-Á 1995;

Acronicta (=Apatele) megacephala (Denis \& Schiffermüller, 1775) - Á 1990; Á 1992a; Á 1992b; Á-U 1994; Á-U 1998; K 1953; Ré 1972; T 1983-1984; U 1976a; U 1976b; U 1978a; U 1978b; U 1978c; U 1981a; U 198lc; U-Á 1995;

Acronicta (=Apatele) strigosa (Denis \& Schiffermüller, 1775) - Á 1990; Á 1992a; Á-U 1998; Gyl et al 1979; T I983-1984; U 1976a; U 1978a; U 1978b; U 1978c; U 1981b; U 1981c; U 1983; U 1984b; U-Á 1995;

Acronicta (=Apatele) auricoma (Denis \& Schif'f'ermüller, 1775) - Á 1990; Á 1992a; Á 1992b; Á-U 1994; Á-U 1998; K 1953; U 1976a; U 1976b; U 1978a; U 1978b; U 1978c; U 1981a; U 198Ic; U 1983; U-Á 1995;

Acronicta (=Apatele) euphorbiae (Denis \& Schiffermüller, I775) - Á 1990; Á-U 1994; K 1953; U 1976a; U 1978c; U 198Ib; U 198lc; U-Á 1995;

Acronicta (=Apatele) rumicis (Linnaeus, 1758) - A 1990; Á 1992a; Á 1992b; Á-U 1994; Á-U 1998; K 1953; Ré 1972; T 1983-1984; U 1976a; U 1976b; U 1978a; U 1978b; U 1978c; U 1981a; U 1981c; U 1983; U-Á 1995;

Craniophora ligustri (Denis \& Schiffermüller, I775) - Á 1990; Á 1992a; Á 1992b; ÁU 1994; Á-U 1998; K 1953; Ré 1972; T 19831984; U 1976a; U 1976b; U 1978a; U 1978b; U 1978c; U I981a; U 1981c; U-Á 1995;

Simyra nemosa (Denis \& Schiffermüller, 1775) - Á 1990; K 1953; Ré 1972; U 1976a; U I978c; U-Á 1995;

Simyra albovenosa (Goeze, 1781) - Á 1990; Á 1992a; Á 1992b; A-U 1994; Á-U 1998; K 1973; Ré 1972; T 1983-1984; U 1976a; U 1976b; U 1978a; U 1978b; U 1978c; U 1981c; U 1983; U-Á 1995; 


\section{Bryophilinae}

Cryphia receptricula (Hübner, 1803) (=Bryophila strigula) - U 1983;

Cryphia fraudatricula (Hübner, 1803) - Á 1990; Á 1992a; Á 1992b; Á-U 1994; K 1953; Ré 1972; T 1983-1984; U 1976a; U 1976b; U 1978a; U 1978b; U 1978c; U 1981c; U 1983; U-Á 1995;

Cryphia algae (Fabricius, 1775) - Á 1990; Á 1992a; Á 1992b; Á-U 1994; Á-U 1998; K 1953; Ré 1972; U 1976a; U 1978a; U 1978b; U 1978c; U 1981c; U 1983; U-ᄉ́ 1995;

Cryphia raptricula (Denis \& Schiffermüller, 1775) - Á 1990; Á 1992a; Á 1992b; Á-U 1994; K 1953; Ré 1972; U 1976a; U 1978a; U 1978b; U 1981c; U-Á 1995;

\section{Herminiinae}

Idia (=Epizeuxis) calparia (Denis \& Schiffermüller, 1775) - Á 1990; Á-U 1994; K 1953; U 1976a; U 1978b; U-Á 1995;

Simplicia rectalis (Eversmann, 1842) - Á 1990; Á-U 1994; K 1953; Ré 1972; U 1976a; U 1976b; U 1978a; U 1978b; U 1978c; U 1981c; U-Á 1995;

Paracolax tristalis (Fabricius, 1794) (=derivalis) - Á 1992a; Á 1992b; Á-U 1994; ÁU 1998; K 1953; Ré 1972; T 1983-1984; U 1976a; U 1976b; U 1978a; U 1978b; U 1978c; U 1981a; U 198Ic; U 1983; U-Á 1995;

Macrochilo (=Herminia) cribrumalis (Hübner, 1793) - Á 1990; Á 1992a; Á 1992b; Á-U 1994; K 1953; Ré 1972; U 1976a; U 1978a; U 1978b; U 1978c; U 1981a; U 198 lb; U 1981c; U 1983; U-Á 1995;

Herminia tarsicrinalis (Knoch, 1782) - Á 1990; Á 1992a; Á 1992b; Á-U 1994; Á-U 1998; K 1953; K 1956; Ré 1972; T $1983-$ 1984; U 1976a; U 1976b; U 1978a; U 1978b; U 1978c; U 1981a; U 1981c; U 1983; U-Á 1995;

Herminia grisealis (Denis \& Schiffermüller, 1775) (=nemoralis) - Á 1992a; Á 1992b; Á-U 1994; Á-U 1998; K 1953; K 1956; Ré 1972; T 1983-1984; U 1976a; U 1976b; U 1978a; U 1978b; U 1978c; U 1981a; U 1981c; U 1983; U-Á 1995;

Herminia tenuialis (Rebel, 1899) - GyP et al 1974; T 1983-1984; U 1976a; U 1976b; U 1978b; U 1978c; U 1981b; U 1981c; U 1983; U 1984b; U-Á 1995;

Polypogon tentacularia (Linnaeus, 1758) - Á 1990; Á 1992a; Á 1992b; Á-U 1994; Á-U 1998; K 1953; Ré 1972; T 1983-1984; U 1976a; U 1976b; U 1978a; U 1978b; U 1981c; U 1983; U-Á 1995;
Polypogon gryphalis (Herrich-Schäffer, 1851) Á 1992b; Â-U 1994; Á-U 1998; GyI et al 1979; GyP et al 1974; U 1976a; U 1976b; U 1978b; U 1978c; U 1981a; U 1981b; U 1981c; U 1983; U 1984b; U-Á 1995;

Pechipogo (=Herminia) strigilata (Linnacus,

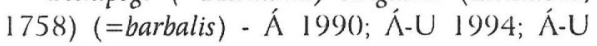
1998; K 1953; Ré 1972; 'T 1983-1984; U 1976a; U 1976b; U 1978a; U 1978b; U 1978c; U 1981a; U 1981c; U 1983; U-Á 1995;

Zanclognatha lunalis (Scopoli, 1763) - Á 1990; Á 1992a; Á 1992b; Á-U I994; K 1953; Ré 1972; U 1976a; U 1976b; U 1978a; U 1978b; U 1978c; U 1981a; U 198 Ic; U 1983; U-Á 1995;

Zanclognatha zelleralis (Wocke, 1850) - Á 1990;

Zanclognatha (=Herminia) tarsipennalis Treitschke, 1835; A 1899; Á 1990; Á 1992a; Á 1992b; Á-U 1994; Á-U 1998; K 1953; Ré 1972; T 1983-1984; U 1976a; U 1978a; U 1978b; U 1978c; U 1981a; U 1981c; U 1983; U-Á 1995;

\section{Strepsimaninae}

Hypenodes (=Schrankia) humidalis Doubleday, 1850 (=turfosalis) - Á 1990; K 1953; K 1958;

Schrankia (=Hypenodes) costaestrigalis (Stephens, 1834) - Á 1990; Á 1992b; Á-U 1994; Á-U 1998; K 1953; T 1983-1984; U 1976a; U 1978c; U. 1981c; U-Á 1995;

Schrankia (=Hypenodes) taenialis (Hübner, 1809) - Á 1990; Á 1992a; Á-U 1994; K 1953; U 1981b; U 1981c; U 1983; U-Á 1995;

\section{Catocalinae}

Catocala sponsa (Linnaeus, 1767) - Á 1990; Á 1992a; Á-U 1994; Á-U 1998; K 1953; Ré 1972; U 1978a; U 1981c;

Catocala dilecta (Hübner, 1808) - Á 1990; Á-U 1994; K 1953;

Catocala fraxini (Linnaeus, 1758) - Á 1990; Á 1992a; Á-U 1994; K 1953; U 1978a; U 1981a; U 198Ic; U-Á 1995;

Catocala nupta (Linnaeus, 1767) - Á 1990; Á 1992a; Á 1992b; Á-U 1994; Á-U 1998; K 1953; Ré 1972; U 1976a; U 1976b; U 1978a; U 1978b; U 1978c; U 1981a; U 1981c; U-Á 1995;

Catocala elocata (Esper, 1787) - Á 1990; Á 1992b; Á-U 1994; K 1953; Ré 1972; U 1976a; U 1976b; U 1978a; U 1978b; U 198Ic; U-Á 1995;

Catocala puerpera (Giorna, 1791) - Á 1990; K 1953; Ré 1972;

Catocala promissa (Denis \& Schiffermüller, 1775) - Á 1990; Á-U 1994; K 1953; Ré 1972; U 1978a; U 1981a; U 1981c; U-Á 1995; 
Catocala electa (Vieweg, 1790) - Á 1990; ÁU 1994; Á-U I998; K 1953; Ré 1972; U 1976a; U 1976b; U 1978a; U 1978b; U 1981a; U 1981c; U-Á 1995;

Catocala nymphagoga (Esper, 1787) - $\Lambda$ 1990; Á 1992b; ÁU 1994; K 1953; U 1978a; U 1978b; U 1981 a; U 1981c;

Catocala hymenaea (Denis \& Schiffermüller, 1775) - Á 1990; Á-U 1994; K I953; Ré 1972;

Catocala (=Ephesia) fulminea (Scopoli, 1763) (=paranympha) - Á 1990; Á 1992a; Á 1992b; Â-U 1994; Á-U 1998; K 1953; U 1976a; U 1978c; U 1981a; U 1981c; U 1983; U-Á 1995;

Minucia lunaris (Denis \& Schiffermüller, 1775) - Á 1990; Á 1992a; Á-U 1994; Á-U 1998; K 1953; Ré 1972; U 1978a; U 1978c; U 1981a; U 1981c; U 1983; U-Á 1995;

Dysgonia algira (Linnacus, 1767) - Á 1990; Á-U 1994; K 1953; U 1979;

Prodotis (=Grammodes) stolida (Fabricius, 1775) - Á 1990; Á-U 1994;

Lygephila lusoria (Linnaeus, 1758) - Á 1990; Á 1992b; Á-U 1994; K 1953; Ré 1972;

Lygephila pastinum (Treitschke, 1826) - Á 1990; Á 1992a; Á 1992b; Á-U 1994; Á-U 1998; K 1953; T 1983-1984; U 1976a; U 1976b; U 1978a; U 1978b; U $1978 \mathrm{c}$; U 1981c; U 1983; U-Á 1995;

Lygephila craccae (Denis \& Schiffermüller, 1775) - Á 1990; Á 1992a; Á 1992b; Á-U 1994; Á-U 1998; K 1953; Ré 1972; U 1978a; U 1981a; U 198lc;

Lygephila (=Toxocampa) procax (Hübner, 1813) (=limosa) - Á 1990; Á-U 1994; K 1953; K 1956; Ré 1972;

Catephia alchymista (Denis \& Schiffermüller, 1775) - Á 1990; Á-U 1994; K 1953; U 1978a; U 1978b; U I98Ib; U I98 Ic; U.Á 1995;

Aedia funesta (Esper, 1786) - Á 1990; Á 1992a; Á 1992b; Á-U 1994; Á-U 1998; K 1953; Ré 1972; T 1983-1984; U 1978a; U 1978b; U 1978c; U 1981c; U-Á 1995;

Aedia leucomelas (Linnaeus, 1758) - coll: SMM

Tyta (=Tarache) luctuosa (Denis \& Schiffermüller, 1775) - Á 1990; ᄉ́ 1992a; Á 1992b; Á-U 1994; Á-U 1998; K 1953; Ré 1972; T 1983-1984; U 1976a; U 1976b; U I978a; U 1978b; U 1978c; U I981a; U 198 lc; U 1983; U-Á 1995;

Callistege mi (Clerck, 1759) - Á 1990; Á-U 1994; K 1953; U 1976b; U 1978c; U 1981c; U-Á 1995;
Euclidia glyphica (Linnaeus, 1758) - Á 1990; Á 1992a; Á 1992b; Á-U 1994; Á-U 1998; K 1953; Ré 1972; U 1976a; U 1976b; U 1978a; U 1978b; U 1978c; U 1981a; U 1981c; U-Á 1995;

Laspeyria flexula (Denis \& Schiffermüller, 1775) - ^ 1990; Á 1992a; Á 1992b; Á-U 1994; Á-U I998; K 1953; T 1983-1984; U 1976a; U 1976b; U 1978a; U 1978b; U 1978c; U 1981a; U 1981c; U 1983; U-Á 1995;

Arytrura musculus (Ménétriés, 1859) - K 1953;

\section{Calpinae}

Scoliopteryx libatrix (Linnaeus, 1758) - Á 1990; X̂ 1992a; Á 1992b; Á-U 1994; Á-U 1998; K 1953; Ré 1972; T 1983-1984; U 1976a; U 1976b; U 1978a; U 1978b; U 1978c; U 1981a; U 1981c; U-Á 1995;

Calyptra thalictri (Borkhausen, 1790) - Á 1990; Á 1992a; Á 1992b; Á-U 1994; U 1976a; U 1978c; U.Á 1995;

\section{Hypeninae}

Hypena proboscidalis (Linnaeus, 1758) - Á 1990; Á 1992a; Á 1992b; Á-U 1994; Á-U 1998; K 1953; Ré 1972; T 1983-1984; U 1976a; U 1976b; U 1978a; U 1978b; U 1978c; U 1981a; U 1981c; U 1983; U-Á 1995;

Hypena rostralis (Linnaeus, 1758) - Á 1990; Á 1992a; Á 1992b; Á-U 1994; Á-U 1998; K 1953; Ré 1972; T 1983-1984; U 1976a; U I976b; U 1978a; U 1978b; U 1978c; U 1981 a; U 1981c; U 1983; U-Á 1995;

Phytometra viridaria (Clerck, 1759) - Á 1990; Á 1992a; Á 1992b; Á-U 1994; Á-U 1998; K 1953; Ré 1972; U 1976a; U 1978a; U 1978b; U 1978c; U 1981a; U 198 Ic; U 1983; U-Á 1995;

Rivula sericealis (Scopoli, 1763) - Á 1990; Á 1992a; Á 1992b; Á-U 1994; Á-U 1998; K 1953; Ré 1972; T 1983-1984; U 1976a; U 1976b; U 1978a; U 1978b; U 1978c; U 1981a; U 1981c; U 1983; U-Á 1995;

Parascotia fuliginaria (Linnaeus, 1761) - Á 1990; Á 1992a; Ấ 1992b; Á-U 1994; K 1953; U 1976a; U 1976b; U 1978a; U 1978b; U 1978c; U 1981a; U 1981c; U 1983; U-Á 1995;

Colobochyla salicalis (Denis \& Schiffermüller, 1775) - Á 1990; Á 1992a; Á 1992b; Á-U 1994; Á-U 1998; K 1953; T 19831984; U 1976a; U 1978a; U 1978b; U 1978c; U 1981a; U 1981c; U 1983; U-Á 1995;

\section{Euteliinae}

Eutelia adulatrix (Hübner, 1813) - Ré I972; 


\section{Plusiinae}

Euchalcia modestoides Poole, 1989 (=modesta) Á 1990; Á-U 1994; K 1953;

Euchalcia consona (Fabricius, 1787) - $A$ 1990; Á-U 1994;

Lamprotes c-aureum (Knoch, 1781) - Á 1990; Á 1992a; Á 1992b; Á-U 1994; Gyl et al 1979; K 1953; U 1976a; U 1978b; U I $981 a ; U$ I981c; U-Á 1995;

Diachrysia chrysitis (Linnaeus, 1758) - Á 1990; Á 1992a; Á 1992b; Á-U 1994; Á-U 1998; K 1953; K 1956; Ré 1972; T 19831984; U 1976a; U 1976b; U 1978a; U 1978b; U 1978c; U 1981a; U 198Ic; U 1983; U.Á 1995;

Diachrysia nadeja (Oberthür, 1880) - U 198 Ib; U 1981c; U 1984b; U-Á 1995; V 1981;

Diachrysia zosimi (Hübner, 1822) - Á 1990; Á 1992a; Á 1992b; Á-U 1994; K 1953; U 1976a; U 1976b; U 1978a; U 1978b; U-Á 1995;

Diachrysia chryson (Esper, 1789) - Á 1990; 1992a; Á 1992b; Á-U 1994; GyP et al 1974; K 1953; U 1976a; U 1976b; U 1978a; U 1978b; U 1981a; U 1981c; U 1984b; U-Á 1995;

Macdunnoughia confusa (Stephens, 1850) - Á 1990; Á 1992a; Á 1992b; Á-U 1994; Á-U 1998; K 1953; PS 1942; Ré 1972; T 19831984; U 1976a; U 1976b; U 1978a; U 1978b; U 1978c; U 1979; U 1981a; U 1981c; U 1983; U-Á 1995;

Plusia festucae (Linnaeus, 1758) - Á 1990; Á 1992a; Á 1992b; Á-U 1994; Á-U 1998; K 1953; Ré 1972; T 1983-1984; U 1976a; U 1976b; U 1978a; U 1978b; U 1981a; U 1981c; U-Á 1995;

Autographa gamma (Linnaeus, 1758) - Á 1990; Á 1992a; Á 1992b; Á-U 1994; Á-U 1998; K 1953; Ré 1972; T 1983-1984; U 1976a; U 1976b; U 1978a; U 1978b; U 1978c; U 1979; U 1981a; U 1981c; U 1983; U-Á 1995;

Autographa bractea (Denis \& Schiffermüller, 1775) - coll: SMM

Autographa pulchrina (Haworth, 1809) $(=c$ aureum) - U $1981 \mathrm{la}$; U 1981c; U 1984b;

Autographa jota (Linnaeus, 1758) - Á 1990; Á 1992b; A-U 1994; K 1953; U 1981a; U 198Ic;

Trichoplusia ni (Hübner, 1803) - Á 1990; ÁU 1994; Á-U 1998; K 1953;

Chrysodeixis chalcites (Esper, 1789) - Á 1990; Á-U 1994; U 1979;

Abrostola tripartita (Hufnagel, 1766) - Á 1990; Á 1992a; Á 1992b; Â-U 1994; Á-U 1998; K 1953; Ré 1972; T 1983-1984; U 1976a; U 1976b; U 1978a; U 1978b; U 1978c;
U 1981a; U 198Ic; U 1983; U-Á 1995;

Abrostola asclepiadis (Denis \& Schiffermüller, 1775) - Á 1990; Á 1992a; Á 1992b; ÁU 1994; K 1953; T 1983-1984; U 1976a; U 1978a; U 1978b; U 1978c; U 198Ic; U 1983; U-Á 1995;

Abrostola triplasia (Linnacus, 1758) - $A$ 1990; Á 1992a; Á 1992b; Á-U 1994; Á-U 1998; K 1953; Ré 1972; T 1983-1984; U 1976a; U 1976b; U 1978a; U 1978b; U 1978c; U 1981a; U 1981c; U 1983; U-Á 1995;

\section{Acontiinae}

Emmelia trabealis (Scopoli, 1763) - Á 1990; Á 1992a; Á 1992b; Á-U 1994; Á-U 1998; K 1953; Ré 1972; T 1983-1984; U 1976a; U 1976b; U 1978a; U I978b; U 1978c; U 1981 a; U 1981c; U 1983; U-Á 1995;

Acontia (=Tarache) lucida (Hufnagel, 1766) - Á 1990; Á 1992a; Á 1992b; Á-U 1994; Á-U 1998; K 1953; Ré 1972; T 1983-1984; U 1976a; U 1978a; U 1978b; U 1981c; U 1983; U-Á 1995;

\section{Eustrotiinae}

Protodeltote (=Jaspidia) pygarga (Hufnagel, 1766) - Á 1990; Á 1992a; Á 1992b; Á-U 1994; Á-U 1998; K 1953; Ré 1972; U 1976a; U 1976b; U 1978a; U 1978b; U I981a; U 1981c; U 1983; U-Á 1995;

Deltote (=Jaspidia) deceptoria (Scopoli, 1763) - Á 1990; Á 1992a; Á-U 1994; K 1953; Ré 1972; T 1983-1984; U 1978c; U 1981a; U 1981b; U 1981c; U-Á 1995;

Deltote (=Jaspidia) uncula (Clerck, 1759) - Á 1990; Á 1992a; Á 1992b; Á-U 1994; Á-U 1998; K 1953; Ré 1972; T 1983-1984; U 1976a; U 1976b; U 1978a; U 1978b; U 1978c; U I981a; U I98Ic; U-Á 1995;

Deltote (=Jaspidia) bankiana (Fabricius, 1775) - Á 1990; Â 1992a; Á I992b; Á-U I994; Á-U 1998; K 1953; Ré 1972; T 1983-1984; U 1976a; U 1976b; U 1978a; U 1978b; U 1978c; U 1981a; U 1981c; U 1983; U.Á 1995;

Pseudeustrotia (=Deltote) candidula (Denis \& Schiffermüller, 1775) - Á 1990; Á 1992a; Á 1992b; Á-U 1994; Á-U 1998; K 1953; Ré 1972; T 1983-1984; U 1976a; U 1976b; U 1978a; U 1978b; U 1978c; U 1981 a; U I981c; U 1983; U-Á 1995;

Odice arcuinna (Hübner, 1790) - K 1953;

Calymma communimacula (Denis \& Schiffermüller, 1775) - Á 1990; Á-U 1994; K 1953; Ré 1972;

Eublemma (=Porphyrinia) minutata (Fabricius, 1794) (=noctualis) - Á 1990; K 1953; 
Eublemma ostrina (Hübner, 1808) - U 1978c; U 1979; U 1981c; U-Á 1995;

Eublemma parva (Hübner, 1808) - Á 1990; Á 1992b; Á-U 1994; K 1953; K 1958;

Eublemma (=Thalpochares) purpurina (Denis \& Schiffermüller, 1775) - Á 1990; Á 1992a; $A$ 1992b; Á-U 1994; K 1953; Ré 1972; U 1976a; U 1978a; U 1978c; U 1981a; U 1981c; U-Á 1995;

Metachrostis dardouini (Boisduval, 1840) - Á 1990; Á-U 1994; K 1953;

Trisateles emortualis (Denis \& Schiffermüller, 1775) - Á 1990; Á 1992a; Á 1992b; Á-U 1994; Á-U 1998; K 1953; U 1976a; U 1976b; U 1978a; U 1978b; U 1978c; U 1981a; U 1981c; U 1983; U-Á 1995;

\section{Cuculiinae}

Cucullia scopariae Dorfmeister, 1853; Á 1990; B 1985; K 1953; K 1958;

Cucullia fraudatrix Eversmann, 1837; Á 1990; Á 1992a; Á 1992b; Á-U 1994; K 1953; T 1983-1984; U 1976a; U 1976b; U 1978a; U 1978b; U 1981c; U 1983; U-Á 1995;

Cucullia absinthii (Linnaeus, 1761) - Á 1990; Á-U 1994; K 1953; U 1978a; U 1981 a; U 1981c;

Cucullia argentea (Hufnagel, 1766) - Á 1990; Á-U 1994; K 1953; Ré 1972;

Cucullia artemisiae (Hufnagel, 1766) - Á 1990; Á-U 1994; K 1953; Ré 1972; U 1978a; U 1981a;

Cucullia lactucae (Denis \& Schiffermüller, 1775) - Á 1990; Á 1992a; Á.U 1994; K 1953; Ré 1972; U 1978a; U 1981b; U 1981c; U-Á 1995;

Cucullia umbratica (Linnaeus, 1758) - Á 1990; ᄉ́ 1992a; Á 1992b; Á-U 1994; Á-U 1998; K 1953; Ré 1972; Ro 1909; T 1983-1984; U 1976a; U 1976b; U 1978a; U 1978b; U 1978c; U 1981a; U 1981c; U 1983; U-Á 1995;

Cucullia chamomillae (Denis \& Schiffermüller, 1775) - Á 1990; Á-U 1994; K 1953; U 1976a; U 1978c; U 1981a; U 1981c; U-Á 1995;

Cucullia tanaceti (Denis \& Schiffermüller, 1775) - Á-U 1994; K 1953;

Shargacucullia scrophulariae (Denis \& Schiffermüller, 1775) - A-U 1994; Á-U 1998; K 1953; Ré 1972; U 1976a; U 1978c; U 1981a; U 1981c; U-Á 1995;

Shargacucullia blattariae (Esper, 1790) - Á 1990; Â-U 1994; K 1953;

Shargacucullia thapsiphaga (Treitschke, 1826) - Á 1990; K 1953;

Shargacucullia verbasci (Linnaeus, 1758) - Á 1990; Á1992a; Á-U 1994; K 1953; Ré 1972;

Shargacucullia prenanthis (Boisduval, 1840) Á 1990; Á-U 1994;
Calophasia lunula (Hufnagel, 1766) - Á 1990; A 1992a; Á 1992b; Â-U 1994; Á-U 1998; K 1953; Ré 1972; T 1983-1984; U 1976a; U 1976b; U 1978a; U 1978b; U I978c; U 1981a; U 198Ic; U 1983; U-Á 1995;

Calophasia opalina (Esper, 1793) (=casta) K 1953; Ré 1972;

\section{Amphipyrinae}

Amphipyra pyramidea (Linnaeus, 1758) - Á 1990; ᄉ́ 1992a; ᄉ́-U 1994; Á-U 1998; K 1953; Ré 1972; 'T 1983-1984; U 1976a; U 1978a; U $1981 \mathrm{a} ;$ U 1981b; U 1981c; U-Á 1995;

Amphipyra berbera Rungs, 1949; Á 1990; Á 1992a; Á-U 1994; Ré 1972;

Amphipyra livida (Denis \& Schiffermüller, 1775) - $\Lambda$ 1990; Á 1992a; Á-U 1994; Á-U 1998; K 1953; Ré 1972; U 1976a; U 1978a; U 1978b; U 1978c; U 1981a; U 1981c; U-Á 1995;

Amphipyra tragopoginis (Clerck, 1759) - Á 1990; Á 1992a; Á 1992b; Á.U 1994; Á-U 1998; K 1953; Ré 1972; T 1983-1984; U 1976a; U 1978a; U 1978b; U 1978c; U 1981a; U 1981c; U 1983; U-Á 1995;

\section{Psaphidinae}

Asteroscopus sphinx (Hufnagel, 1766) - Á 1990; Á 1992b; Á-U 1994; K 1953; Ré 1972; U 1976a; U 1978b; U 1978c; U I981a; U 1981c; U 1983; U-Á 1995;

Brachionycha nubeculosa (Esper, 1785) - Á 1990; Á 1992b; Á-U 1994; K 1953; Ré 1972; U 1981a; U 1981c; U 1983; U-Á 1995;

Lamprosticta culta (Denis \& Schiffermüller, 1775) - Á-U 1994; K 1953;

\section{Dilobinae}

Diloba (=Episema) caeruleocephala (Linnaeus, 1758) - Á I 990; Á 1992a; Á 1992b; Á-U 1994; Á-U 1998; K 1953; Ré 1972; U 1976a; U 1978a; U 1978b; U 1978c; U 1981a; U 1981c; U 1983; U.Á 1995;

\section{Stiriinae}

Panemeria tenebrata (Scopoli, 1763) - Á 1990; Á 1992a; Á 1992b; Á-U 1994; Á-U 1998; K 1953; U 1978a; U 1981a; U 198 Ic; U 1985; U-Á 1995;

Aegle kaekeritziana (Hübner, 1799) - Á 1990; Á-U 1994; K 1953; K 1956; Ré 1972;

\section{Heliothinae}

Schinia cardui (Hübner, 1790) - Á 1990; ÁU 1994; Á-U 1998; K 1953;

Schinia cognata (Freyer, 1833) - K 1953; 
Schinia scutosa (Denis \& Schiffermüller, 1775) - Á 1990; Á-U 1994; K 1953; Ré 1972; U 1976a; U 1978c; U 1979; U-Á 1995;

Heliothis (=Chloridea) piriplaca (Hufnagel, 1766) (=dipsacea) - Á 1990; Á 1992a; Á-U 1994; Á.U 1998; K 1953; Ré 1972; U 1976a; U 1976b; U 1978a; U 1978b; U 1978c; U 1981a; U 1981c; U 1983; U-Á 1995;

Heliothis maritima Graslin, 1855; Á 1990; Á 1992b; Á-U 1994; Á-U 1998; K 1953; Ré 1972; T 1983-1984; U 1976a; U 1976b; U 1978a; U 1978b; U 1978c; U 1981c; U-ᄉ́ 1995;

Heliothis ononis (Denis \& Schiffermüller, 1775) - K 1953;

Heliothis peltigera (Denis \& Schiffermüller, 1775) -Á 1990; Á 1992b; Á-U 1994; K 1953; U 1976a; U 1978a; U 1978c; U 1979; U 1981a; U 1981c; U 1983; U-Á 1995;

Heliothis nubigera Herrich-Schäffer, 1851; Á-U 1998;

Helicoverpa armigera (Hübner, 1808) - Á 1992a; Á-U 1994; U 1978a; U 1979; U 1981c;

Pyrrhia umbra (Hufnagel, 1766) - Á 1992a; Á 1992b; Á-U 1994; Á-U 1998; K 1953; U 1976a; U 1976b; U 1978a; U 1978b; U 1978c; U 1981a; U 198Ic; U 1983; U-Á 1995;

Periphanes delphinii (Linnaeus, 1758) - Á 1990; A-U 1994; K 1953; Ré 1972;

\section{Hadeninae}

Elaphria (=Agrotis) renustula (Hübner, 1790) - Á 1992a; Á-U 1994; Á-U 1998; K 1953; Ré 1972; T 1983-1984; U 1976a; U 1976b; U 1978a; U 1978b; U 1978c; U 198 Ia; U 1981c; U 1983; U-Á 1995;

Acosmetia caliginosa (Hübner, 1813) - Á 1990; Á-U 1994; K 1953; K 1956; Ré 1972; U 1976a; U 1976b; U 1978b; U 1978c; U 1981a; U 1981c; U 1983; U-Á 1995;

Caradrina morpheus (Hufnagel, 1766) - Á 1990; Á 1992a; Á 1992b; Á-U 1994; Á-U 1998; K 1953; Ré 1972; T 1983-1984; U 1976a; U 1978a; U 1978b; U 1978c; U 1981a; U 1981c; U 1983; U-Á 1995;

Platyperigea (=Caradrina) kadenii (Freyer, 1836) - Á 1990; Á İ992a; Á 1992b; Á-U 1994; K 1953; Ré 1972; U 1976a; U 1978a; U 1978b; U 1978c; U 1981a; U 1981c; U-Á 1995;

Paradrina (=Caradrina) clavipalpis (Scopoli, 1763) (=quadripunctata) - Á 1992a; Á 1992b; Á-U 1994; Á-U 1998; K 1953; Ré 1972; T 1983-1984; U 1976a; U 1976b; U 1978a; U 1978b; U 1978c; U 1981a; U 1981c; U 1983; U-Á 1995;
Hoplodrina (=Caradrina) octogenaria (Goeze, 1781) (=alsines) - Á 1990; Á 1992a; Á 1992b; Á-U 1994; Á-U 1998; K 1953; Ré 1972; Ro 1909; T 1983-1984; U 1976a; U 1976b; U 1978a; U 1978b; U 1978c; U 1981a; U 1981c; U 1983; U-Á 1995;

Hoplodrina blanda (Denis \& Schiffermüller, 1775) - Á 1990; Á 1992b; Á-U 1994; Á-U 1998; K 1953; Ré 1972; U 1976a; U 1978a; U 1978b; U 1978c; U 1981a; U I981c; U 1983; U-Á 1995;

Hoplodrina superstes (Ochsenheimer, 1816). Á 1990; Á-U 1994; K 1953;

Hoplodrina respersa (Denis \& Schiffermüller, 1775) - Á 1992b; Á-U 1994; Réd l972;

Hoplodrina ambigua (Denis \& Schiffermüller, 1775) - Á 1990; Á 1992a; Á 1992b; ÁU 1994; Á-U 1998; K 1953; Ré 1972; T 19831984; U 1976a; U 1976b; U 1978a; U 1978b; U 1978c; U 1981a; U 1981c; U 1983; U-Á 1995;

Charanyca (=Meristis) trigrammica (Hufnagel, 1766) - Á 1990; Á 1992a; Á 1992b; Á-U 1994; Á-U 1998; K 1953; Ré 1972; T 1983-1984; U 1976a; U 1976b; U 1978a; U 1978b; U 1978c; U 1981a; U 1981c; U 1983; U-Á 1995;

Atypha pulmonaris (Esper, 1790) - Á 1990; Á 1992a; Â 1992b; Á-U 1994; Á-U 1998; K 1953; U 1976a; U 1976b; U 1978a; U 1978b; U 1978c; U 1981a; U 1981c; U-Á 1995;

Spodoptera exigua (Hübner, 1808) - Á 1990; Á 1992a; Á 1992b; Á-U 1994; K 1953; U 1978c; U 1979; U 1981c; U-Á 1995;

Chilodes maritima (Tauscher, 1806) - Á 1990; Á 1992a; Á 1992b; Á-U 1994; K 1953; Ré 1972; T 1983-1984; U 1976a; U 1976b; U 1978a; U 1978b; U 1978c; U 198 la; U 198lc; U-Á 1995;

Athetis gluteosa (Treitschke, 1835) - Á 1990; Á 1992a; Á İ'992b; Á-U 1994; Á-U 1998; K 1953; K 1956; Ré 1972; T 1983-1984; U 1976a; U 1976b; U 1978a; U 1978b; U 1978c; U 1981a; U 1981c; U 1983; U-Á 1995;

Athetis furvula (Hübner, 1808) - Á 1990; ÁU 1994; K 1953; Ré 1972; U 1976a; U 1978b; U 1981c; U 1983; U-Á 1995;

Athetis pallustris (Hübner, 1808) - Á 1992b; Proxenus lepigone (Möschler, 1860) - Á 1990; Á 1992a; Á-U 1994; K 1953; Ré 1972; T I983-1984; U 1976a; U 1978b; U 1978c; U 1981a; U 1981c; U-Á 1995;

Dypterygia scabriuscula (Linnaeus, 1758) - Á 1990; Á 1992a; Á 1992b; Á-U 1994; Á-U 1998; K 1953; Ré 1972; Ro 1909; T 19831984; U 1976a; U 1976b; U 1978a; U 1978b; 
U 1978c; U 1981a; U 1981c; U 1983; U-Á 1995;

Rusina ferruginea (Esper, 1785) - Á 1990; $\hat{\Lambda}$ 1992a; Á 1992b; Á-U 1994; Á-U 1998; K 1953; K 1956; Ré 1972; T 1983-1984; U 1976a; U 1976b; U 1978a; U 1978b; U 1978c; U 1981a; U 1981c; U 1983; U-Á 1995;

Mormo maura (Linnaeus, 1758) - Á 1990; Á-U 1994;

Polyphaenis sericata (Esper, 1787) - Á 1990; Á 1992b; Á-U 1994; Á-U 1998; K 1953; U 1976a; U 1978c; U 1981a; U 1981c; U-Á 1995;

Thalpophila matura (Hufnagel, 1766) - Á 1990; A 1992a; Á 1992b; Á.U 1994; Á-U 1998; K 1953; K 1956; Ré 1972; T 19831984; U 1976a; U 1978a; U 1978c; U 1981a; U 1981c; U 1983; U. $\Lambda$ 1995;

Trachea atriplicis (Linnaeus, 1758) - Á 1990; Á 1992a; Á 1992b; Á-U 1994; Á-U 1998; K 1953; Ré 1972; T 1983-1984; U 1976a; U 1976b; U 1978a; U 1978b; U 1978c; U 198la; U 1981c; U 1983; U-Á 1995;

Euplexia lucipara (Linnaeus, 1758) - Á 1990; Á 1992a; Â 1992b; Á-U 1994; Á-U 1998; K 1953; Ré 1972; T 1983-1984; U 1976a; U 1976b; U 1978a; U 1978b; U 1978c; U 198la; U 198lc; U 1983; U.Á 1995;

Phlogophora meticulosa (Linnaeus, 1758) - Á 1990; ᄉ 1992a; Á 1992b; Á-U 1994; 1998; K 1953; Ré 1972; U 1976a; U 1978a; U 1978b; U 1978c; U 1979; U 1981a; U 1981c; U 1983; U-Â 1995;

Auchmis detersa (Esper, 1787) - Á-U 1994; Ré 1972;

Actinotia polyodon (Clerck, 1759) - Á 1990; Á 1992a; Á 1992b; Á-U 1994; Á-U 1998; K 1953; Ré 1972; T 1983-1984; U 1976a; U 1976b; U 1978a; U 1978b; U 1978c; U 1981a; U 1981c; U 1983; U-Á 1995;

Actinotia radiosa (Esper, 1804) - Á 1990; ÁU 1998; K 1953; U 1976a; U 1976b; U 1978c; U 1981c; U.Á 1995;

Chloantha hyperici (Denis \& Schiffermüller, 1775) - Á 1990; Á-U 1994; Á-U 1998; K 1953; Ré 1972; U 1976a; U 1978c; U-Á 1995;

Callopistria jupentina (Stoll, 1782 ??) - Á 1990; Á 1992a; Á 1992b; Á-U 1994; Á-U 1998; K 1953; U 1976a; U 1978a; U 1978c; U 1983; U-Á 1995;

Eucarta amethystina (Hübner, 1803) - Á 1990; Á 1992a; Á 1992b; Á-U 1994; Á-U 1998; K 1953; T 1983-1984; U 1976a; U 1976b; U 1978a; U 1978b; U 1978c; U 1981a; U 1981c; U 1983; U 1984b; U-Á 1995;

Eucarta pirgo (Treitschke, 1835) - Á 1990; 1992a; ́́ 1992b; Á-U 1994; Á-U 1998; K
1953; Ré 1972; T 1983-1984; U 1976a; U 1976b; U 1978a; U 1978b; U 1978c; U 1981 a; U I981c; U 1983; U-Á 1995;

Ipimorpha retusa (Linnaeus, 1761) - Á 1990; Á 1992a; Á 1992b; Á-U 1994; Á-U 1998; K 1953; T 1983-1984; U 1976a; U 1976b; U 1978b; U 1981a; U 1981b; U 1981c; U 1983; U-Á 1995;

Ipimorpha subtusa (Denis \& Schiffermüller, 1775) - Á 1992b; Á-U 1994; Á-U 1998; K 1953; Ré 1972; U 1976a; U 1978c; U 1981a; U 1981b; U 1981c; U 1983; U.Á 1995;

Parastichtis suspecta (Hübner, 1817) - Á 1992b; Á-U 1994; K 1953; Ré 1972; U 1976a; U 1978c; U I98Ic; U 1983; U-Á 1995;

Parastichtis (=Sidemia) ypsillon (Denis \& Schiffermüller, 1775) - Á 1990; Á 1992a; Á-U 1994; Á-U 1998; K 1953; Ré 1972; U 1976a; U 1978b; U 1985; U-Á 1995;

Mesogona acetosellae (Denis \& Schiffermüller, 1775) - Á 1990); Á 1992a; Á-U 1994; K 1953; U 1976a; U 1978c; U 1981a; U 1981c; U 1983; U-Á 1995;

Mesogona oxalina (Hübner, 1803) - Á 1990; Á 1992a; Á-U 1994; Á-U 1998; K 1953; U 1978c; U 1981c; U-Á 1995;

Cosmia diffinis (Linnaeus, 1767) - Á 1992a;

Cosmia affinis (Linnacus, 1767) - Á 1990; $A$ I992a; Á I992b; Á-U 1994; K 1953; U 1976a; U 1978a; U 1978b; U 1978c; U 1981a; U I981c; U-Á 1995;

Cosmia pyralina (Denis \& Schiffermüller, 1775) - Á 1990; Á 1992a; Á 1992b; Á-U 1994; Á-U 1998; K 1953; K 1956; Ré 1972; U 1976a; U 1978a; U 1978b; U 1978c; U 1981 a; U 1981c; U 1983; U-Á 1995;

Cosmia trapezina (Linnaeus, 1758) - Á 1990; Á 1992a; Á 1992b; Á-U 1994; Á-U 1998; K 1953; Ré 1972; U 1976a; U 1976b; U 1978a; U 1978b; U 1978c; U 1981a; U 1981c; U 1983; U-Á 1995;

Atethmia centrago (Haworth, 1809) - Á 1992a; Á 1992b; Á-U 1994; Á-U 1998; K 1953; U 1976a; U 1978a; U 1978b; U 1978c; U 1981a; U 1981c; U 1983; U-Á 1995;

Atethmia ambusta (Denis \& Schiffermüller, 1775) - Á 1990; Á 1992b; Á-U 1994;

Xanthia (=Cosmia) togata (Esper, 1788) (=lutea) - Á 1990; Á 1992a; Á 1992b; Á-U 1994; A-U 1998; K 1953; U 1976a; U 1978a; U 1978b; U 1978c; U 1981a; U 1981c; U 1983; U-Á 1995;

Xanthia (=Cosmia) aurago (Denis \& Schiffermüller, 1775) - Á 1990; Á 1992a; Á 1992b; Á-U 1994; Á-U 1998; K 1953; U 
1976a; U 1978a; U 1978b; U 1978c; U 1981a; U 1981c; U-Á 1995;

Xanthia (=Cosmia) sulphurago (Denis \& Schiffermüller, 1775) (=fulvago) - Á 1990; Á 1992a; Á 1992b; Á-U 1994; K 1953; U 1976a; U 1978a; U 1978b; U 1981a; U 1981c; U-Á 1995;

Xanthia (=Cosmia) icteritia (Hufnagel, 1766) (=fulvago) - Á 1990; ́́ 1992a; Á 1992b; Á-U 1994; Á-U 1998; U 1976a; U 1978a; U 1978b; U 1978c; U 1981a; U 1981c; U 1983; U-Á 1995;

Xanthia (=Cosmia) gilvago (Denis \& Schiffermüller, 1775) - Á 1990; Á 1992a; Á 1992b; Á-U 1994; Á-U 1998; K 1953; Ré 1972; U 1981b; U 1981c; U-Á 1995;

Xanthia (=Cosmia) ocellaris (Borkhausen, 1792) - Á 1990; Á 1992a; Á-U 1994; K 1953; K 1956; Ré 1972; U 1976a; U 1978c; U 1981c; U 1983; U-Á 1995;

Xanthia (=Cosmia) citrago (Linnaeus, 1758) Á 1990; Á 1992a; Á 1992b; Á-U 1994; K 1953; U 1978c; U 1981 a; U 1981c; U-Á 1995;

Agrochola lychnidis (Denis \& Schiffermüller, 1775) - Á 1990; Á 1992a; Á 1992b; Á-U 1994; K 1953; Ré 1972; U 1978a; U 1981a; U 1981c; U-Á 1995;

Agrochola circellaris (Hufnagel, 1766) - Á 1990; Á 1992a; Á 1992b; Á-U 1994; Á-U 1998; K 1953; Ré 1972; U 1976a; U 1978a; U 1978b; U 1978c; U 1981a; U 1981c; U 1983; U-Á 1995;

Agrochola lota (Clerck, 1759) - Á 1990; Á 1992a; Á 1992b; Á-U I994; Á-U 1998; K 1953; Ré 1972; U 1976a; U 1978b; U 1978c; U 1981a; U 1981c; U 1983; U-Á 1995;

Agrochola macilenta (Hübner, 1809) - Á 1990; Á 1992a; Á 1992b; Á-U 1994; Á-U 1998; K 1953; Ré 1972; U 1976a; U 1978b; U I978c; U 1981a; U 1981c; U-ᄉ́ 1995;

Agrochola nitida (Denis \& Schiffermüller, 1775) - Á 1992a; Á 1992b; Á-U 1994; Á-U 1998; K 1953; U 1976a; U 1978a; U 1978b; U 1978c; U 1981a; U 1981c; U 1983; U-র́ 1995; Agrochola helvola (Linnaeus, 1758) - Á 1990; Á 1992a; Á 1992b; Á-U 1994; Á-U 1998; K 1953; T 1983-1984; U 1976a; U 1978a; U 1978b; U 1978c; U 1981a; U 1981c; U 1983; U-Á 1995;

Agrochola humilis (Denis \& Schiffermüller, 1775) - Á 1990; Á 1992a; 人́ 1992b; ́́-U 1994; K 1953; T 1983-1984; U 1976a; U 1978a; U 1978b; U 1978c; U 1981a; U 1981c; U-Á 1995;

Agrochola litura (Linnaeus, 1758) - Á 1992a; Á 1992b; Á-U 1994; K 1953; K 1956; Ré 1972; T 1983-1984; U 1976a; U 1978a; U 1978b; U 1978c; U 1981a; U 1981c; U 1983; U-Á 1995;

Agrochola laevis (Hübner, 1803) - Á 1990; Á 1992a; Á 1992b; Á-U 1994; K 1953;

Spudaea ruticilla (Esper, 1791) - Á 1990; ÁU 1994; K 1953;

Eupsilia transversa (Hufnagel, 1766) - Á 1990; Á 1992a; Á 1992b; A-U 1994; Á-U 1998; K 1953; Ré 1972; U 1976a; U 1978a; U 1978b; U 1978c; U 1981a; U 1981c; U 1983; U-Á 1995;

Jodia croceago (Denis \& Schiffermüller, 1775) - Á 1990; Á-U 1994; K 1953; Ré 1972; U 1981a; U 1981c;

Conistra vaccinii (Linnaeus, 1761) - Á 1990; Á 1992a; Á 1992b; Á-U 1994; Á-U 1998; K 1953; Ré 1972; T 1983-1984; U 1976a; U 1978a; U 1978b; U 1978c; U 1981a; U 1981c; U 1983; U-Á 1995;

Conistra ligula (Esper, 1791) - Á 1992a; ÁU 1994; K 1953; U 1981a; U 1981b; U 1981c; U-Á 1995;

Conistra rubiginosa (Scopoli, 1763) - Á 1990; Á 1992a; Ấ 1992b; Á.U 1994; K 1953; U 1978a; U 198la; U 1981c; U 1983; U-Á 1995;

Conistra veronicae (Hübner, 1813) - Á 1992b; Á-U 1994; K 1953; U 1978a;

Conistra rubiginea (Denis \& Schiffermüller, 1775) - Á 1990; Á 1992a; Á 1992b; Á-U 1994; Á-U 1998; K 1953; Ré 1972; U 1976a; U 1978b; U 1978c; U I981a; U 1981c; U-Á 1995;

Conistra erythrocephala (Denis \& Schiffermüller, 1775) - Á 1990; Á 1992a; Á 1992b; ÁU 1994; Á-U 1998; K 1953; Ré 1972; U 1976a; U 1978b; U 1981a; U 198lc; U 1983; U-Á 1995;

Orbona fragariae (Vieweg, 1790) - Á 1990; Á-U 1994; K 1953;

Episema ( $=$ Derthisa) glaucina (Esper, 1789) Á 1990; Â 1992b; Á-U 1994; K 1953; Ré 1972; U 1976a; U I978a; U 1978b; U 1978c; U 1981a; U 1981c; U 1983; U-Á 1995;

Episema (=Derthisa) tersa (Denis \& Schiffermüller, 1775) (=trimacula) - Á-U 1994; K 1953; T 1983-1984; U 1976a; U 1978b; U 1981a; U 1981c; U.Á 1995;

Cleoceris scoriacea (Esper, 1789) - Á 1990; Á 1992b; Á-U 1994; U 1978a; U 1981a; U 1981c; U-Á 1995;

Brachylomia viminalis (Fabricius, 1776) - Á 1992a; Á 1992b; Á-U 1994; Á-U 1998; U-Á 1995;

Aporophyla lutulenta (Denis \& Schiffermüller, 1775) - Á 1990; Á 1992a; Á 1992b; ÁU 1994; Á.U 1998; Ré 1972; U 1976a; U 
I978a; U 1978c; U 1981a; U 1981c; U 1983; U-Á 1995;

Lithophane semibrunnea (Haworth, 1809) A-U 1994; K 1953;

Lithophane socia (Hufnagel, 1766) - Á 1990; ヘ 1992b; Á-U 1994; Á-U 1998; K 1953; U 1976a; U 1978b; U 1978c; U 1981b; U 198Ic; U-ヘ́ 1995;

Lithophane ornitopus (Hufnagel, I766) - Á 1990; Á 1992a; Á 1992b; Á-U 1994; Á-U 1998; K 1953; Ré 1972; U 1976a; U 1978a; U 1978b; U 1978c; U I981a; U 198lc; U 1983; U.Á 1995;

Lithophane furcifera (Hufnagel, 1766) - Á 1990; Á 1992a; Á-U 1994; K 1953; U 1976a; U 1978b; U 1978c; U 198la; U 1981c; U I984a; U-Á 1995;

Scotochrosta pulla (Denis \& Schiffermüller, 1775) - Á-U 1994; K 1953;

Xylena petusta (Hübner, 1813) - Á-U 1994; K 1953; U 1976a; U 1978b; U 1981a; U 1981c; U 1983; U-Á 1995;

Xylena exsoleta (Linnaeus, 1758) - Á 1990; Á-U 1994; K 1953; Ré 1972; U 1981a; U 1981c;

Meganephria bimaculosa (Linnaeus, 1767) Á 1990; Á-U 1994; K 1953;

Allophyes oxyacanthae (Linnaeus, 1758) $-\Lambda$ 1990; Á 1992a; Á 1992b; Á-U 1994; Á-U I998; K 1953; Ré 1972; U 1976a; U 1978a; U 1978b; U 1978c; U 1981a; U 1981c; U 1983; U.Á 1995;

Rileyiana forea (Treitschke, 1825) - Á 1990; K 1953;

Valeria oleagina (Denis \& Schiffermüller, 1775) - Á 1990; $\Lambda$ 1992a; $́$ 1992b; Á-U I 994; K 1953; Ré 1972; U 1976a; U 1978a; U 1978b; U 1978c; U 1981a; U 1981c; U-Á 1995;

Dichonia aprilina (Linnacus, 1758) - Á 1990; Á 1992a; ᄉ́ 1992b; ́̂-U 1994; Á-U 1998; K 1953; Ré 1972; U 1976a; U 1978b; U 1978c; U I981a; U 1981c; U- $\Lambda$ 1995;

Dichonia convergens (Denis \& Schiffermüller, 1775) - Á-U 1994; U 1978a; U 1981a; U 1981 b; U 1981c; U-Á 1995;

Dryobotodes eremita (Fabricius, 1775) (=protea) - Á 1990; Á 1992b; Á-U 1994; K 1953; Ré 1972; U 1981a; U 1981c;

Dryobotodes monochroma (Esper, 1790) - Á 1990; Á-U 1994;

Ammoconia caecimacula (Denis \& Schiffermüller, 1775) - Á 1990; Á 1992a; Á 1992b; Á-U 1994; K 1953; Ré 1972; U 1976a; U 1978c; U 1981a; U 1981c; U-Á 1995;

Polymixis polymita (Linnaeus, 1761) - Á 1990; Á-U 1994; K 1953; U 1981b; U 1981c; U-Á 1995;
Blepharita satura (Denis \& Schiffermüller, 1775) - Á 1990; Á I992a; Á 1992b; Á-U 1994; Á-U 1998; K 1953; U 1976a; U 1978a; U 1978b; U 1978c; U 1981 a; U 1981c; U 1983; U-Á 1995;

Apamea monoglypha (Hufnagel, 1766) - Á 1990; A 1992a; A 1992b; Á-U 1994; Á-U 1998; K 1953; Ré 1972; U 1976a; U 1976b; U 1978a; U 1978b; U 1981 a; U 198lc; U 1983; U-Á 1995;

Apamea sicula tallosi Kovács et Varga, 1969; Á 1992b; Á-U 1994; Gyl et al 1979; U 1978a; U 1978c; U 198Ia; U 1981b; U I981c; U-Á 1995;

Apamea lithoxylaea (Denis \& Schiffermüller, 1775; Á 1990; Á 1992a; Á-U 1994; K 1953; Ré 1972; U 1976a; U 1978a; U 1978b; U 1978c; U 1981a; U 1981 c; U 1983; U-Á 1995;

Apamea sublustris (Esper, 1788) - Á 1992a; K 1953; Ré 1972; U 1976a; U 1978a; U 1978c; U 1981c; U 1983; U-Á 1995;

Apamea crenata (Hufnagel, 1766) - Á 1990; ヘ́ 1992a; Á 1992b; Á-U 1994; Á-U I998; U 1978a; U 1978c; U 1981a; U I981b; U 1981c; U I984b; U-Á 1995;

Apamea epomidion (Haworth, 1809) (=characterea) - Á I 990; Á I992a; Á-U 1994; K 1953; U 198Ib; U 198Ic; U-Á 1995;

Apamea aquila Donzel, 1837; Á 1990; Á-U 1994; Á-U 1998; K 1953; Ré 1972; U 198Ic; U 1983; U-Á 1995;

Apamea remissa (Hübner, 1809) - Á 1990; Á 1992a; Á 1992b; Á-U 1994; Á-U I998; K 1953; U 1976a; U 1978a; U 1978c; U 1981a; U 1981c; U-Á 1995;

Apamea unanimis (Hübner, 1813) - Á 1990; Á 1992a; Á-U 1994; U 1981b; U 1981c; U-Á 1995;

Apamea illyria Freyer, 1846; Á-U 1994; U 1981a; U 1981c;

Apamea anceps (Denis \& Schiffermüller, 1775) - A 1990; Á 1992a; Á 1992b; Á-U 1994; K 1953; Ré I972; U 1978a; U 1978c; U. I981c; U-Á 1995;

Apamea sordens (Hufnagel, 1766) - Á 1990; Á 1992a; Á 1992b; Á-U 1994; K 1953; Ré 1972; T 1983-1984; U 1976a; U 1978a; U 1978b; U 1978c; U 1981a; U 198lc; U 1983; U-Á 1995;

Apamea scolopacina (Esper, 1788) - Á 1990; Á 1992a; Á 1992b; Á-U 1994; Á-U 1998; K 1953; T 1983-1984; U 1976a; U 1978a; U I978b; U 1978c; U 1981a; U I98lc; U 1983; U-Á 1995;

Apamea ophiogramma (Esper, 1794) - Á 1990; Á 1992à Â-U 1994; Á-U 1998; K 1953; U 1976a; U 1978a; U 1978b; U 1978c; U 
$1981 \mathrm{a} ; \mathrm{U}$ 1981c; U-ᄉ́ 1995;

Eremobina pabulatricula (Brahm, 1791) - Á 1990; Á 1992a; Á 1992b; Á-U 1994; Á-U 1998; K 1953; U 1976a; U 1978c; U 1981a; U 1981c; U 1983; U-Á 1995;

Oligia strigilis (Linnaeus, I758) - Á 1990; Á 1992a; Á 1992b; Á-U 1994; Á-U 1998; K 1953; Ré 1972; T 1983-1984; U 1976a; U 1978a; U 1978b; U 1978c; U 1981 a; U 1981 c; U 1983; U-Á 1995;

Oligia versicolor (Borkhausen, 1792) - Á 1990; Â 1992a; Á-U 1994; U 1978a; U 1978c; U 1981a; U 1981c; U 1983; U-Á 1995;

Oligia latruncula (Denis \& Schiffermüller, 1775) - Á 1990; Á 1992a; Á 1992b; Á-U 1994; Á-U 1998; K 1953; Ré 1972; T 1983-1984; U 1976a; U 1978a; U 1978b; U 1978c; U 198la; U 1981c; U 1983; U-Á 1995;

Mesoligia furuncula (Denis \& Schiffermüller, 1775) - Á 1990; Á 1992a; Á 1992b; Á-U 1994; K 1953; Ré 1972; T 1983-1984; U 1976a; U 1978c; U 1981a; U 1981c; U 1983; U-Á 1995;

Mesoligia literosa (Haworth, 1809) - Á 1992b;

Mesapamea secalis (Linnaeus, 1758) - Á 1990; Á 1992a; Á 1992b; Á-U 1994; Á-U 1998; K 1953; Ré 1972; T 1983-1984; U 1976a; U 1976b; U 1978a; U 1978b; U 1978c; U 1981a; U 1981c; U 1983; U-Á 1995;

Photedes minima (Haworth, 1809) - Á 1990; Á 1992a; Á 1992b; Á-U 1994; Á-U 1998; K 1953; U 1976a; U 1978a; U 1978b; U 1978c; U 1981a; U 1981c; U 1983; U-Á 1995;

Luperina testacea (Denis \& Schiffermüller, 1775) - Á 1990; Á 1992a; Á 1992b; Á-U 1994; Á-U 1998; K 1953; Ré 1972; T 1983-1984; U 1976a; U 1978a; U 1978b; U 1978c; U 1981a; U 1981c; U 1983; U-Á 1995;

Rhizedra lutosa (Hübner, 1803) - Á 1990; Á 1992a; Á 1992b; Á-U I 994; Á-U 1998; K 1953; Ré 1972; T 1983-1984; U 1976a; U 1978a; U 1978c; U 1981a; U 1981c; U-Á 1995;

Amphipoea oculea (Linnaeus, 1761) - Á 1990; Á-U 1994; K 1953; T 1983-1984; U 1981a; U 1981c; U-Á 1995;

Amphipoea fucosa (Freyer, 1830) - Á 1990; U-Á 1995;

Hydraecia micacea (Esper, 1789) - Á 1992a; Á 1992b; Á-U 1994; Á-U 1998; K 1953; T 1983-1984; U 1976a; U 1976b; U 1978a; U 1978b; U 1978c; U 1981a; U 1981c; U 1983; U-Á 1995;

Gortyna flavago (Denis \& Schiffermüller, 1775) - Á 1992a; Á 1992b; Á-U 1994; K 1953; U 1976a; U 1976b; U 1978a; U 1978b; U 1978c; U 1981a; U 1981c; U 1983; U-Á 1995;
Calamia tridens (Hufnagel, 1766) - Á 1990; Á-U 1998; K 1953; Ré 1972; U 1976a; U 1978c; U-Á 1995;

Staurophora celsia (Linnaeus, 1758) - Á 1990; Á 1992a;

Celaena leucostigma (Hübner, 1808) - Á 1990; Á 1992a; Á 1992b; Á-U 1994; K 1953; Ré 1972; U 1976a; U 1976b; U 1978a; U 1978b; U I978c; U 1981a; U 1981c; U.Á 1995;

Nonagria typhae (Thunberg, 1784) - Á 1990; Á 1992a; Á 1992b; Á-U 1994; K 1953; Ré 1972; U 1976a; U 1978c; U 1981a; U 1981c; U-Á 1995;

Phragmatiphila nexa (Hübner, 1808) - Á 1990; Á 1992a; Á 1992b; Á-U 1994; K 1953; K 1958; U 1976a; U 1978b; U 1981b; U 1981c; U-Á 1995;

Archanara geminipuncta (Haworth, 1809) Á 1990; Á 1992b; Á-U 1994; Á-U 1998; K 1953; Ré 1972; U 1976a; U 1978a; U 1978b; U 1981b; U 1981c; U-Á 1995;

Archanara neurica (Hübner, 1808) - Á 1990; Á 1992a; Á 1992b; Á-U 1994; Á-U 1998; T 1983-1984; U 1978a; U 1981b; U 1981c; U-Á 1995;

Archanara dissoluta (Treitschke, 1825) - Á 1990; Á 1992a; Á 1992b; Á-U 1994; Á-U 1998; K 1953; Ré 1972; U 1976a; U 1976b; U 1978b; U 1978c; U 1981c; U-Á 1995;

Archanara sparganii (Esper, 1790) - Á 1990; Á 1992a; Á 1992b; Á-U 1994; K 1953; Ré 1972; T 1983-1984; U 1978a; U 1978c; U 1981a; U 1981c; U 1983; U-Á 1995;

Archanara algae (Esper, 1789) (=cannae) - Á 1990; Á 1992a; Á-U 1994; K 1953; U 1976a; U 1978b; U 1985; U-Á 1995;

Sedina buettneri (E. Hering, 1858) - Á 1990; Á 1992a; Á 1992b; Á-U 1994; Á-U 1998; K 1953; T 1983-1984; U 1978a; U 1978c; U 1981a; U 1981c; U 1983; U.Á 1995;

Chortodes (=Arenostola) extrema (Hübner, 1809) - Á 1990; Á 1992a; Á 1992b; Á-U 1994; Á-U 1998; K 1953; T 1983-1984; U 1976a; U 1978a; U 1978b; U 1978c; U 1981a; U 198lc; U 1983; U-Á 1995;

Chortodes (=Arenostola) fluxa (Hübner, 1809) - Á 1990; Á 1992a; Á 1992b; Á-U 1994; K 1953; Ré 1972; T 1983-1984; U 1976a; U 1976b; U 1978a; U 1978b; U 1978c; U 1981a; U 1981c; U 1983; U-Á 1995;

Chortodes (=Arenostola) pygmina (Haworth, 1809) - Á 1990; Á 1992a; Â 1992b; Á-U 1994; Á-U 1998; K 1953; Ré 1972; T 1983-1984; U 1976a; U 1978a; U 1978b; U 1978c; U 1981a; U 1981c; U 1983; U.Á 1995; 
Chortodes (=Arenostola) morrisii (Dale, 1837) - Ré 1972;

Discestra trifolii (Hufnagel, 1766) - Á 1990; Á 1992a; Á 1992b; Á-U 1994; Á-U 1998; K 1953; Ré 1972; T 1983-1984; U 1976a; U 1976b; U 1978a; U 1978b; U 1978c; U 1981a; U 1981c; U 1983; U.Á 1995;

Discestra dianthi (Tauscher, 1809) - Á 1992b; Á-U 1994;

Lacanobia (=Mamestra) w-latinum (Hufnagel, 1766) - Á 1990; Á 1992a; Á 1992b; Á-U 1994; Á-U 1998; K 1953; Ré 1972; T 1983-1984; U 1976a; U 1976b; U 1978a; U 1978b; U 1978c; U 198 I a; U 1981 c; U-Á 1995;

Lacanobia (=Mamestra) aliena (Hübner, 1808) - U 1985; U-人́ 1995;

Lacanobia (=Mamestra) splendens (Hübner, 1808) - Á 1992a; Á 1992b; Á-U 1994; Á-U 1998; K 1953; Ré 1972; T 1983-1984; U 1976a; U 1978a; U 1978b; U 1978c; U 1981a; U 1981c; U-Á 1995;

Lacanobia (=Mamestra) oleracea (Linnaeus, 1758) - Á 1990; Á 1992a; ᄉ 1992b; Á-U 1994; Á-U 1998; K 1953; Ré 1972; T 1983-1984; U 1976a; U 1976b; U 1978a; U 1978b; U 1978c; U 1981a; U 1981c; U 1983; U-Á 1995;

Lacanobia (=Mamestra) thalassina (Hufnagel, 1766) - Á 1990; Á 1992a; Á 1992b; Á-U 1994; Á-U 1998; K 1953; T 1983-I984; U 1976a; U 1976b; U 1978a; U 1978b; U 1978c; U 1981 a; U 1981c; U 1983; U-Á 1995;

Lacanobia (=Mamestra) contigua (Denis \& Schiffermüller, 1775) - Á 1990; Á 1992a; Á 1992b; Á-U 1994; Á-U 1998; K 1953; K 1956; Ré 1972; T 1983-1984; U 1976a; U 1976b; U 1978a; U 1978b; U 1978c; U 198 Ia; U 198 Ic; U 1983; U-Á 1995;

Lacanobia (=Mamestra) suasa (Denis \& Schiffermüller, 1775) - Á 1990; Á 1992a; Á 1992b; Á-U 1994; Á-U 1998; K 1953; Ré 1972; T 1983-1984; U 1976a; U 1976b; U 1978a; U 1978b; U 1978c; U $1981 \mathrm{a}$; U 1981c; U 1983; U-Á 1995;

Hada plebeja (Linnaeus, 1761) (=nana) - Á 1990; Á 1992a; Á 1992b; Á-U 1994; Á-U 1998; K 1953; Ré 1972; Ro 1909; T 1983-1984; U 1976a; U 1976b; U 1978a; U 1978b; U 1978c; U 1981a; U I98Ic; U 1983; U-Á 1995;

Aetheria dysodea (Denis \& Schiffermüller, 1775) - Á 1990; Á-U 1994; K 1953; Ré 1972; U 1976a; U 1978a; U 1978c; U 1981c; U-Á 1995;

Aetheria bicolorata (Hufnagel, 1766) - K 1953; U 1983; U.Á 1995;

Hadena bicruris (Hufnagel, 1766) - Á 1990; Á 1992a; Á 1992b; Á-U 1994; Á-U 1998; K
1953; Ré 1972; T 1983-1984; U 1976a; U I976b; U 1978a; U 1978b; U 1978c; U 1981 a; U 1981c; U 1983; U-Á 1995;

Hadena confusa (Hufnagel, 1766) - Á 1990; Á-U 1994; K 1953; T 1983-1984; U 1976a; U 1978b; U 1981b; U 1981c; U I983; U-Á 1995;

Hadena (=Dianthoecia) rivularis (Fabricius, 1775) (=cucubali) - Á 1990; Á 1992a; Á 1992b; Á-U 1994; Á.U 1998; K 1953; Ré 1972; T 1983-1984; U 1976b; U 1978a; U 1978b; U 1978c; U-Á 1995;

Hadena (=Harmodia) perplexa (Denis \& Schiffermüller, I775) (=lepida) - Á 1990; Á 1992a; Á 1992b; Á-U 1994; Á-U 1998; K 1953; K 1956; Ré 1972; T 1983-1984; U 1976a; U 1978a; U 1978b; U 1978c; U 1981a; U 1981c; U 1983; U-Á 1995;

Hadena silenes (Hübner, 1822) - K 1953; Ré 1972; Hadena (=Epia) irregularis (Hufnagel, 1766) Á 1990; Á 1992a; Á.U 1994; K 1953; U 1976a; U 1978c; U 198lb; U 1981c; U-Á 1995;

Sideridis (Leucania) lampra (Schawerda, 1913) (=eridens) - Á-U 1998; U I976a; U 1978c; U.Á I995;

Sideridis albicolon (Hübner, 1813) - Á 1992a; Á-U 1998; K 1953; Ré 1972; U 1976a; U 1978b; U 1978c; U-Á 1995;

Heliophobus reticulata (Goeze, 1781) - K 1953; K 1956; Ré 1972;

Conisania leineri (Freyer, I836) - K 1953; Ré 1972;

Conisania (=Hadena) luteago (Denis \& Schiffermüller, 1775) - Á 1990; Á 1992a; Á 1992b; Á-U 1994; Á-U 1998; K 1953; Ré 1972; T 1983-1984; U 1976a; U 1978a; U 1978b; U 1978c; U 1981a; U 1981c; U 1983; U-Á 1995;

Melanchra ( $=$ Mamestra) persicariae (Linnaeus, 176I) - Á 1990; Á 1992a; Á 1992b; Á-U 1994; Á-U 1998; K 1953; K 1956; Ré 1972; T 19831984; U 1976a; U 1976b; U 1978a; U 1978b; U 1978c; U 1981 a; U 1981c; U 1983; U-Á 1995;

Melanchra (=Mamestra) pisi (Linnaeus, 1758) - Á 1992a; Á 1992b; Á-U 1994; Á-U 1998; K 1953; Ré 1972; T 1983-1984; U 1976a; U 1976b; U 1978a; U 1978b; U 1978c; U 1981 a; U 1981c; U 1983; U-Á 1995;

Mamestra brassicae (Linnaeus, 1758) - Á 1990; Á 1992a; Á 1992b; Á-U 1994; Á-U 1998; K 1953; Ré 1972; T 1983-1984; U 1976a; U 1976b; U 1978a; U 1978b; U 1978c; U 1981a; U 1981c; U 1983; U-Á 1995;

Polia nebulosa (Hufnagel, 1766) - Á 1990; Á 1992a; Á 1992b; Á-U 1994; Á-U 1998; K 1953; Ré 1972; U 1976a; U 1978a; U 1978b; U 1978c; U I981a; U 1981c; U 1983; U-Á 1995; 
Mythimna turca (Linnaeus, 1761) - Á 1990; Á 1992a; Á 1992b; Á-U 1994; Á-U 1998; K 1953; Ré 1972; T 1983-1984; U 1976a; U 1976b; U 1978a; U 1978b; U 1978c; U 1981a; U 1981c; U 1983; U-Á 1995;

Mythimna conigera (Denis \& Schiffermüller, 1775) - Á 1992a; Á 1992b; Á-U 1994; Á-U 1998; K 1953; Ré 1972; T 1983-1984; U 1976a; U 1978a; U 1978c; U 1981a; U 1981c; U 1983; U-Á 1995;

Mythimna ferrago (Fabricius, 1787) - Á 1990; Á 1992a; Á 1992b; Á-U 1994; Á-U 1998; Ré 1972; U 1976a; U 1976b; U 1978a; U 1978b; U 1978c; U 1981a; U 1981c; U 1983; U-Á 1995;

Mythimna albipuncta (Denis \& Schiffermüller, 1775) - Á 1990; Á 1992a; Á 1992b; ÁU 1994; Á-U 1998; K I953; Ré I972; T I9831984; U 1976a; U 1976b; U 1978a; U 1978b; U 1978c; U 1981a; U 1981c; U 1983; U-Á 1995;

Mythimna vitellina (Hübner, 1808) - Á 1990; Á-U 1994; K 1953; K 1956; Ré 1972; U 1976a; U 1976b; U 1978a; U 1978b; U 1978c; U 1979; U 1981a; U 1981c; U 1983; U-Á 1995;

Mythimna pudorina (Denis \& Schiffermüller, 1775) - Á 1990; Á 1992a; Á 1992b; ÁU 1994; Á-U 1998; K 1953; Ré 1972; U 1976a; U 1976b; U 1978a; U 1978b; U 1978c; U 1981a; U 1981c; U-Á 1995;

Mythimna straminea (Treitschke, 1825) - Á 1990; Á 1992a; Á 1992b; Á-U 1994; Á-U 1998; K 1953; Ré 1972; Ro 1909; U 1976a; U 1978a; U 1978b; U 1978c; U 1981a; U 1981c; U.Á 1995;

Mythimna impura (Hübner, 1808) - Á 1990; Á 1992a; Á 1992b; Á.U 1994; Á-U 1998; K 1953; Ré 1972; T 1983-1984; U 1978a; U 1978c; U 1981a; U 1981c; U-Á 1995;

Mythimna pallens (Linnaeus, 1758) - Á 1990; Á 1992a; Á 1992b; Á-U 1994; Á-U 1998; K 1953; Ré 1972; T 1983-1984; U 1976a; U 1976b; U 1978a; U 1978b; U 1978c; U 1981a; U 1981c; U 1983; U-Á 1995;

Mythimna obsoleta (Hübner, 1803) - Á 1990; Á-U 1994; Á-U 1998; K 1953; Ré 1972; U 1976a; U 1976b; U 1978a; U 1978b; U 1978c; U 198Ic; U-Á 1995;

Mythimna comma (Linnaeus, 1761) - Á 1992b; Á-U 1994; Á-U 1998; U 1976a; U 1978c; U 1981b; U 1981c; U-Á 1995;

Mythimna (=Senta) flammea (Curtis, 1828) (=stenoptera) - Á 1990; Á 1992a; Á 1992b; Á-U 1994; Á-U 1998; K 1953; Ré 1972; U 1976a; U 1976b; U 1978a; U 1978b; U 1978c; U 1981c; U-Á 1995;
Mythimna l-album (Linnaeus, 1767) - Á 1990; Á 1992a; Á 1992b; Á-U 1994; Á-U 1998; K 1953; Ré 1972; T 1983-1984; U 1976a; U 1978a; U 1978b; U 1978c; U 1981a; U 1981c; U 1983; U-Á 1995;

Mythimna unipuncta (Haworth, 1809) - Á-U 1994; U 1981a; U 1981c;

Orthosia incerta (Hufnagel, 1766) - Á 1990; Á 1992a; Á 1992b; Á-U 1994; Á-U 1998; K 1953; Ré 1972; T 1983-1984; U 1976a; U 1978a; U 1978b; U 1978c; U 1981a; U 1981c; U 1983; U-Á 1995;

Orthosia gothica (Linnaeus, 1758) - Á 1990; Á 1992a; Á 1992b; Á-U 1994; Á-U 1998; K 1953; Ré 1972; T 1983-1984; U 1976a; U 1978a; U 1978b; U 1978c; U 198 la; U 1981c; U I983; U-Á 1995;

Orthosia cruda (Denis \& Schiffermüller, 1775) - Á 1990; Á 1992a; Â 1992b; Á-U 1994; Á-U 1998; K 1953; Ré 1972; U 1976a; U 1978a; U 1978b; U 1978c; U 1981a; U 198Ic; U 1983; U.Á 1995;

Orthosia schmidti (Diószeghy, 1935) - Á 1990; Á-U 1994; K 1956;

Orthosia miniosa (Denis \& Schiffermüller, 1775) - Á 1990; Á 1992a; Á-U 1994; K 1953; Ré 1972; U 1976a; U 1978a; U 1978b; U 1978c; U 1981a; U 1981c; U-Á 1995;

Orthosia opima (Hübner, 1809) - Á-U 1994; K 1953; U 1976a; U 1978a; U 1978b; U 1981a; U 1981c; U-Á 1995;

Orthosia populeti (Fabricius, 1775) - Á-U 1994; K 1953; U 1978c; U 1981c; U-Á 1995; Orthosia cerasi (Fabricius, 1775) (=stabilis) Á 1990; Á 1992a; Á 1992b; Á-U 1994; Á-U 1998; K 1953; Ré 1972; U 1976a; U 1978a; U 1978b; U 1978c; U 1981a; U 1981c; U 1983; U-Á 1995;

Orthosia gracilis (Denis \& Schiffermüller, 1775) - Á 1990; Á 1992a; Á 1992b; Á-U 1994; K 1953; U 1976a; U 1978a; U 1978b; U 1978c; U 1981a; U 198 Ic; U 1983; U-Á 1995;

Orthosia munda (Denis \& Schiffermüller, 1775) - Á 1990; Á 1992a; Á 1992b; Á-U 1994; Á-U 1998; K 1953; Ré 1972; U 1976a; U 1978a; U 1978b; U 1978c; U 1981a; U 1981c; U 1983; U-Á 1995;

Panolis flammea (Denis \& Schiffermüller, 1775) - Á 1990; Á 1992a; Á 1992b; Á-U 1994; Á-U 1998; K 1953; T 1983-1984; U 1976a; U 1978a; U 1978b; U 1978c; U 1980a; U 1981a; U 1981c; U 1983; U-Á 1995;

Egira (=Xilomyges) conspicillaris (Linnaeus, 1758) - Á 1990; Á 1992a; Á 1992b; Á-U 1994; Á-U 1998; K 1953; Ré 1972; U 1976a; U 
1978a; U 1978b; U 1978c; U 1981a; U 198lc; U 1983; U-র 1995;

Perigrapha i-cinctum (Denis \& Schiffermüller, 1775) - Ré 1972;

Hyssia cavernosa (Eversmann, 1842) - Á 1990; Á 1992b; Á-U 1994; K 1953; Ré 1972; T 1983-1984; U 1976a; U 1976b; U I978a; U 1978b; U 1978c; U 198Ia; U 1981c; U 1983; U-Á 1995;

Tholera cespitis (Denis \& Schiffermüller, 1775) - Á 1990; Á 1992a; Á 1992b; Á-U I 994; Á-U 1998; K 1953; Ré 1972; U 1976a; U 1978a; U 1978b; U 1978c; U 1981 a; U 198 l c; U I 983; U-A 1995;

Tholera decimalis (Poda, 1761) - Á 1990; Á 1992a; Á 1992b; Á-U 1994; Á-U 1998; K 1953; Ré 1972; U 1976a; U 1978a; U 1978b; U 1978c; U 1981a; U 1981c; U 1983; U-Á 1995; 1972;

Eriopygodes imbecilla (Fabricius, 1794) - Ré

Axylia putris (Linnaeus, 1761) - Á 1990; Á 1992a; Á 1992b; Á-U 1994; Á-U 1998; K 1953; K 1956; Ré 1972; T 1983-1984; U 1976a; U 1976b; U 1978a; U 1978b; U 1978c; U 1981a; U 1981c; U 1983; U-Á 1995;

\section{Noctuinae}

Ochropleura flammatra (Denis \& Schiffermüller, 1775) - K 1953;

Ochropleura plecta (Linnaeus, 1761) - Á I990; Á I992a; Á 1992b; Á-U 1994; Á-U 1998; K 1953; Ré 1972; T 1983-1984; U 1976a; U 1976b; U 1978a; U 1978b; U 1978c; U 1981a; U 1981c; U 1983; U-Á 1995;

Diarsia brunnea (Denis \& Schiffermüller, 1775) - Á 1992b; Á-U 1994; U 1978c; U $1981 \mathrm{a}$; U 1981c; U 1984b; U-Á 1995;

Diarsia rubi (Vieweg, 1790) - Á 1990; Á 1992a; Á 1992b; Á-U 1994; Á-U 1998; K 1953; Ré 1972; U 1976a; U 1976b; U 1978a; U 1978b; U 1978c; U 1981a; U 1981c; U 1983; U.Á 1995;

Noctua pronuba Linnaeus, 1758; Á 1990; Á 1992a; Á 1992b; Á-U 1994; Á-U 1998; K 1953; Ré 1972; U 1976a; U 1976b; U 1978a; U 1978b; U 1978c; U 1981a; U 198Ic; U 1983; U-Á 1995;

Noctua orbona (Hufnagel, 1766) - Á 1990; Á 1992a; Á 1992b; Á-U 1994; K 1953; K 1956; Ré 1972; U 1976a; U 1978a;

Noctua interposita (Hübner, 1790) - Á 1992a; Á 1992b; Á-U 1994; Á-U 1998; U 1978a; U 198Ia; U I 98lc; U-Á 1995;

Noctua comes Hübner, 1813; Á 1990; Á 1992b; Á-U 1994; Ré 1972; U 1981a;
Noctua fimbriata (Schreber, 1759) - Á 1990; Á 1992a; Á 1992b; Á-U 1994; Á-U 1998; K 1953; U 1976a; U 1976b; U 1978a; U 1978b; U 1978c; U 198la; U 1981c; U-Á 1995;

Noctua janthina (Denis \& Schiffermüller, 1775) - Á 1990; Á 1992a; Á 1992b; Á-U 1994; Á-U 1998; K 1953; K 1956; Ré I972; U 1976a; U 1976b; U 1978a; U 1978b; U 1978c; U I981a; U I98Ic; U 1983; U.Á 1995;

Noctua janthe (Borkhausen, 1792) - Á 1992a; Á-U 1994; Á-U 1998; U-Á 1995;

Noctua interjecta Hübner, 1803; U $1980 \mathrm{~b}$; U $198 \mathrm{Ic}$;

Epilecta linogrisea (Denis \& Schiffermüller, 1775) - Á I990; Á 1992a; Á-U 1994; Á-U 1998; Ré 1972; U 1976a; U 1978c; U 1981b; U 1981c; U-Á 1995;

Chersotis rectangula (Denis \& Schiffermüller, 1775) - Á-U 1994; K 1953;

Chersotis multangula (Hübner, 1803) - Á 1990; Á-U 1994;

Rhyacia simulans (Hufnagel, 1766) - Á 1992a; Á-U 1994; K 1953; Ré 1972; U 1981a; U 1981c;

Rhyacia lucipeta (Denis \& Schiffermüller, 1775) - Á 1990; Á-U 1994; K 1953;

Spaelotis ravida (Denis \& Schiffermüller, 1775) - Á 1990; Á-U 1994; K 1953; Ré 1972; U 1976a; U 1978c; U-Á 1995;

Opigena polygona (Denis \& Schiffermüller, 1775) - Á 1990; Á 1992a; Á 1992b; Á-U 1994; Á-U 1998; K 1953; U 1976a; U 1976b; U 1978a; U 1978b; U-Á 1995;

Eugnorisma depuncta (Linnaeus, 1761) - Á 1990; Á 1992a; Á 1992b; Á-U 1994; Á-U 1998; K 1953; Ré 1972; U 1978a; U 1978c; U 1981 a; U 1981c; U I 983; U-Á 1995;

Xestia (=Agrotis) c-nigrum (Linnaeus, 1758) Á 1990; Á 1992a; Á 1992b; Á-U 1994; Á-U 1998; K 1953; Ré 1972; ' 1 1983-1984; U 1976a; U 1976b; U 1978a; U 1978b; U 1978c; U 1981a; U 198Ic; U 1983; U-Á 1995;

Xestia (=Agrotis) ditrapezium (Denis \& Schiffermüller, 1775) - Á 1990; U 1976a;

Xestia (=Agrotis) triangulum (Hufnagel, 1766) - Á 1992a; Á 1992b; Á-U 1994; Á-U 1998; K 1953; Ré 1972; U 1976a; U 1978a; U 1978b; U 1978c; U 1981 a; U 1981c; U 1983; U-Á 1995;

Xestia (=Agrotis) baja (Denis \& Schiffermüller, 1775) - Á 1990; Á 1992a; Á 1992b; Á-U 1994; Á-U 1998; K 1953; Ré 1972; T 1983-1984; U 1976a; U 1976b; U 1978a; U 1978b; U 1978c; U 1981a; U 1981c; U 1983; U-Á 1995; 
Xestia (=Agrotis) rhomboidea (Esper, 1790) (=stigmatica) - Á 1990; Á 1992a; Á 1992b; Á-U 1994; Á-U 1998; K 1953; T 1983-1984; U 1978c; U 1981a; U 1981c; U-Á 1995;

Xestia (=Agrotis) xanthographa (Denis \& Schiffermüller, 1775) - Á 1990; Á 1992a; Á 1992b; Á-U 1994; Á-U 1998; K 1953; K 1956; Ré 1972; T 1983-1984; U 1976a; U 1978a; U 1978b; U 1978c; U 1981a; U 1981c; U 1983; U-Á 1995;

Cerastis rubricosa (Denis \& Schiffermüller, 1775) - Á 1990; Á 1992a; Á 1992b; Á-U 1994; ÁU 1998; K 1953; Ré 1972; U 1976a; U 1978a; U 1978b; U 1978c; U 1981a; U 1981c; U-Á 1995;

Cerastis leucographa (Denis \& Schiffermüller, 1775) - Á 1990; Á 1992a; Á 1992b; Á-U 1994; Á-U 1998; K 1953; U 1976a; U 1978a; U 1978b; U 1978c; U 1981a; U 1981c; U 1983; U-Á 1995;

Naenia typica (Linnaeus, 1758) - Á 1990; Á 1992a; Á-U 1994; Á-U 1998; K 1953; T 19831984; U 1976a; U 1978c; U 1981a; U 1981c; U 1983; U-Á 1995;

Anaplectoides prasina (Denis \& Schiffermüller, 1775) - Á 1992b; Á-U 1994; U 1981 a; U 1981c; U 1984b; U-Á 1995;

Peridroma saucia (Hübner, 1808) - Á 1990; Á 1992b; Á-U 1994; K 1953; Ré 1972; U 1976a; U 1976b; U 1978a; U 1978b; U 1978c; U 1979; U 1981a; U 1981c; U-Á 1995;

Parexarnis fugax (Treitschke, 1825) - Á 1990; Á-U 1994; K 1956; Ré 1972;

Actebia praecox (Linnaeus, 1758) - Á 1990; Á-U 1994; K 1953; U 1978a; U 198Ia; U 1981c; U-Á 1995;

Euxoa aquilina (Denis \& Schiffermüller, 1775) - Á 1990; Á-U 1994; K 1953; K 1956; Ré 1972; U 1976a; U 1978a; U 1981c;

Euxoa hastifera (Donzel, 1847) - Ré 1972;

Euxoa temera (Hübner, 1808) - Á 1990; Á-U 1994; K 1953; Ré 1972; U 1976a; U 1978c; U-Á 1995;

Euxoa nigricans (Linnaeus, 1761) - Ré 1972; Euxoa segnilis (Duponchel, 1836) - Á 1990; Á 1992a; Â.U 1998; K 1953; Ré 1972; U 1976a; U 1978c; U-Á 1995;

Euxoa tritici (Linnacus, 1761) (=epixantheia) Á 1990; Á 1992a; Á-U 1994; K 1953; Ré I972; U 1976a; U 1978c; U-Á 1995;

Euxoa obelisca (Denis \& Schiffermüller, 1775) - Á 1990; Á 1992a; Á-U 1994; Á-U 1998; Ré 1972; U 1976a; U 1978c; U-Á 1995;

Yigoga (=Agrotis) signifera (Denis \& Schiffermüller, I775) - Á 1990; Á-U 1994; K I953; T 1983-1984;
Yigoga (=Agrotis) forcipula (Denis \& Schiffermüller, 1775) - Á 1990; Á-U 1994; K 1953;

Agrotis (=Scotia) crassa (Hübner, 1803) - Á 1990; Á 1992a; Á 1992b; Á-U 1994; K 1953; Ré 1972; U 1976a; U 1976b; U 1978a; U 1978b; U 1981c; U.Á 1995;

Agrotis (=Scotia) puta (Hübner, 1803) - Á 1990; Á 1998-99; Á-U 1994; K 1953; K 1958;

Agrotis (=Scotia) ipsilon (Hufnagel, 1766) Á 1990; Á 1992a; Á 1992b; Á-U 1994; Á-U 1998; K 1953; Ré 1972; U 1976a; U 1976b; U 1978a; U 1978b; U 1978c; U 1979; U 1981a; U 1981c; U I983; U-Á 1995;

Agrotis (=Scotia) exclamationis (Linnaeus, 1758) - Á 1990; Á 1992a; Á 1992b; Á-U 1994; Á-U 1998; K 1953; Ré 1972; Ro 1909; T 1983-1984; U 1976a; U 1976b; U 1978a; U 1978b; U 1978c; U 1981a; U 1981c; U 1983; U-Á 1995;

Agrotis (=Scotia) clavis (Hufnagel, 1766) - Á 1990; Á-U 1994;

Agrotis (=Scotia) segetum (Denis \& Schiffermüller, 1775) - Á 1990; Á 1992a; Á 1992b; Á-U 1994; Á-U 1998; K 1953; Ré 1972; T 1983-1984; U 1976a; U 1976b; U 1978a; U 1978b; U 1978c; U 1981a; U 1981c; U 1983; U-Á 1995;

Agrotis (=Scotia) pestigialis (Hufnagel, 1766) Á 1990; Á 1992a; Á-U 1994; Á-U 1998; K 1953; K 1956; Ré 1972; U 1976a; U 1978a; U 1978c; U 1981c; U 1983; U-Á 1995;

Agrotis (=Scotia) cinerea (Denis \& Schiffermüller, 1775) - Á 1990; Á-U 1994; K 1953; K 1956; Ré 1972;

\section{Pantheidae}

Colocasia coryli (Linnaeus, 1758) - Á 1990; Á 1992a; Á 1992b; Á-U 1994; Á-U 1998; K 1953; Ré 1972; T 1983-1984; U 1976a; U 1976b; U 1978a; U 1978b; U 1978c; U 1981a; U I98Ic; U 1983; U-Á 1995;

\section{Lymantriidae}

\section{Lymantriinae}

Lymantria monacha (Linnaeus, 1758) - Á 1990; Á 1992a; Á 1992b; Á-U 1994; Á-U 1998; K 1953; T 1983-1984; U 1976a; U 1978c; U 1981a; U 1981c; U 1983; U-Á 1995;

Lymantria dispar (Linnaeus, 1758) - $A$ 1990; Á 1992a; Á 1992b; Á-U 1994; Á-U 1998; K 1953; Ré 1972; T 1983-1984; U 1976a; U 1976b; U 1978a; U.1978b; U 1978c; U 1981a; U 1981c; U 1983; U-Á 1995;

Ocneria rubea (Denis \& Schiffermüller, 1775) - Á 1990; Á-U 1994; K 1953; Ré 1972; 
Calliteara (=Dasychira) pudibunda (Linnaeus, 1758) - Á 1992a; Á 1992b; Á.U 1994; Á-U 1998; K 1953; Ré 1972; T 19831984; U 1976a; U 1976b; U 1978a; U 1978b; U 1978c; U 1981a; U 1981c; U 1983; U-Á 1995 ;

Orgyia recens (Hübner, 1819) (=gonostigma) Á 1990; Á-U 1994; Á-U 1998; K 1953; U 1981c; U 1983; U-Á 1995;

Orgyia antiqua (Linnaeus, 1758) - Á 1990; Á 1992a; Á 1992b; Á-U 1994; Á-U I998; K 1953; Ré 1972; U 1976a; U 1978b; U 1978c; U 1981 a; U 198Ic; U-Á 1995;

Euproctis chrysorrhoea (Linnaeus, 1758) - Á 1992a; Á 1992b; Á-U 1994; Á-U 1998; K 1953; Ré 1972; T 1983-1984; U 1976a; U 1976b; U 1978a; U 1978b; U 1978c; U 1981a; U 1981c; U 1983; U-Á 1995;

Euproctis (=Porthesia) similis (Fuessly, 1775) Á 1990; Á 1992a; Á-U 1994; Á-U 1998; K 1953; Ré 1972; U 1976a; U 1976b; U 1978a; U 1978b; U 1978c; U 1981a; U 1981c; U 1983; U-Á 1995;

Penthophera morio (Linnaeus, 1767) - Á 1992a; Á 1992b; Á-U 1994; Á-U 1998; K 1953; K 1956; Ré 1972; U 1976a; U 1976b; U 1978b; U 1978c; U-Á 1995;

Laelia coenosa (Hübner, 1808) - Á 1990; Á 1992a; Á 1992b; Á-U 1994; K 1953; Ré 1972;

Leucoma salicis (Linnaeus, 1758) - Á 1990; Á 1992a; Á-U 1994; Á-U 1998; K 1953; Ré 1972; U 1976a; U 1978a; U 1978c; U 1981a; U 198Ic; U 1983; U-Á 1995;

Arctornis l-nigrum (Müller, 1764) - Á 1990; Á 1992a; Á 1992b; Á-U 1994; Á-U 1998; K 1953; U 1976a; U 1976b; U 1978a; U 1978b; U 1978c; U 1981a; U 1981c; U I983; U-Á 1995;

\section{Nolidae}

\section{Nolinae}

Meganola togatulalis (Hübner, 1798) - Á 1990; Á 1992a; Á 1992b; Á-U 1994; Á-U 1998; K 1953; U 1976a; U 1978c; U 1981c; U 1983; U-Á 1995;

Meganola strigula (Denis \& Schiffermüller, 1775) - Á 1990; Á 1992a; Á 1992b; Á-U 1994; Á-U 1998; K 1953; T 1983-1984; U 1976a; U 1976b; U 1978a; U 1978b; U 1978c; U 1981a; U I981c; U.Á 1995;

Meganola (=Roeselia) gigantula (Staudinger, 1879) (=kolbi) - Á 1990; Á-U 1994; K 1953; U 1976a; U 198 lb; U 1981c; U-Á 1995;

Meganola (=Roeselia) albula (Denis \& Schiffermüller, 1775) - Á-U 1994; Á-U 1998; K 1953; U 1976a; U 1976b; U 1978c; U 1981c; U 1983; U-Á 1995;
Nola cucullatella (Linnaeus, 1758) - Á 1990; Á 1992a; Á 1992b; Á-U 1994; Á-U 1998; K 1953; K 1956; Ré 1972; U 1976a; U 1976b; U 1978a; U 1978b; U 1978c; U 1981c; U 1983; U-Á 1995;

Nola confusalis (Herrich-Schäffer, 1847) - Á 1990; Á 1992a; Á 1992b; Á-U 1994; Á-U 1998; K 1953; U 1981a; U 1981c;

Nola (=Celama) cicatricalis (Treitschke, 1835) - Á 1990; Á 1992a; Á 1992b; Á-U 1994; K 1953; Ré 1972; U I978c; U I981a; U 1981 c; U-Á 1995 ;

Nola (=Celama) aerugula (Hübner, 1793) (=centonalis) - Á 1992a; Á 1992b; Á-U 1994; ÁU 1998; K 1953; U I976a; U 1978b; U 1978c; U 1981a; U 1981c; U-Á 1995;

Nola chlamitulalis (Hübner, 1813) - Á 1992a; Á-U 1994; K 1953; Ré 1972; T 1983. 1984; U 1981b; U 1981c; U 1983; U-Á 1995;

\section{Chloephorinae}

Nycteola (=Sarrothripus) revayana (Scopoli, 1772) - Á 1990; Á 1992a; Á 1992b; Á-U 1994; K 1953; K 1954; K 1958; U 1976a; U 1978b; U 1981b; U 1981c; U-Á 1995;

Nycteola asiatica (Krulikovsky, 1904) - Á 1990; Á 1992a; Á 1992b; Á-U 1994; Á-U 1998; K 1956; Ré 1972; U 1976a; U 1976b; U 1978a; U 1978b; U 1981a; U 1981b; U 1981c; U-Á 1995; Nycteola siculana (Fuchs, 1899) - Á 1990; ÁU 1994; K 1956;

Bena bicolorana (Fuessly, 1775) - Á 1990; Á 1992b; Á-U 1994; K 1953; U 1978a; U 1978c; U $1981 \mathrm{c}$; U-Á 1995 ;

Pseudoips (=Hylophila) prasinana (Linnaeus, 1758) (=fagana) - Á 1990; Á 1992a; Á 1992b; Á-U 1994; Á-U 1998; K 1953; Ré 1972; U 1976a; U 1976b; U 1978a; U 1978b; U 1978c; U 1981a; U 1981c; U 1983; U-Á 1995;

\section{Eariadinae}

Earias clorana (Linnaeus, 1761) - Á 1990; Á 1992a; Á 1992b; Á-U 1994; Á-U 1998; K 1953; Ré 1972; U 1976a; U 1976b; U 1978a; U 1978b; U 1978c; U 1981a; U 198lc; U 1983; U-Á 1995;

Earias nemana (Fabricius, 1787) - Á 1990; Á 1992a; Á 1992b; Á-U 1994; Á-U I 998; K 1953; Ré 1972; U 1976a; U 1978a; U 1978b; U 1978c; U 198la; U I98Ic; U-Á 1995;

\section{Arctiidae}

\section{Lithosiinae}

Thumatha senex (Hübner, 1808) - Á 1990; Á 1992a; Á 1992b; Á-U 1994; Á-U 1998; K 1953; Ré 1972; U 1976a; U 1978a; U 1978b; U 
1978c; U 1981a; U 1981c; U I983; U-Á 1995;

Miltochrista miniata (Forster, 1771) - Á 1992a; Á 1992b; Á-U 1994; Á-U 1998; K 1953; Ré 1972; T 1983-1984; U 1976a; U 1976b; U 1978a; U 1978b; U 1978c; U 1981 a; U 198lc; U 1983; U-Á 1995;

Cybosia mesomella (Linnaeus, 1758) - $\Lambda$ 1990; Á 1992a; Á 1992b; Á-U 1994; Á-U 1998; K 1953; Ré 1972; T 1983-1984; U 1976a; U 1978a; U 1978b; U 1978c; U 1981a; U 1981c; U 1983; U-Á 1995;

Pelosia muscerda (Hufnagel, 1766) - $\Lambda$ 1990; Á 1992a; Á 1992b; Á-U 1994; Á-U 1998; K 1953; Ré 1972; T 1983-1984; U 1976a; U 1976b; U 1978a; U 1978b; U 1978c; U 198la; U 1981c; U 1983; U-Á 1995;

Pelosia obtusa (Herrich-Schäffer, I847) - $\Lambda$ 1990; ᄉ́ 1992a; Á 1992b; $\Lambda$-U 1994; $\Lambda$-U 1998; K 1953; Ré 1972; U 1976a; U I978b; U 1978c; U 1981a; U 1981c; U-Á 1995;

Atolmis rubricollis (Linnacus, 1758) - $A$ 1990; K 1953;

Lithosia quadra (Linnaeus, 1758) - Á 1990; Á 1992a; Â 1992b; Á-U 1994; Á-U 1998; K 1953; Ré 1972; T 1983-1984; U 1976a; U 1976b; U 1978a; U 1978b; U 1978c; U 1981a; U 1981c; U 1983; U-Á 1995;

Eilema depressa (Esper, 1787) - Á 1990; Á 1992a; Á 1992b; Á.U 1994; Á-U 1998; K 1953; U 1976a; U 1978a; U 1978c; U 1981c; U 1983; U-Á 1995;

Eilema griseola (Hübner, 1803) - Á 1990; Á 1992a; Á-U 1994; Á-U 1998; K 1953; U 1976a; U 1976b; U 1978a; U 1978b; U 1978c; U 1981a; U 1981c; U 1983; U-Á I995;

Eilema lurideola (Zincken, 1817) - Á 1990; Á 1992a; Á 1992b; Á-U 1994; Á-U 1998; K 1953; Ré I972; U 1976a; U I978a; U 1978c; U 198Ia; U 1981c; U 1983; U-Á 1995;

Eilema complana (Linnaeus, 1758) - Á 1990; Á 1992a; Á 1992b; Á-U 1994; Á-U 1998; K 1953; Ré 1972; T 1983-1984; U 1976a; U 1976b; U 1978a; U 1978b; U 1978c; U 1981a; U 198Ic; U 1983; U-Á 1995;

Eilema caniola (Hübner, 1808) - Á 1990;

Eilema palliatella (Scopoli, 1763) - Á 1992a; Á 1992b; Á-U 1994; Á-U 1998; K 1953; Ré 1972; U 1976a; U 1976b; U 1978c; U 1981c; U 1983; U-Á 1995;

Eilema pygmaeola (Doubleday, 1847) - Á 1990; Á 1992a; Á 1992b; Á-U 1994; Á-U 1998; K 1953; Ré 1972; U 1978c; U 1981c; U 1983; U-Á 1995;

Eilema lutarella (Linnaeus, 1758) - Á 1990; Á 1992a; Á 1992b; Á-U 1994; Á-U 1998; K 1953;
Ré 1972; U 1976a; U 1978a; U 1978b; U 1978c; U 1981a; U 1981c; U 1983; U-Á 1995;

Eilema sororcula (Hufnagel, 1766) - Á 1990; Á 1992a; Á 1992b; Á-U 1994; Á-U 1998; K 1953; Ré 1972; T 1983-1984; U 1976a; U 1976b; U 1978a; U 1978b; U 1978c; U 1981a; U I98Ic; U 1983; U-Á 1995;

Setina roscida (Denis \& Schiffermüller, 1775) - Á 1990; K 1953; Ré 1972; U 1978a;

\section{Syntominae}

Amata phegea (Linnaeus, 1758) - Á 1990; $\hat{A}$ 1992a; $\Lambda$ 1992b; Á-U 1994; Á-U 1998; K 1953; PS 1942; Ré 1972; U 1976a; U 1976b; U 1978a; U 1978c; U 1981a; U 1981c; U-Á 1995;

Dysauxes ancilla (Linnaeus, 1767) - Á 1990; Á 1992a; Á 1992b; Á-U 1994; Á-U 1998; K 1953; Ré 1972; T 1983-1984; U 1976a; U 1976b; U 1978b; U 1978c; U 1981a; U 1981c; U 1983; U-Á 1995;

\section{Arctiinae}

Spiris (=Coscinia) striata (Linnaeus, 1758)-

K 1953; Ré 1972; U 1976a; U 1976b; U 1978b; U 1978c; U-Á 1995;

Coscinia cribraria (Linnaeus, 1758) - Á 1990; Á-U 1994;

Ocnogyna parasita (Hübner, 1790) - Á 1990; K 1953; Ré 1972;

Chelis maculosa (Gerning, 1780) - Á 1990; K 1953; Ré 1972;

Watsonarctia casta (Esper, 1785) (=deserta) Á 1990; Á-U 1994;

Phragmatobia fuliginosa (Linnaeus, 1758) - Á 1990; Â 1992a; Á 1992b; Á-U 1994; Á-U 1998; K 1953; K 1956; Ré 1972; T 19831984; U 1976a; U 1976b; U 1978a; U 1978b; U 1978c; U 1981a; U 1981c; U 1983; U-Á 1995;

Spilosoma lutea (Hufnagel, 1766) (=lubricipeda) - Á 1990; Á 1992a; Á 1992b; ÁU 1994; Á-U 1998; K 1953; K 1956; Ré 1972; U 1976a; U 1976b; U 1978a; U 1978b; U 1978c; U 198 Ia; U 1983; U-Á 1995;

Spilosoma lubricipeda (Linnaeus, 1758) (=menhastri) - Á 1990; Á 1992a; Á 1992b; Á-U 1994; Á-U 1998; K 1953; K 1956; Ré 1972; T 1983-1984; U 1976a; U 1976b; U 1978a; U 1978b; U 1978c; U 1981a; U 1981c; U 1983; U-Á 1995;

Spilosoma urticae (Esper, 1789) - Á 1990; Á 1992a; Á 1992b; Á-U 1994; Â-U 1998; K 1953; PJ 1916; Ré 1972; U 1976a; U 1976b; U 1978a; U 1978b; U 1978c; U 1981a; U 1981c; U-Á 1995;

Hyphantria cunea (Drury, 1773) - Á 1990; Á 
1992a; Á 1992b; Á-U 1994; Á-U 1998; K 1953; Ré 1972; T 1983-1984; U 1976a; U 1976b; U 1978a; U 1978b; U 1978c; U I98Ic; U-Á 1995;

Diaphora mendica (Clerck, 1759) - Á 1990; Á-U 1994; Á-U 1998; K 1953; U 1976a; U I978c; U 1981c; U 1983; U-Á 1995;

Rhyparia purpurata (Linnaeus, 1758) - Á 1990; ヘ̂ 1992a; Á 1992b; Á-U 1994; Á-U 1998; K 1953; T 1983-1984; U 1976a; U 1978b; U 1978c; U 1981a; U 1981c; U 1983; U-Á 1995;

Diacrisia sannio (Linnaeus, 1758) - Á 1990; Á 1992a; Á 1992b; Á-U 1994; Á-U 1998; K 1953; Ré 1972; T 1983-1984; U 1976a; U 1976b; U I978a; U 1978b; U 1978c; U 1981a; U 1981c; U 1983; U-Á 1995; 1953;

Hyphoraia aulica (Linnaeus, 1758) - K

Arctia caja (Linnaeus, 1758) - Á 1990; Á 1992a; Á 1992b; Á-U 1994; Á-U 1998; K 1953; Ré 1972; T 1983-1984; U 1976a; U 1976b; U 1978a; U 1978b; U 1978c; U 1981a; U 1981c; U 1983; U.Á 1995;

Arctia millica (Linnaeus, 1758) - Á 1990; Á 1992a; Á 1992b; Á-U 1994; Á-U 1998; K 1953; Ré 1972; T 1983-1984; U 1976a; U I976b; U 1978a; U 1978b; U 1978c; U 1981a; U 1981c; U 1983; U-Á 1995;

Callimorpha dominula (Linnaeus, 1758) - Á 1990; Á 1992a; Á 1992b; Á-U 1994; Á-U 1998; K 1953; T 1983-1984; U 1976a; U 1978a; U I978b; U 1978c; U 1981a; U 1981c; U-Á 1995;

Euplagia quadripunctaria (Poda, 1761) - Á 1990; Á 1992a; Á 1992b; Á-U 1994; Á-U 1998; K 1953; Ré 1972; U 1976a; U 1976b; U 1978a; U 1978b; U 1978c; U 1981a; U I981c; U-Á 1995;

Tyria jacobaeae (Linnaeus, 1758) - Á 1990; Á 1992a; Á 1992b; Á.U I994; K 1953; U 1976a; U 1976b; U 1978c; U 1981c; U-Á 1995;

\section{Köszönetnyilvánítás}

A szerzők ôszinte köszönetüket fejezik ki Paizs Ottó tanár úrnak (Nagybajom), hogy önzetlen segítséget nyújtott a rovartani szakirodalom átnézésében Somogy megyei adatok után kutatva. 
1. táblázat: Somogy megye területéról ismert nagylepke fajok száma családok szerinti megoszlása

\begin{tabular}{|c|c|c|c|c|c|}
\hline Család & Alcsalád & Fajszám & Család & Alcsalád & Fajszám \\
\hline \multirow[t]{2}{*}{ Lasiocampidae } & Poecilocampinae & 2 & Notodontidae & Thaumetapoeinae & 1 \\
\hline & Lasioca mpinae & 13 & & \begin{tabular}{|l|} 
Pygaerinae \\
\end{tabular} & 4 \\
\hline \multicolumn{2}{|l|}{ Endromidae } & 1 & & Notodontinae & 22 \\
\hline \multirow[t]{2}{*}{ Saturniidae } & Agliinae & 1 & & Phalerinae & 3 \\
\hline & Saturniinae & 4 & & Heterocampinae & 3 \\
\hline \multicolumn{2}{|l|}{ Lemonidae } & 2 & Noctuidae & Acronictinae & 16 \\
\hline \multirow[t]{3}{*}{ Sphingidae } & Smerinthinae & 4 & & Bryophilinae & 4 \\
\hline & Sphinginae & 4 & & Herminiinae & 13 \\
\hline & Macroglossinae & 10 & & Strepsimaninae & 3 \\
\hline \multirow[t]{3}{*}{ Hesperidae } & Pyrginae & 10 & & Catocalinae & 26 \\
\hline & Heteropterinae & 2 & & Calpinae & 2 \\
\hline & Hesperiinae & 4 & & Hypeninae & 6 \\
\hline \multirow[t]{2}{*}{ Papilionidae } & Parnassiinae & 2 & & Euteliinae & 1 \\
\hline & Papilioninae & 2 & & Plusiinae & 18 \\
\hline \multirow[t]{3}{*}{ Pieridae } & Dismorphiinae & 3 & & Acontiinae & 2 \\
\hline & Pierinae & 6 & & Eustrotiinae & 13 \\
\hline & Coliadinae & 7 & & Cuculiinae & 16 \\
\hline \multirow[t]{2}{*}{ Lycaenidae } & Riodininae & 1 & & Amphipyrinae & 4 \\
\hline & Lycaeninae & 39 & & Psaphidinae & 3 \\
\hline \multirow[t]{6}{*}{ Nymphalidae } & Libytheinae & 1 & & Dilobinae & 1 \\
\hline & Heliconiinae & 9 & & Stiriinae & 2 \\
\hline & Nymphalinae & 20 & & Heliothinae & 11 \\
\hline & Limenitinae & 2 & & Hadeninae & 196 \\
\hline & Apaturinae & 3 & & Noctuinae & 50 \\
\hline & Satyrinae & 17 & Pantheidae & & 1 \\
\hline \multirow[t]{2}{*}{ Drepanidae } & Thyatirinae & 10 & Lymantriidae & Lymantriinae & 12 \\
\hline & Drepaninae & 7 & Nolidae & Nolinae & 9 \\
\hline \multirow[t]{6}{*}{ Geometridae } & Archiearinae & 3 & & Chloephorinae & 5 \\
\hline & Ennominae & 87 & & Eariadinae & 2 \\
\hline & Oenochrominae & 2 & Arctiidae & Lithosünae & 17 \\
\hline & Geometrinae & 12 & & Syntominae & 2 \\
\hline & Sterrhinae & 56 & & Arctiinae & 19 \\
\hline & Larentiinae & 145 & & & \\
\hline
\end{tabular}




\section{Irodalom}

Abafl- Algner, L., PÁvel , J. ÉS UhrYK F. 1899: Ordo. Lepidoptera in: A Magyar Birodalom Állatvilága - Fauna Regni Hungariae. Budapest pp 1-82.

ABAFI-AIgNER, L. 1917: Magyarország pillangói. - Rovartani Lapok 24: 115-124.

ÁBrahÁM, L. 1990): Nattán Miklós nagylepke-gyúijteménye (Lepidoptera) a pécsi Janus Pannonius Múzeumban. - $\Lambda$ Janus Pannonius Múzeum Évkönyve 34 (1989): 63-71.

ÁBrAHÁM, L. 1992a: Boronka-melléki Tájvédelmi Körzet nagylepkefaunájának természetvédelmi feltárása I. (Lepidoptera). - Dunántúli Dolg. Term. tud. Sorozat 7: 24l-27l.

ÁBrAHÁM, L. 1992b: A Zselici Tájvédelmi Körzet Macrolepidoptera faunájának ismeretéhez (Lepidoptera). - Somogyi Múzeumok Közleményei 9: 293-306.

ÁвRAнйM, L. 1998: A Leptidea reali Reissinger, 1989 a hazai nappalilepke-fauna új tagja (Lepidoptera: Picridac). - Dunántúli Dolg. Term. tud. Sorozat 9: 387-394.

ÁBRAHÁM, L. 1998-1999: Az Agrotis puta (Hübner, 1803) újabb példánya a hazai bagolylepke- faunában (Lepidoptera: Noctuidac). - Fol Hist nat Mus. Matraensis 23: 249-251.

ÁвRAHÁm, L., UHERKOVICH, $\Lambda$. 1994: $\Lambda$ Zselic nagylepkéi (Lepidoptera) I. Bevezetés és faunisztikai alapvetés. - A Janus Pannonius Múzeum Évkönyve 38: (1993): 47-59.

ÁBRAHÁM, L. UHERKOVICH, ヘ́. 1998: ^ Dráva mente nagylepke faunája és jellegzetes élöhelyei (Lepidoptera). - Dunántúli Dolg. Term. tud. Sorozat 9: 359-385.

BusCHMANN, F. 1985: Néhány adat Balatonszántód és a Tihanyi-félsziget nagylepkefaunájához (Lepidoptera). - Folia ent. hung. 46 (1): 257-258.

FAZEKAS, I: 1977: Adatok Dél-Dunántúl Eupithecini-faunájának elterjedéséhez és fenológiájához. A Janus Pannonius Múzcum Évkönyve 20-2l (1975-76): 49-56.

GozmáNY, L. 1968: Nappali lepkék - Diurna. - Magyarország Állatvilága XVI. kötet 13: 1-204.

GozmÁNY, L. 1970: Bagolylepkék I - Noctuidae I. - Magyarország Állatvilága XVI. kötet 11: 1-151.

GozmánY, L. 1971: Megemlékezés Nattán Miklósról - Folia ent. hung. 24(2): 279-280.

GYUlAI, I., GyulaI, P., Uherkovich, Á., VARGA, Z. 1979: Újabb adatok a magyarországi nagylepkék elterjedéséhez II. (Lepidoptera). - Folia ent. hung. 32 (2): 219-227.

GYULAI, P., UHERKOVICH, Á., VARGA, Z. 1974: Újabb adatok a magyarországi nagylepkék elterjedéséhez (Lepidoptera). - Folia ent. hung. 27 (2): 75-83.

Karsholt, O. \& RazowSKI, J. 1996: The Lepidoptera of Europe. A Ditributional Checklist. Appollo Book, Stenstrup.

KovÁCS, L. 1953: A magyarországi nagylepkék és elterjedésük. - Folia ent. hung. 6: 76-165.

KovÁCS, L. 1954: Új fajok és fajváltozatok a magyar nagylepkefaunában. - Folia ent. hung. 7: 53-64

KovÁCS, L. 1955: A lepke-fajok terjedésének kérdése. - Folia ent. hung. 8: 1-16.

KovÁcs, L. 1956: A magyarországi nagylepkék és elterjedésük II. - Folia ent. hung. 9: 89-140.

KovíCS, L. 1957: A magyar nagylepkefauna gyarapodása 1956-ban. - Folia ent. hung. 10: 125-132.

KovÁCs, L. 1958: Változások a magyarországi nagylepkék adataiban a Fauna Regni Hungariae, illetőleg Abafi-Aigner lepkekönyvének megjelenése óta. - Folia ent. hung. 11: 309-365.

PAzsiczKY, J. 1917: Spilosoma urticae Esp. ab. Alexandri Pazs. Elterjedéséhez. - Rovartani Lapok 24: 88.

PAZSICZKY, S. 1942: Lepidopterologiai érdekességek Kaposvár környékéról. - Folia ent. hung. 7: 65-72.

PAzsıczic, S. 1947: Három kaposvári lepkész emlékezete - Folia ent. hung. 2(1): I-3..

RÉZBÁNYAI, L. 1972: Vizsgálatok a Balaton délkeleti (Balatonszabadi-Zamárdi) partvidékének nagylepkefaunáján (Lep.). - Folia ent. hung. 25: 229-252.

RothSCHILD, N. CH. 1909: Adatok Magyarország lepkefaunájához. - Rovartani Lapok 16: 130-148.

SZENT-IVÁNY, J. 1938: Lepidopterologiai jegyzetek I. - Folia ent. hung. 3: 113-1 15.

THÚRóczy, Cs. 1983-84: Somogy megyei fénycsapdák Macrolepidoptera anyagának állatföldrajzi és rajzásdinamikai értékelése I. - A Vas Megyei Múzeumok Értesítője 17-18: 61-70.

UHERKovich, Á. 1975: Apatura ilia nattani ssp. nov. Magyarországról (Lepidoptera: Nymphalidae). - Folia ent. hung. 27(I): 209-212.

UherKoviCH, Á. 1976a: Adatok a Dél-Dunántúl nagylepkefaunájához (Macrolepidoptera). - Folia ent. hung. p. 119-137.

UherkoviCH, Â. 1976b: Adatok a Drávasík nagylepkefaunájának (Macrolepidoptera) ismeretéhez. - A Vas Megyei Múzeumok Értesítôje 5-6 (1971-72): 115-145. 
UHERKOVICH, Á. 1978a: Belsô-Somogy és a Zselic határvidékẹnek lepideptorológiai viszonyai (Lepidoptera). - Somogyi Múzeumok Közleményei 3: 503-538.

UHERKOVICH, Á. 1978b: Komlósd környékének nagylepkefaunája (Macrolepidoptera). - A Janus Pannonius Múzeum Évkönyve 22 (1977): 73-87.

Uherkovich, Á. 1978c: A Barcsi Ôsborókás nagylepkefaunája I. (Lepidoptera). - Dunántúli Dolg. Term. tud. Sorozat I: 93-125.

UHERKOVICH, Á. 1978d: Dél- és Nyugat-Dunántúl nagylepkéinek néhány állatföldrajzi kérdése. Állattani Közlemények 65: 153-162

UHERKovich, Á. 1979: Vándorlepke-megfigyelések a Dél-Dunántúlon, 1966-1977. (Lepidoptera). - A Janus Pannonius Múzeum Évkönyve 23 (1978): 5 I-70.

UHERKOVICH, Á. 1980a: A Dél- és Nyugat-Dunántúl túlevelúeken éló nagylepkéi (Lepidoptera) A Janus Pannonius Múzeum Évkönyve 24 (1979): 77-91.

Uherkovich, Á. 1980b: A Noctua interjecta Hbn. magyarországi előfordulása (Lepidoptera: Noctuidae). - Folia ent. hun. 42 (2): 378.

Uherkovich, Á. 1981a: A Zselici Tájvédelmi Körzet nagylepkefaunája. - Somogyi Múzeumok Közleményei 4 (1): 5-24.

UHERKovich, Á. 1981b: A Barcsi Borókás nagylepkefaunája II. (Lepidoptera). - Dunántúli Dolg. Term. tud. Sorozat 2: 89-125.

UHERKovich, Á. I98IC: Data to the Macrolepidoptera fauna of South Transdanubia (Lepidoptera) II. - Folia ent. hung. 42 (2): 239-252.

UherKovich, Á. 1983: A Barcsi Borókás nagylepkefaunája III. (Lepidoptera). - Dunántúli Dolg. Term. tud. Sorozat 3: 55-72.

UHERKOVICH, Á. 1984a: Lepidoptera on birch and alder in South and West Transdanubia, Hungary. - A Janus Pannonius Múzeum Évkönyve 28 (1983): 39-49.

UHERKOVICH, Á. 1984b: Jelenkori terjedési jelenségek dél-dunántúli nagylepkéknél (Lepidoptera). - Állattani Közlemények 71: 165-176.

UHERKOVICH, Á. 1985: Néhány további adat a Barcsi borókás nagylepke faunájához (Lepidoptera). - Dunántúli Dolg. Term. tud. Sorozat 5: 236-238.

UHERKOVICH, Á. és ÁBRAHÁM, L. 1995: A nagylepke (Lepidoptera: Macrolepidoptera) kutatások faunisztikai exedményei a Dráva mentén. - Dunántúli Dolg. Term. tud. Sorozat 8: 139-159.

VARGA Z. 1981: Diachrysia nadeja (Orberthur, 1880) - a hazai fauna új tagja Lepidoptera:, Noctuidae). Dunántúli Dolg. Term. tud. Sorozat 2: 127-131.

VojNiTs, A. 1976: New Geometrid Subspecies from Hungary (Lepidoptera: Geometridae). - Folia ent. hung. 30 (1): 167-171.

Vojnrrs, A, 1980: Araszolólepkék I. - Geometridae I. - Magyarország Állatvilága XVI. kötet 14: 1-157.

Z. HoRvÁTH, J. 1999: A Zselic rovarvilága. - Erdészeti Lapok 9: 286. 


\title{
Checklist of the butterfly and larger moth fauna of Somogy county (Lepidoptera: Macrolepidoptera)
}

\section{LEVENTE ÁBRAHÁM \& ÁKos UHERKOVICH}

The investigation of butterfly and larger moth fauna of Somogy county has nearly a 100 years of history. The first faunistical data from the county were published in Fauna Regni Hungariae (ABAFI et al 1899). Between the World Wars, several important collections were set up by private collectors, such as I. Karvajszky, A. Hámori, A. Ház, S. Pazsiczky. After the Second World War, M. Nattán carried out an intensive investigation in the area around Kaposvár for three decades. However, the rest of the county had not been researched until the mid-1970`s (RÉZBÁNYAI 1972, UHERKOVICH, 1978). Á. Uherkovich led an intesive fieldwork organized by the Natural History Department of Janus Pannonius Museum that focused on the southern part of the county: the region alongside River Dráva, Zselic, and Inner Somogy.

After its foundation in 1985, the Natural History Department of Somogy County Museum joined this project and extended the butterfly and larger moth fauna investigation on the researched area (ÁBrAHÁM 1990, $1992 \mathrm{a}, \mathrm{b}$, ÁBRAHÁM \& UHERKOVICH 1994, 1998).

Until now, the occurrence of 973 butterfly and larger moth species has been reported in Somogy county. The authors of this paper present a complete checklist of the fauna with the cited literature as well.

\author{
Authors' address: \\ Dr. Levente ÁBRAHÁM \\ Natural History Department \\ Somogy County Museum \\ H-7400 Kaposvár \\ Fố utca 10. P.O. Box 70. \\ HUNGARY \\ DR. Ákos UherKovich \\ Natural History Department \\ Janus Pannonius Museum \\ H-760l Pécs \\ P. O. Box 347. \\ HUNGARY
}

